\title{
NUMERICAL INVESTIGATION ON COOLING OF SMALL FORM FACTOR COMPUTER CASES
}

A THESIS SUBMITTED TO

THE GRADUATE SCHOOL OF NATURAL AND APPLIED SCIENCES

$\mathrm{OF}$

MIDDLE EAST TECHNICAL UNIVERSITY

BY

ÖMER EMRE ORHAN

\author{
IN PARTIAL FULFILLMENT OF THE REQUIREMENTS \\ FOR \\ THE DEGREE OF MASTER OF SCIENCE \\ IN \\ MECHANICAL ENGINEERING
}

JANUARY 2007 
Approval of the Graduate School of Natural and Applied Sciences

Prof. Dr. Canan ÖZGEN

Director

I certify that this thesis satisfies all the requirements as a thesis for the degree of Master of Science.

Prof. Dr. Kemal İDER

Head of Department

This is to certify that we have read this thesis and that in our opinion it is fully adequate, in scope and quality, as a thesis for the degree of Master of Science.

Asst. Prof. Dr. İlker TARI

Supervisor

Examining Committee Members

Prof. Dr. Rüknettin OSKAY

(METU, ME)

Asst. Prof. Dr. İlker TARI

(METU, ME)

Prof. Dr. Haluk AKSEL

(METU, ME)

Asst. Prof. Dr. Cüneyt SERT

(METU, ME)

Dr. M. Barış Doğruöz

(FLUENT INC.) 
I hereby declare that all information in this document has been obtained and presented in accordance with academic rules and ethical conduct. I also declare that, as required by these rules and conduct, I have fully cited and referenced all material and results that are not original to this work.

Name, Last name: Ömer Emre ORHAN

Signature : 


\author{
ABSTRACT \\ NUMERICAL INVESTIGATION ON COOLING OF SMALL FORM \\ FACTOR COMPUTER CASES \\ ORHAN, Ömer Emre \\ M.S. Department of Mechanical Engineering \\ Supervisor: Asst. Prof. Dr. İlker TARI \\ January 2007, 101 pages
}

In this study, cooling of small form factor computer is numerically investigated. The numerical model is analyzed using a commercial computational fluid dynamics software Icepak ${ }^{\mathrm{TM}}$. The effects of grid selection, discretization schemes and turbulence models are discussed and presented. In addition, physical phenomena like recirculation and relaminarization are addressed briefly. For a comparison with the computational fluid dynamics results, an experiment is conducted and some temperature measurements are obtained from critical locations inside the chassis. The computational results were found to be in good agreement with the experimental ones.

Key Words: Small Form Factor; Electronics Cooling; Computational Fluid Dynamics; Conjugate Heat Transfer . 


\title{
öz
}

\section{KÜÇÜK BOYUTTAKİ BILGISAYAR KASALARININ SOĞUMASININ SAYISAL OLARAK INNCELENMESI}

\author{
ORHAN, Ömer Emre \\ Yüksek Lisans, Makina Mühendisliği Bölümü \\ Tez Yöneticisi: Yrd. Doç. Dr. İlker TARI \\ Ocak 2007, 101 Sayfa
}

$\mathrm{Bu}$ çalışmada küçük kasa bilgisayarların soğutulması sayısal olarak incelenmiştir. Oluşturulan sayısal model, ticari bir hesaplamalı akışkanlar dinamiği yazılımı olan Icepak $^{\mathrm{TM}}$ kullanılarak analiz edilmiştir. Eleman seçiminin, diskretizasyon ve türbülans modellerinin etkileri tartışıllmış ve sunulmuştur. Bunun yanında, resirkülasyon ve relaminarizasyon gibi fiziksel konulardan da kısaca bahsedilmiştir. Hesaplamalı akışkanlar dinamiği sonuçları ile karşılaştırmak amacıyla, bir deney gerçekleştirilmiş ve kasa içerisindeki kritik yerlerden sıcaklık ölçümleri alınmıştır. Sayısal sonuçların, deneysel sonuçlarla iyi bir uyum içinde oldukları gözlenmiştir.

Anahtar Kelimeler: Küçük Kasa; Elektronik Soğutma; Hesaplamalı Akışkanlar Dinamiği (HAD); Konjuge Isı Transferi. 
To my family, without them I will be worthless. 


\section{ACKNOWLEDGEMENTS}

I wish to express my deepest gratitude to my supervisor Asst. Prof. Dr. İlker Tarı for his close guidance, inspiration and invaluable help throughout the study. Without his understanding, this study will not be possible.

I wish to express my sincere appreciation to Dr. M. Barış Doğruöz for his continous support and encouragement throughout this work.

I am very thankful to Aselsan Inc. MGEO Division, especially their support about letting me study and use Icepak ${ }^{\mathrm{TM}}$ throughout this study.

I am grateful to my colleagues Devrim and Özgür Anıl twins for their practical help during the thesis and experiments. Without them, the experiments will not be possible.

Finally, I express my deepest gratitude to my family for their continuous encouragement, understanding and support. 


\section{TABLE OF CONTENTS}

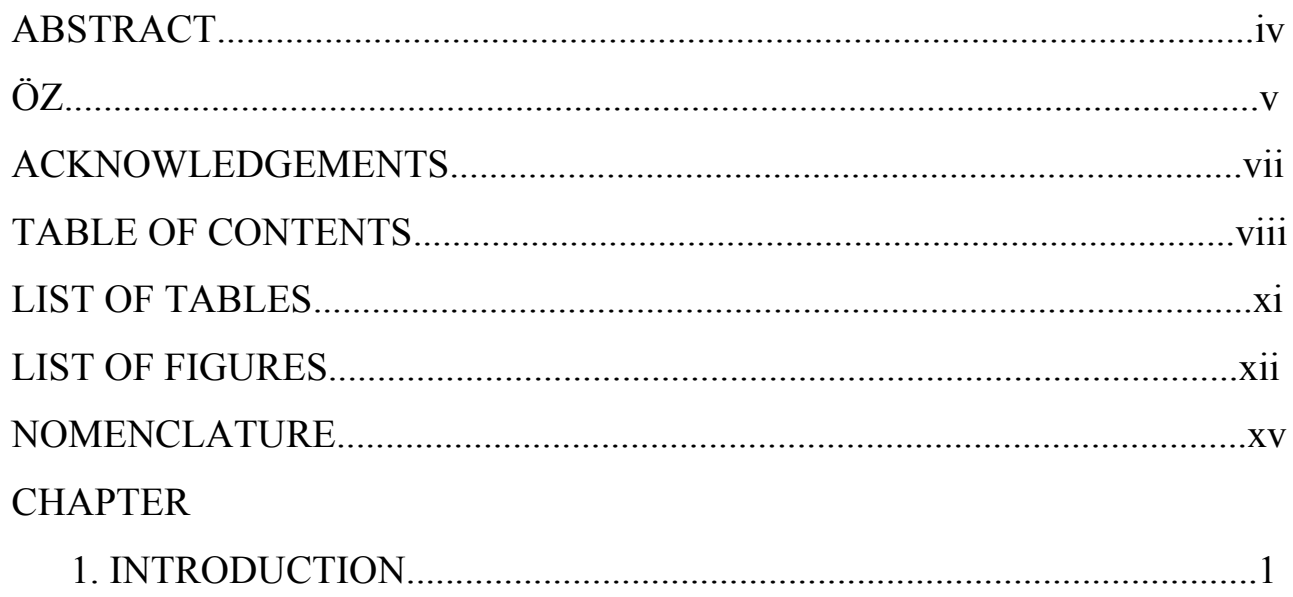

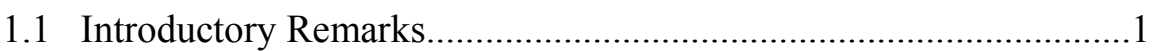

1.1.1 Types of Computer Cases.....................................................2

1.1.2 Small Form Factor Computers............................................6

1.2 Literature Search and Past Studies.................................................

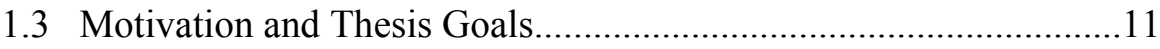

2. COMPUTATIONAL MODELS, EQUATIONS SOLVED AND

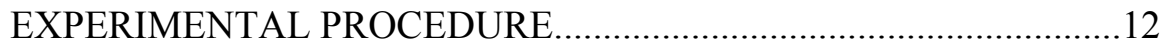

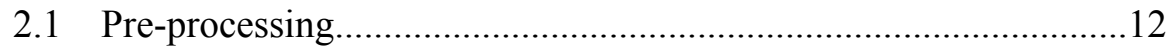

2.1.1 Computational Domain......................................................... 15

2.1.2 Details of the Computational Domain...................................15

2.1.2.1 Computer Chassis.....................................................16

2.1.2.2 CPU and the Chipset..............................................16

2.1.2.3 Heat Pipe System...................................................18

2.1.2.4 Chipset Heat Sinks...................................................20

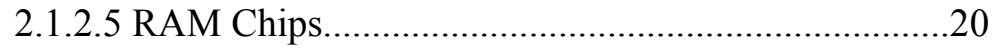

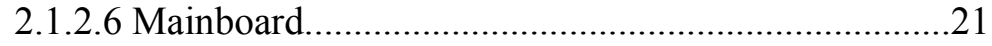

2.1.2.7 Hard Disk Drive and DVD Rom...............................21

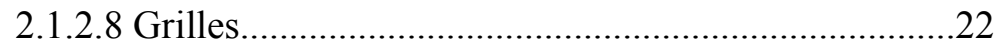

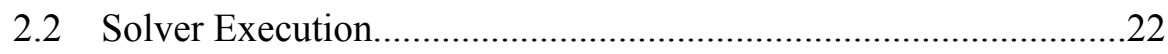

2.2.1 Governing Equations of Fluid Flow.....................................23 
2.2.1.1 Governing Equations to be Solved .24

2.2.2 Boundary Conditions.........................................................29

2.2.2.1 Velocity Boundary Conditions..................................29

2.2.2.2 Heat Transfer Coefficients at Chassis Walls...............30

2.2.2.3 Power Budget for the Chassis....................................32

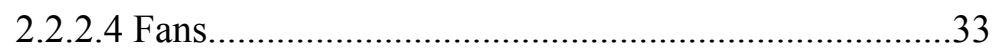

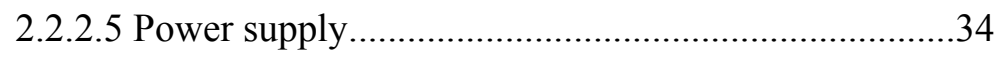

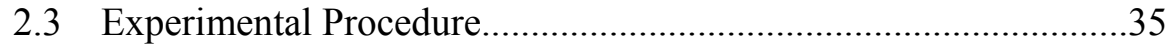

2.3.1 Details of the Experimental Setup..........................................36

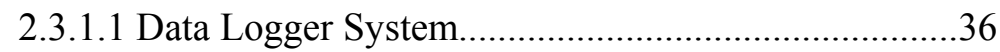

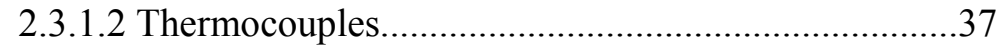

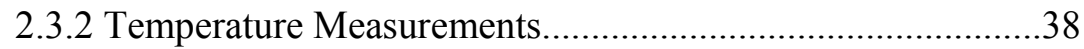

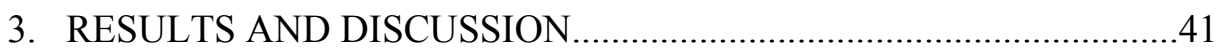

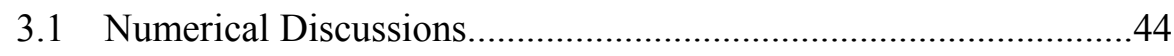

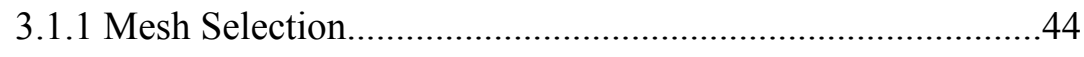

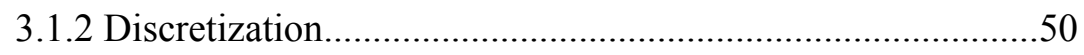

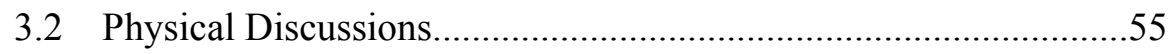

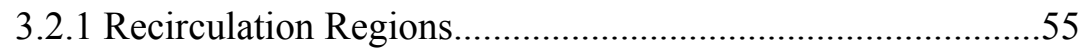

3.2.2 Turbulence Modelling........................................................58

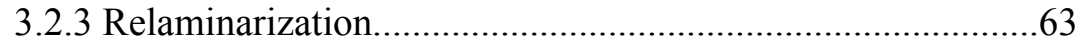

3.2.4 Effects the DVD and the Hard Disk Drive Power Ratings

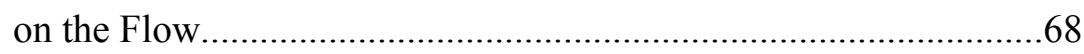

3.3 Uncertinty Analysis of Temperature Measurements.......................70

3.4 Comparison of Experimental Results with CFD Results................73

4. CONCLUSION AND RECOMMENDATIONS ...................................78

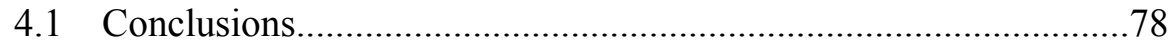

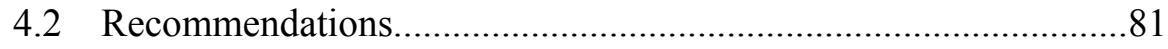

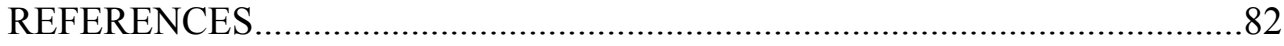

APPENDICES

APPENDIX A Mesh Generation and Quality of the Mesh.................................86

APPENDIX B Turbulence Modeling..............................................................92

APPENDIX C Thermocouple Locations.........................................................96 


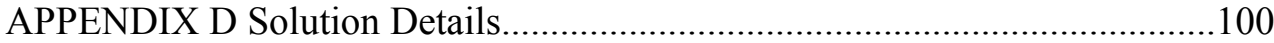




\section{LIST OF TABLES}

Table 2.1 Power Power budget of the components............................................33

Table 3.1 Temperature values, $\Delta \mathrm{T}$, for different grids for an ambient temperature of $28^{\circ} \mathrm{C}$

Table 3.2 Temperature values, $\Delta \mathrm{T}$, for different discretization schemes for an ambient temperature of 28 . .51

Table 3.3 Temperature values, $\Delta \mathrm{T}$, for different turbulence models for an ambient temperature of $28^{\circ} \mathrm{C}$ .59

Table 3.4 Maximum and mean temperature values on several components with power consumption. .69

Table 3.5 Sensitivity values for the temperature measurement locations............72

Table 3.6 Comparison of experimental results of Shuttle SK21G with CFD

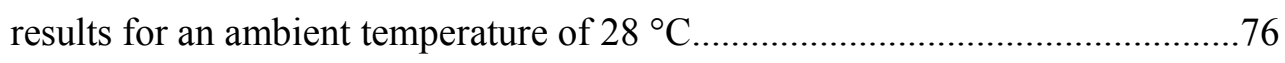

Table 3.7 Comparison of experimental results of Shuttle SS59GV2 with CFD

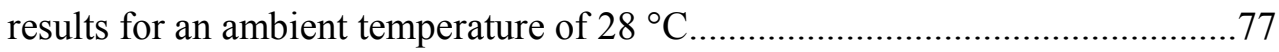

Table D.1 Simulation times for different mesh configurations................100

Table D.2 Volumetric flow rates through the grilles....................... 100

Table D.3 Fan Operating Points........................................101 


\section{LIST OF FIGURES}

Figure 1.1 ATX chassis features....................................................

Figure 1.2 Example of a micro-ATX system.............................4

Figure 1.3 NLX board and riser example................................5

Figure 1.4 Example BTX system layout.................................5

Figure 1.5 Shuttle XPC SN25P..................................... 6

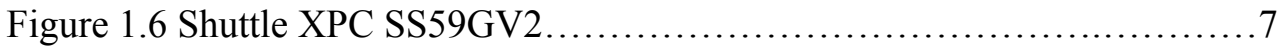

Figure 2.1 Shuttle XPC SK21G used in this study.........................................13

Figure 2.2 Computational grid obtained in Icepak ${ }^{\mathrm{TM}}$.......................................14

Figure 2.3 Computational domain created in Icepak ${ }^{\mathrm{TM}}$.................................15

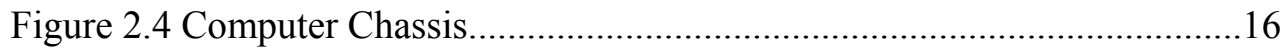

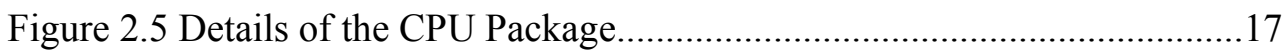

Figure 2.6 Details of North Bridge Package.......................................................17

Figure 2.7 Details of South Bridge Packages....................................................18

Figure 2.8 Details of the Heat Pipe System.....................................................19

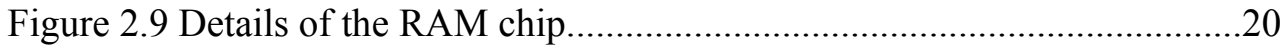

Figure 2.10 Mainboard and components on it...............................................21

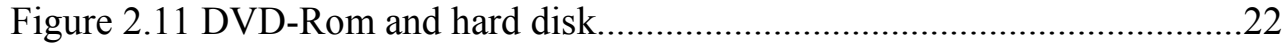

Figure 2.12 Performance curves for the heat pipe and power supply fan............34

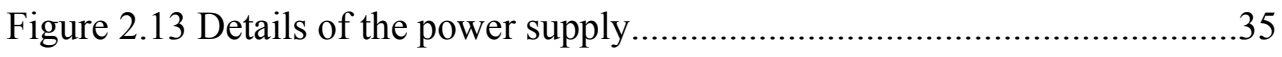

Figure 2.14 Data logger system during temperature measurements....................37

Figure 2.15 Example of thermocouple locations................................................38

Figure 2.16 Sample of temperature recordings reaching steady state................40

Figure 3.1 Location of the comparison line on the heat pipe block....................46

Figure 3.2.Temperature values drawn for a line passing through the center of the

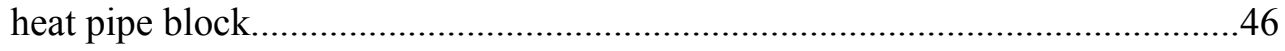

Figure 3.3.2D velocity vectors passing through the center of the north bridge heat sink for coarse, base and fine meshes..........................................................48

Figure 3.4.Temperature contours of CPU for coarse, base and fine meshes.......49 
Figure 3.5 Comparison line on the top plate of the power supply.....

Figure 3.6.Temperature values drawn for a line passing through the center of the top plate of the power supply.....

.52

Figure 3.7. $2 \mathrm{D}$ velocity vectors passing through the center of the north bridge heat sink for the first and second order discretizations .53

Figure 3.8.Temperature contours of CPU for first and second order discretization schemes. .54

Figure 3.9.General visualization of the flow field inside the computer chassis and the recirculation zones. .56

Figure 3.10 Particle traces of the recirculation zones from 1-3 in detail.............56

Figure 3.11 Particle traces of the recirculation zone 5 in detail..........................57

Figure 3.12 Particle traces of the recirculation zone 4 in detail. .57

Figure 3.13.A graphical comparison of a line passing through the center of the heat pipe block for zero and two equation $(k-\varepsilon)$ turbulence models.

Figure 3.14.2D velocity vectors passing through the center of the north bridge heat sink for zero and two equation $(k-\varepsilon)$ turbulence models.

Figure 3.15 Temperature contours of $\mathrm{CPU}$ for zero and two equation $(k-\varepsilon)$ turbulence models.

Figure 3.16 Locations of the plane cuts on the heat sinks 63

Figure 3.17 Velocity magnitude contours of the north and south bridge heat sinks

Figure 3.18 Particle traces s for turbulent and laminar solutions around the heat sinks

Figure 3.19 Velocity magnitude contours of the north and south bridge heat sinks after a laminar solution is obtained around them.

Figure 3.20 Model of the SS59GV2 in Icepak ${ }^{\mathrm{TM}}$ .73

Figure 3.21 Particle traces from a cut plane $(\mathrm{x}=0.17 \mathrm{~m})$ for $\mathrm{SK} 21 \mathrm{G}$ and SS59GV2. .75

Figure A.1 Elements with low and high skewness values .88

Figure A.2 General view of the generated mesh..............................................90

Figure A.3 Example of a non-conformal mesh..............................91

Figure A.4. North Bridge Heat Sink Mesh. 
Figure C.1 Thermocouples inside the heat pipe block above the CPU and south

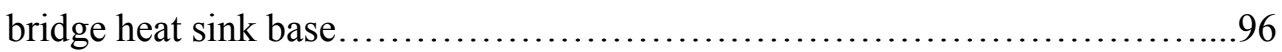

Figure C.2 Thermocouple inside the north bridge heat sink base...............97

Figure C.3 Thermocouple on the power supply plate...............................97

Figure C.4 Thermocouples inside the north bridge and south bridge heat sink

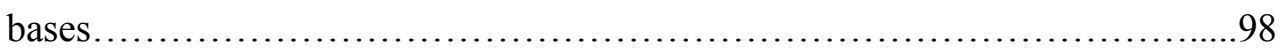

Figure C.5 Thermocouple inside the heat pipe block over the CPU..............99

Figure C.6 Thermocouple on the power supply plate........................99 


\title{
NOMENCLATURE
}

\author{
Latin Symbols \\ A $\quad$ surface area \\ d distance from the wall \\ $D_{h} \quad$ hydraulic diameter \\ e internal energy \\ $f_{\mathrm{x},} f_{\mathrm{y},} f_{\mathrm{z}} \quad$ body force components \\ $g$ \\ gravitational acceleration \\ $G_{b}$ \\ generation of turbulence kinetic energy due to buoyancy \\ $G_{k}$ \\ generationof turbulence kinetic energy due to mean \\ velocity gradients \\ Gr Grashof number \\ $h$ \\ $k$ \\ heat transfer coefficient \\ thermal conductivity \\ $k \quad$ turbulence kinetic energy \\ $k_{\text {eff }} \quad$ effective thermal conductivity \\ $k_{t} \quad$ turbulent thermal conductivity \\ $l \quad$ mixing length of zero equation turbulence model \\ $l_{c l} \quad$ loss coeficients defined in all directions \\ $L \quad$ length \\ $L_{c h} \quad$ characteristic length \\ $\mathrm{Nu} \quad$ Nusselt number \\ $p \quad$ pressure \\ $P \quad$ perimeter \\ $\operatorname{Pr} \quad$ Prandtl number \\ $q$ heat flux as a source term \\ R gas constant \\ $R a \quad$ Rayleigh number
}


$S_{k}, S_{\varepsilon}$

$T$

$T_{s}$

$T_{\infty}$

$u, v, w$

$\vec{V}$

V

$v$

$v_{a p p}$

$W$

$\Delta p$

$\Delta T$

$\frac{\partial T}{\partial x}, \frac{\partial T}{\partial y} \frac{\partial T}{\partial z}$

$\frac{\partial T}{\partial V}$

$\delta x, \delta y, \delta z$

$\delta V$

Greek Symbols

$\alpha$

$\beta$

$\varepsilon$

$\Phi$

$\varphi$

$\kappa$

$\lambda$ modulus of the mean rate of strain tensor

user defined source terms

temperature

average wall temperature

ambient temperature

velocity components

velocity vector

voltage

kinematic viscosity

approach velocity

width of the cross section

pressure drop

temperature difference

sensitivities of temperature with respect to spatial

coordinates

sensitivity of temperature with respect to voltage

uncertainties for spatial coordinates

uncertainty for the voltage thermal diffusivity

thermal expansion coefficient

turbulence dissipation rate

viscous dissipation function

any physical variable

von Karman constant

second viscosity coefficient 
$\mu_{t}$

$\rho$

$\sigma_{k}$

$\sigma_{\varepsilon}$

Subscripts

app

b

$c 1$

ch

eff

$h$

$i, j$

$k$

$L$

$\max$

$t$

$x, y, z$

$\varepsilon$

Superscripts

$n$

$T M$ molecular viscosity coefficient

effective viscosity

turbulent viscosity

density

turbulent Prandtl number for $k_{\text {turb }}$

turbulent Prandtl number for $\varepsilon$

viscous stress approach

buoyancy

coefficients

characteristic

effective

hydraulic

three components of the variables in $\mathrm{x}, \mathrm{y}$ and $\mathrm{z}$ directions

turbulence kinetic energy

length

maximum

turbulent

spatial coordinate directions

turbulence dissipation rate

velocity dependence for $\Delta p$

Trade Mark 
Abbreviations

$\begin{array}{ll}\text { AGP } & \text { Accelerated Graphics Port } \\ \text { AT } & \text { Advanced Technology } \\ \text { CFD } & \text { Computational Fluid Dynamics } \\ \text { cfm } & \text { feet }^{3} \text { per minute } \\ \text { FF } & \text { Form Factor } \\ \text { GPU } & \text { Graphics Processing Unit } \\ \text { HDD } & \text { Hard Disk Drive } \\ \text { inAq } & \text { inches of water } \\ \text { MCM } & \text { Multi Chip Module } \\ \text { SFF } & \text { Small Form Factor }\end{array}$




\section{CHAPTER 1}

\section{INTRODUCTION}

\subsection{Introductory Remarks}

It has been the aim of the electronics industry to reduce the power densities of the electronic components to be able to decrease the operating temperatures. However, there is a continuous increase in the heat they dissipate as well as a tremendous demand for them in electronic systems. Therefore, cooling technology has always been and will be an important and inevitable step in proper functioning and reliability of the electronic components. Kim and Lee [1] mention two important fundamental reasons why cooling technology will always be important in the design of the electronic equipment:

1- All electronic devices are undergoing an irreversible process which results in heat generation that must be removed in order to maintain continuous operation.

2- The reliability and performance of electronic devices are temperature dependent with lower the better.

The proper functioning and the reliability of the electronic components are directly related to the heat they dissipate and the temperatures they operate. The less heat dissipation means lower temperatures. However, it is getting harder to achieve lower temperatures, since the power densities are going up to $10 \mathrm{~W} / \mathrm{cm}^{3}$ while the components are shrinking in size. Therefore, the casing which makes up that 
volume is also very important in terms of power management of the electronic systems [1].

For desktop computers, the case is not only vital for holding the computer together, but also it is an important part of the computer. It also serves to keep the devices cool inside the computer to prolong the life of electronic circuits [3].

There are many different desktop computer case and motherboard specifications called form factors and the details of some recent ones are given in the next section.

\subsubsection{Types of Computer Cases}

Desktop cases or chassis are available in different shapes and sizes. Form Factor (FF) is the most important feature about a case, because it determines what kind of motherboard and which power supply fit that case. Cases are available in different form factors [4]:

AT and Baby AT: The motherboards in computers earlier than 1997 were relatively large that their sizes are reduced to a new form factor called AT (Advanced Technology). This form factor was used in computers such as 386 and later versions. Since there has been some problems related with the size of the board, Baby AT form factor is introduced. With this form factor, the size of the motherboard is decreased [5].

ATX: Since there has been a need for a more compact form factor, ATX was introduced in the mid 1990's. The ATX brought many advances to the computer reducing the overall size of it. This form factor brought new changes to the motherboard together with the power supply and the case. In short, it was totally a 
better improvement in terms of form factor issue. [5]. The layout of an ATX form factor can be seen in Figure 1.1.

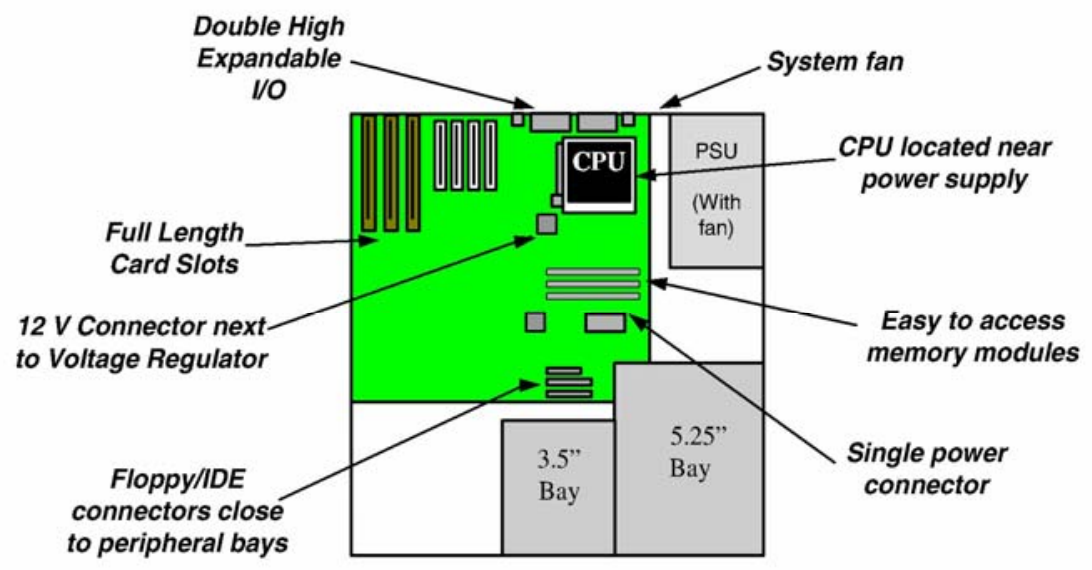

Figure 1.1 ATX chassis features (adapted from [6])

Micro-ATX: Micro-ATX for which the details can be seen in Figure 1.2, has the same benefits as the ATX form factor, however with the overall reduction in the size of the motherboard, and the cost. 


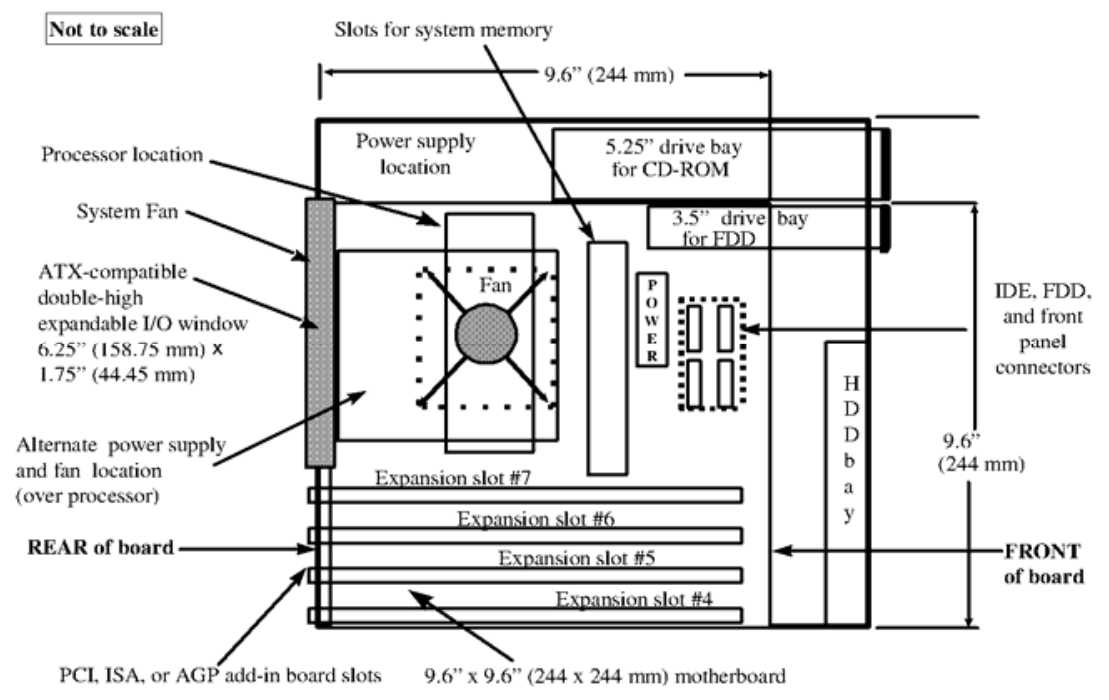

Figure 1.2 Example of a micro-ATX system (adapted from [7])

LPX: LPX is totally a new and non-standard form factor which is used in low profile cases. Most of the LPX form factors have sound and video on-board to allow for smaller case sizes. However, this also limits the expansion slots. Having sound and video on-board saves money and space but disables the upgrading of the computer. In addition, these form factors have poor cooling characteristics compared with other form factors [5].

NLX: In the late 1990's, another standard type form factor, NLX, hit the market offering upgrading and repair abilities which LPX could not offer. In addition to this, NLX, Figure 1.3, was also suitable for larger memory modules which made it appropriate for the mass market sales [5]. 


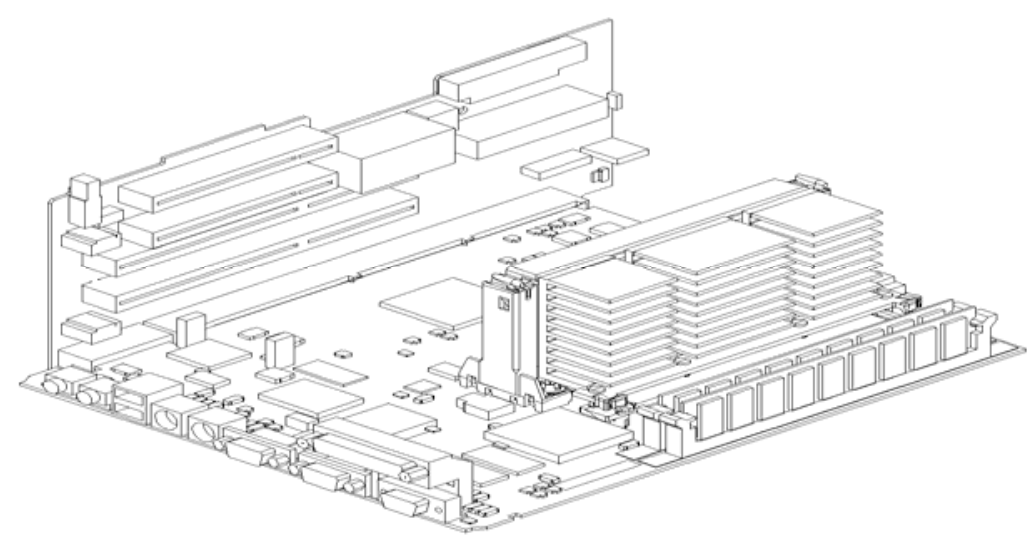

Figure 1.3 NLX board (adapted from [8])

BTX: BTX, Balanced Technology Extended, form factor is not completely different from the ATX form factor. However, it has some advantages such as reduced noise and in-line airflow decreasing the number of fans inside the case. In addition, BTX is designed to use the recently developed technologies like ATA, USB 2.0 and PCI Express. BTX is smaller than micro-ATX, although changes were made for enabling better component placements. The layout of these placements is given in Figure 1.4. There are different versions of BTX form factors like picoBTX, microBTX and regular BTX [5].

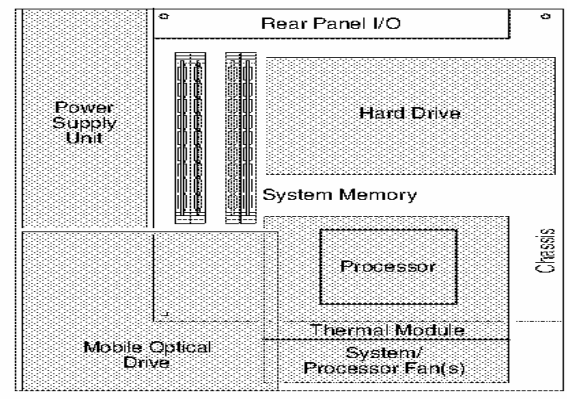

Figure 1.4 Example BTX system layout (adapted from [9]) 
Other than the form factors mentioned above, there is a form factor called Small Form Factor (SFF) which is the main interest of this study. This form factor is new compared to the others and has some new features in terms of computer chassis.

\subsubsection{Small Form Factor (SFF) Computers}

Small Form Factor is a general term which implies that this form factor is smaller than the standard form factors like micro-ATX and BTX. The size of a typical SFF computer is as big as a shoebox with a square front profile [10].

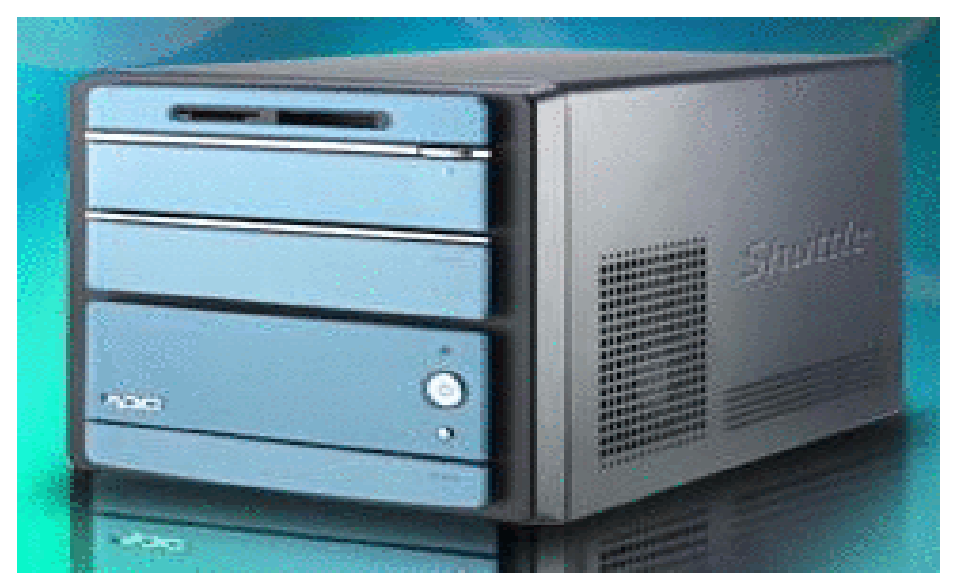

Figure 1.5 Shuttle XPC SN25P (adapted from [10]).

As a result of a smaller form factor, the primary advantage of the SFF computers is its size. Since they take up smaller amount of space, they are used in areas where space limitation is a major concern [10]. In addition, they are very suitable for mobile applications such as home theater PCs and for gamers who prefer not to carry around heavy systems. Finally, because of their reduced size and components, they tend to use less power than larger systems [11]. 
Apart from these advantages, there are some disadvantages regarding SFF computers. First of all in order to save space, many internal expansion and memory slots are removed causing the lack of expansion problem [11]. Second disadvantage is the cost. Since it is more difficult to make the components work in a smaller space, SFF computers are more expensive than regular desktop PC's. Lastly, due to the small space requirements of SFF systems; they can not be cooled as easily as regular systems. This difference in cooling technology makes up the idea behind this study.

There are many SFF computer manufacturers on the market however Shuttle is the leader brand with more than 30 different products. In this study, two SFF computers, Shuttle SK21G and Shuttle SS59GV2 are used. Computational models are generated in Icepak ${ }^{\mathrm{TM}}$ and two experiments are conducted later.

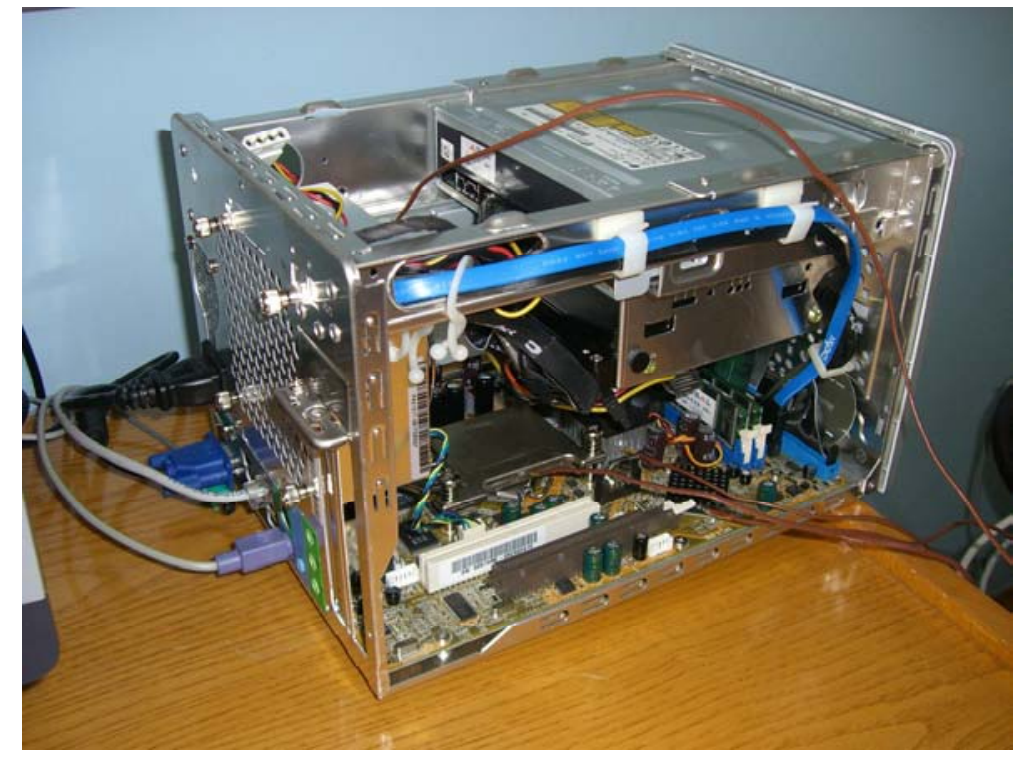

Figure 1.6 Shuttle XPC SS59GV2 


\subsection{Literature Search and Past Studies}

Although known for a long time, Computational Fluid Dynamics (CFD) has not been used for electronics cooling for a long period. In the last decade, there has been a great decrease in the cost of CFD applications with the development of new workstations and personal computers [12].

CFD is a very powerful tool in the sense that qualitative issues and quantitative data can be obtained if CFD is complemented by experiments. The number of data that one can obtain is limited in experiments, but CFD is very useful to offer a large set of data. Therefore CFD can be used to minimize the number of experiments and design alternatives. Previous works with CFD show that there have been successful applications of CFD in terms of design and experimental purposes.

Tucker [13] compared several commercial and non-commercial CFD codes in the systems related with electronics cooling. THEBES, FLOTHERM, FLUENT, FLOTRAN, FIDAP/Icepak ${ }^{\mathrm{TM}}$, CFX4, PHOENIX/HOTBOX and STAR-CD were discussed mainly with non-commercial programs originating from Massachusetts Institute of Technology (MIT). General thermo-fluid capabilities, user friendliness and peripheral aspects were checked and for all comparisons with measurement, agreement was found to be within $30 \%$. Finally, he concluded that none of the programs had superior performance over the others.

Marongiu, et al. [14], discussed the investigation of micro-heat pipes and other high thermal conductivity materials that was incorporated into Multi Chip Modules (MCM). Parameters that affect the heat dissipation capabilities such as fin material, fin height, heat pipe configuration and pumping power were changed and analyzed using Icepak ${ }^{\mathrm{TM}}$. 
$\mathrm{Yu}$ and Webb [15] used Icepak ${ }^{\mathrm{TM}}$ to analyze the flow and heat transfer inside a desktop computer which had an $80 \mathrm{~W}$ CPU. The design was for a total chassis power of $313 \mathrm{~W}$. In their model, motherboard, PCI/AGP cards and memory were modeled as zero thickness rectangular plates with heat generated uniformly on the component side. The HDD and DVD were modeled as solid blocks generating a specified amount of heat inside the volume. Finally the power supply and the CPUheat sink were modeled as a volume resistance. In this study, the key design parameter was to minimize chassis air flow requirements.

Yeh [16] employed CFD to check the feasibility of a proposed cooling scheme of using a fan card to cool the printed circuit boards within the rack. A commercial CFD package, Ideas-ESC was used for the analysis. The main idea of the cooling scheme was to utilize cooling fans to keep the boards at a specific temperature. Since the air flow through the printed circuit boards were questionable, CFD analysis was necessary.

Some studies included the application of CFD together with results experiments conducted to validate CFD. Abakr et al. [17] used CFD in a completely different manner to investigate a telecommunications board. In this study, a mathematical model was developed to simulate some thermal performance parameters such as radiation, conduction and convection heat transfer. Then a steady state simulation was done using Fluent and the results were compared with full sized experimental data. There was a very good agreement between the simulation and the experimental results with error less than $5 \%$.

Another example is Sun [18], combining CFD with experiments to produce and prove the concept design. Since the importance of Graphics Processing Unit (GPU) is increasing in Accelerated Graphics Port (AGP) of modern computers, this study focused on the concept design of a fan sink for an AGP card. Only the GPU and the fan sink were modeled using Icepak ${ }^{\mathrm{TM}}$, other components of the AGP were not modeled. Prototype samples were tested proving the concept design and meeting the 
design criteria. As a result, the CFD results were found to be within $\pm 10 \%$ of experimental results.

With the advancements in the processor technology, processor powers increase considerably. Roknaldin and Sahan [20] discussed heat sink optimization for the final design process in which heat sink space and the cost of the thermal solution is a big concern. They modeled a $1 \mathrm{U}$ server including inlet/exhaust vents, hard drives, blower/fans, power supply, boards and components, heat sink and PCI cards using Icepak $^{\mathrm{TM}}$. They worked on two new strategies for heat sink optimization and managed to obtain a cheaper and a cooler solution.

There are also CFD and experimental studies related to laptop computers since heat dissipation is a big concern for them because of space limitations.

First one is a thesis work in which Icepak ${ }^{\mathrm{TM}}$ was used to simulate a compact two phase cooling system for a laptop computer by Ali [19]. In this study, two alternative cooling systems for a laptop computer were designed. Some parameters that affected the thermal performance of the system like fill ratio of the coolant, initial system pressure and pump flow rate were examined using CFD. Between the two alternative cooling systems, Icepak ${ }^{\mathrm{TM}}$ was used to identify the better one.

Another work by Lin and Huang [21] was related with generating a small forwardcurved fan for the cooling management of laptop computers. This was an integrated study including fan design, mockup manufacture, experimental verification and numerical simulation. Then fan performances were verified by both experimental and numerical approaches. As a commercial code for the numerical simulations STAR-CD was used and numerical results were in good agreement with the experimental ones. The flow rate was found to be within $2 \%$ to $6 \%$ error range.

Kobayashi et al. [22] described a thermal design and simulation method for a closed cabinet with a heat exchanger. Since the system had a total power of $630 \mathrm{~W}$, the air 
inside the cabinet had an increase of $30 \mathrm{~K}$ in temperature. So a heat pipe and heat exchanger system was installed. In addition, air flow path was also changed which managed to reduce the inner air temperature rise to $15 \mathrm{~K}$. A numerical model was developed for the improvement of the inner temperature rise and the optimum structure was examined. The numerical results were compared with the measured values and they were in good agreement.

Finally, Öztürk [12] investigated the forced cooling of heat sinks mounted on CPUs. Thermal parameters such as heat sink effectiveness, turbulence models, radiation and geometry of heat sinks were analyzed using commercial CFD programs Fluent and Icepak ${ }^{\mathrm{TM}}$. Later some improvements on heat sinks were decided upon after carrying out several simulations and the results were found to be in good agreement with the experimental values.

\subsection{Motivation and Thesis Goals}

Due to the space limitation, cooling of an SFF computer is more important compared to the other computer cases. However, in the literature, there is a lack of detailed information about the cooling of SFF computers. Hence, the main motivation of this study is to understand the cooling phenomena inside an SFF computer.

This motivation forms the basis of this study and the thesis goals are developed on this motivation. Thesis goals can be summarized as follows:

- To obtain accurate models of Shuttle SK21G and Shuttle SS59GV2 and obtain CFD solutions for these models.

- To investigate the flow characteristics and cooling inside the chassis.

- To perform experiments with two different SFF models.

- To compare the CFD results with the experimental ones. 


\section{CHAPTER 2}

\section{COMPUTATIONAL MODELS, GOVERNING EQUATIONS AND EXPERIMENTAL PROCEDURE}

In order to obtain a CFD solution, there are several steps that should be taken. The first step is pre-processing. This step is the most time consuming part during which the computational grid is created and details of the model is decided upon. The second step is the solver execution. The details of the solver such as boundary conditions, numerical and physical models are discussed in this section. This step is ended when the solution is converged. The last step is the post-processing part where the results are displayed and investigated.

In this chapter, only SK21G model is discussed, although the same steps are also taken and simulations are repeated for a Shuttle SS59GV2 model computer.

\subsection{Pre-Processing}

After the decision of the parts in the computer chassis that will be modeled such as hard disk, DVD-Rom, heat pipe, the dimensions of these parts are carefully measured directly from the computer chassis. A model of SK21G for which the measurements are taken can be seen in Figure 2.1. 


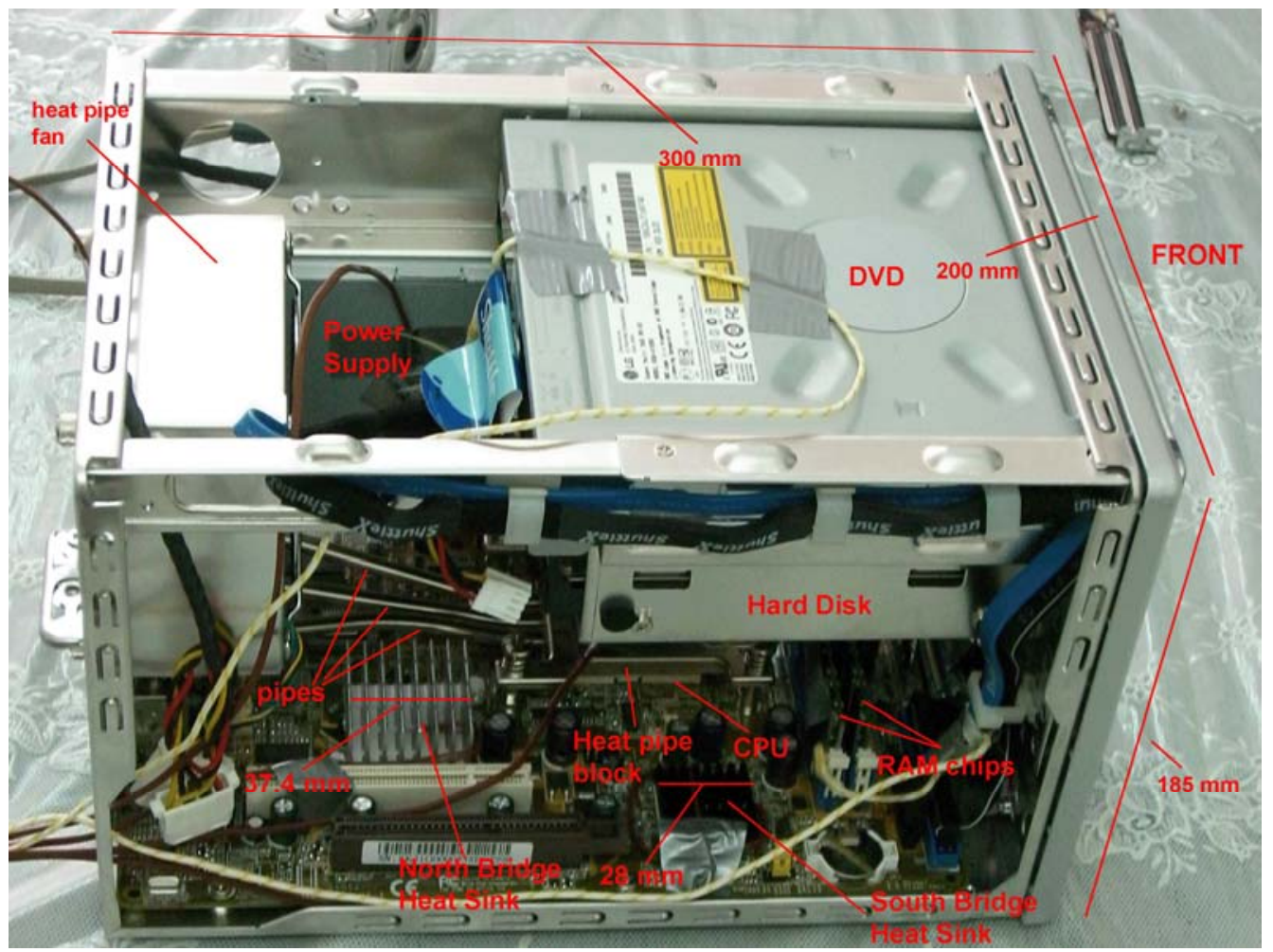

Figure 2.1 Shuttle XPC SK21G used in this study.

The modeling of the computer chassis is done in Icepak ${ }^{\mathrm{TM}}$. Here there are some important aspects to be considered;

- The size of the computational domain.

- The density and the quality of the computational grid.

The computational domain should be large enough to resolve the flow characteristics inside the chassis, and should be small enough to be computationally inexpensive. In this study, the computational domain is taken as the whole computer chassis. Although there are natural convection effects outside the chassis, these effects are taken into account using the lumped parameter modeling approach of Icepak $^{\mathrm{TM}}$ and a suitable heat transfer coefficient is assigned for the outsides of the 
chassis walls. Inside the chassis, only the parts that have major effect on the heat transfer are modeled such as hard disk, CPU, chipset, RAM. However, components like transistors, capacitors, resistors, cables, etc. are considered as negligible. When these components are modeled, the number of elements will be unnecessarily high that it will take a very long time to obtain a reasonable solution. Besides, the contribution of these elements to the flow characteristics is very small when compared to the other components such as power supply, hard disk, heat pipe. So, omitting these components can be considered as a reasonable assumption.

The density and quality of the computational grid is another important issue. The density of the mesh is increased in the areas where the resolution of the flow is important. However, a non-conformal computational grid is created in order to be able to decrease the computation time as much as possible. Finally, a high quality, unstructured hexahedral mesh is generated before the characteristic equations are solved and converged. Figure 2.2 shows a general mesh around the computer chassis. Details of the mesh generation are discussed in Appendix A.

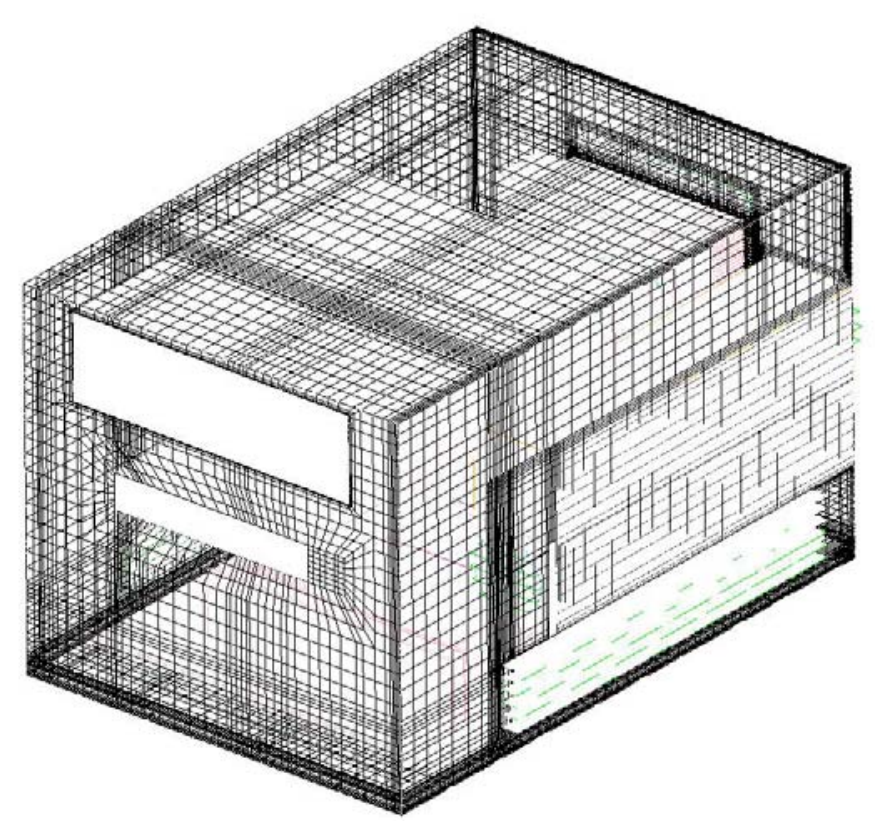

Figure 2.2 Computational grid obtained in Icepak ${ }^{\mathrm{TM}}$. 


\subsubsection{Computational Domain}

Computational domain is taken as the 3D computer chassis in this study. CPU, CPU heat pipe, chipset (including North Bridge and South Bridge and their heat sinks), power supply, RAM, hard disk, DVD Rom, mainboard, fans and grilles are modeled. Details of the computational domain can be seen in Figure 2.3.

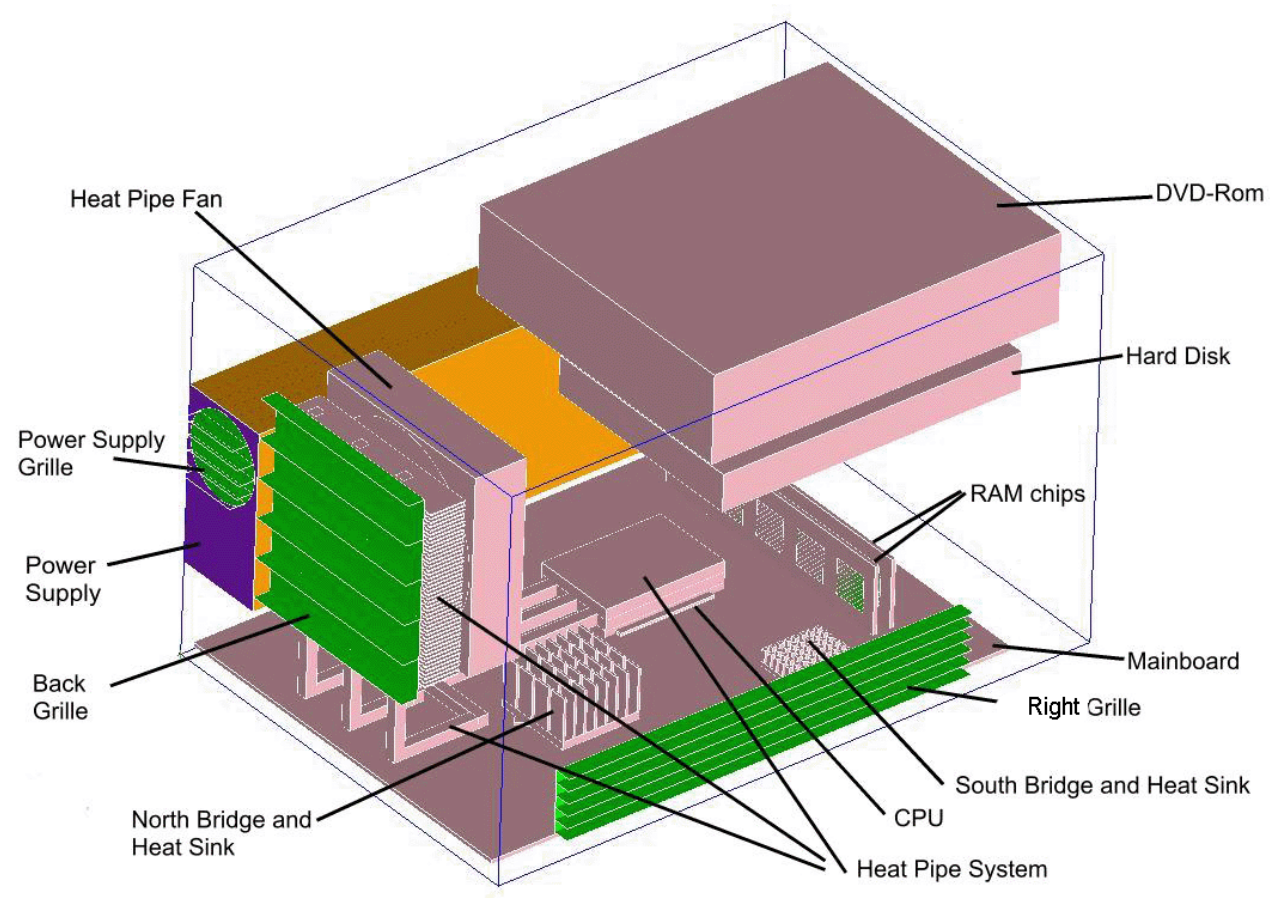

Figure 2.3 Computational domain created in Icepak ${ }^{\mathrm{TM}}$.

\subsubsection{Details of the Computational Domain}

In this section, the modeled components, except for the fans and the power supply, are discussed in detail. The details of the fans and the power supply will be given in the boundary conditions section. 


\subsubsection{Computer Chassis}

Computer chassis which is given in Figure 2.4, defines the outer boundary of the computational domain. Since free convection is the heat transfer mechanism outside the walls, a heat transfer coefficient is calculated for the vertical and horizontal walls. There exists no mesh outside the computer chassis, so these coefficients are applied to the outer walls. Finally, grilles are drawn to the left, right and back of the chassis to account for the flow through these grilles.

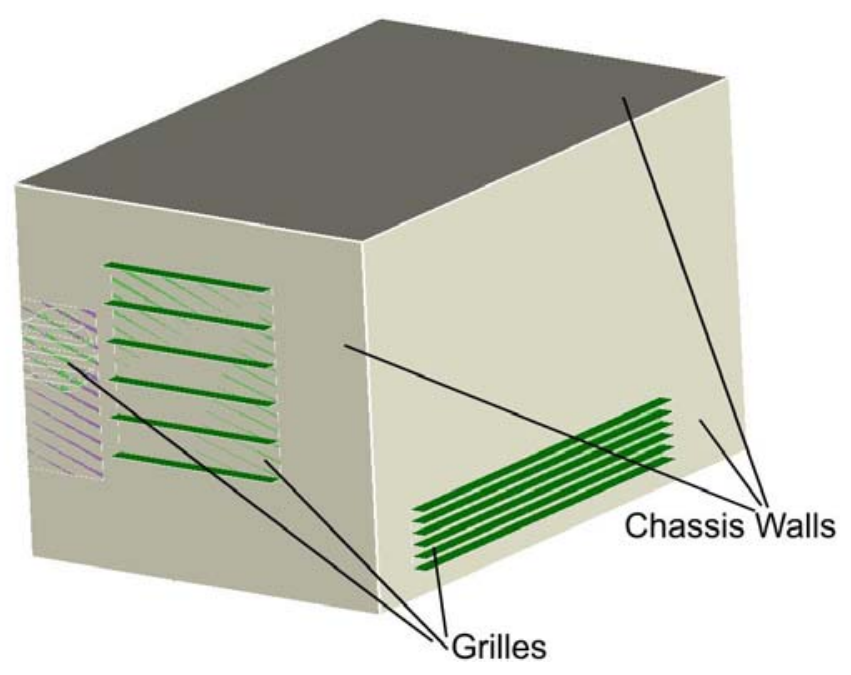

Figure 2.4 Computer Chassis

\subsubsection{CPU and Chipset}

CPU and the chipset are modeled using the same modeling approach. Since these components are "Integrated Circuits", they are formed as assemblies consisting of a solder, substrate, mold, die and a heat source component. This approach is called "compact conduction modeling" [32]. At the bottom of the package, there exists the solder material. Just above, there is a substrate and the mold material in turn. 
Finally, at the core there is the die with a source representing the power consumed by the CPU. They are the most detailed parts of the computer chassis for which the drawings can be seen in Figures 2.5, 2.6 and 2.7.

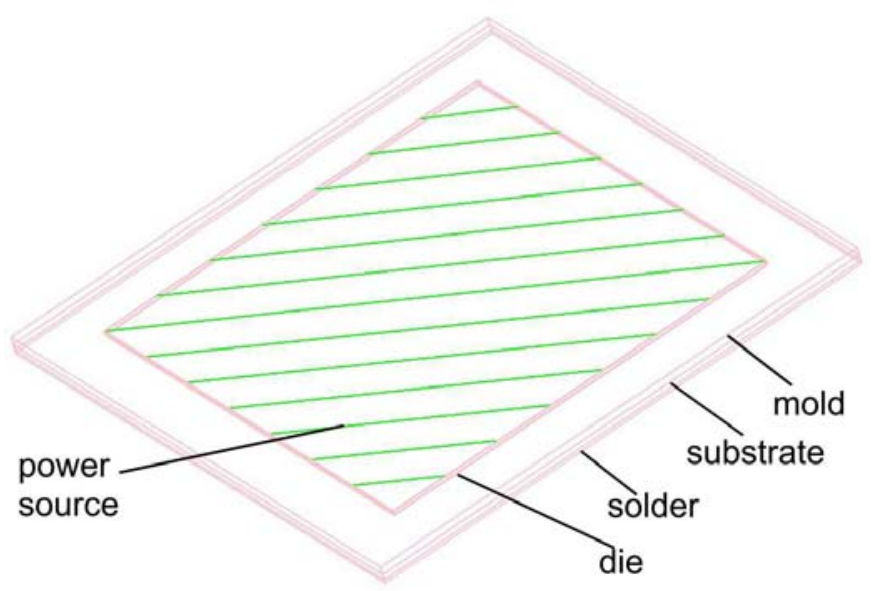

Figure 2.5 Details of the CPU Package.

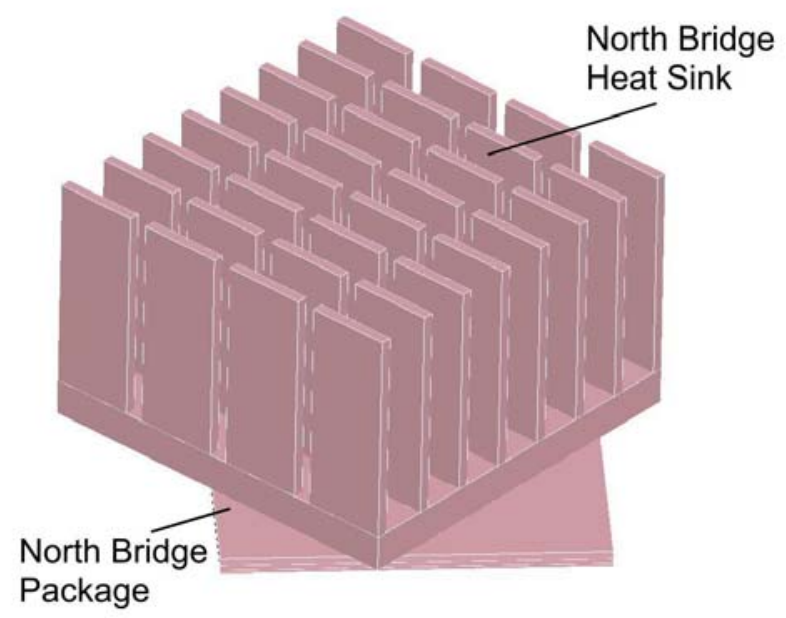

Figure 2.6 Details of North Bridge Package. 


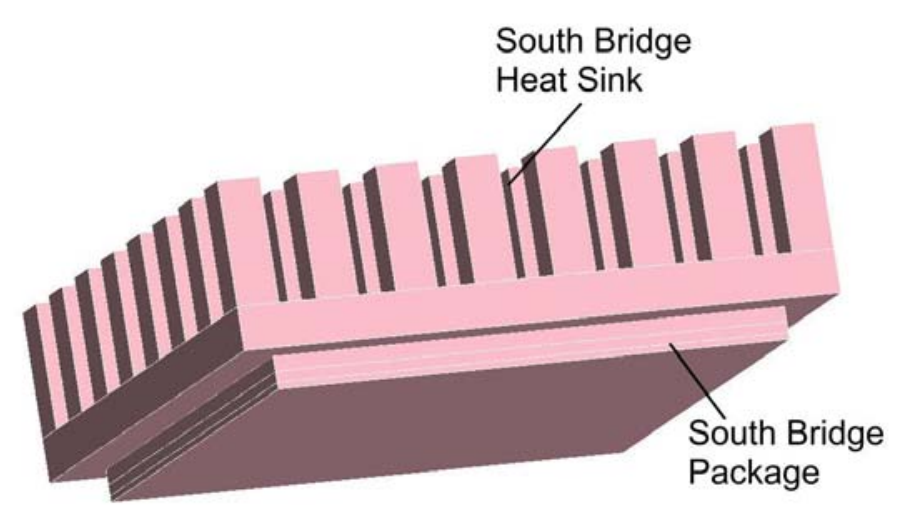

Figure 2.7 Details of South Bridge Packages.

\subsubsection{Heat Pipe System}

Heat pipes are passive devices that transport heat from a heat source (evaporator) to a heat sink (condenser) over relatively long distances via the latent heat of evaporation of a working fluid [30]. Since there exists no model for heat pipes in Icepak $^{\mathrm{TM}}$, heat pipe system, in Figure 2.8, should be modeled in order to represent the effects of the real system. For this to happen, pipes in the system are modeled as solid blocks with very high conductivities for the main heat transfer direction. This conductivity should be large enough to result in the same heat as that taken by the boiling heat pipe fluid [31]. These conductivity values change between 20000 $\mathrm{W} / \mathrm{mK}$ and $50000 \mathrm{~W} / \mathrm{mK}$. In this model, this conductivity value is chosen as 20000 $\mathrm{W} / \mathrm{mK}$. The conductivity values in the other directions can be taken as the conductivity of the heat pipe material. In addition of the pipes of the system, there are also very thin aluminum plate fins where the condensation takes place. These plate fins are $0.4 \mathrm{~mm}$ thick with $1.45 \mathrm{~mm}$ spacing and provide enough area for heat transfer. Finally, a $90 \mathrm{~mm}$ fan blows through the plates for forced convection. 

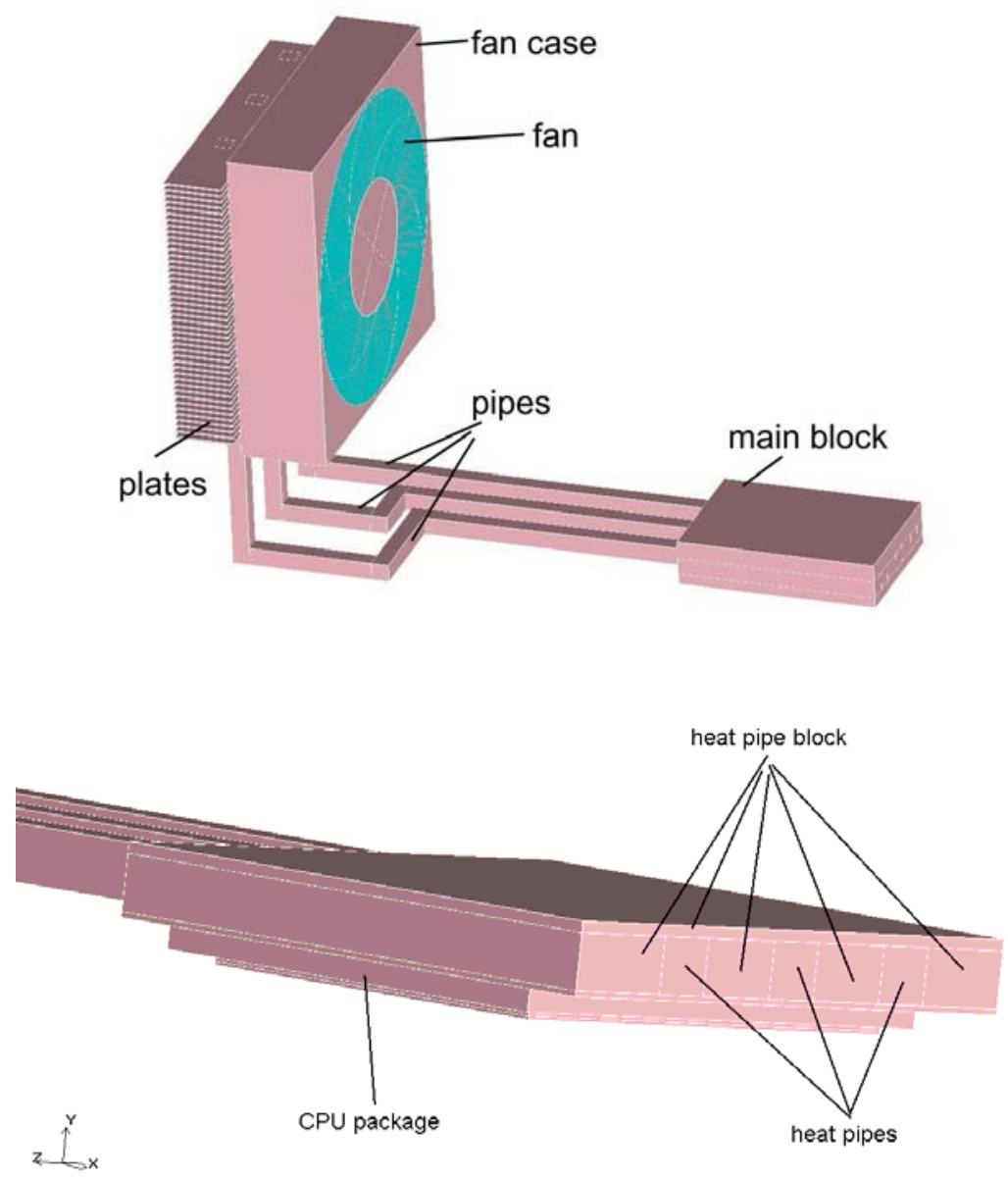

$z \stackrel{x}{x}$

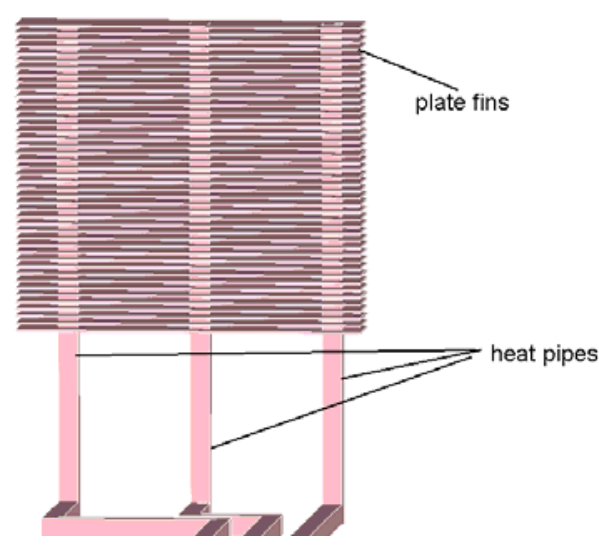

Figure 2.8 Details of the Heat Pipe System. 


\subsubsection{Chipset Heat Sinks}

There are two heat sinks on the North Bridge and South Bridge chips of the mainboard. They are passive heat sinks since there are no fans associated with them. A detailed modeling of the heat sinks is done together with a fine mesh around them in order to resolve the flow field correctly. Details of the heat sinks can be seen in Figures 2.6 and 2.7.

\subsubsection{RAM Chips}

There are two slots for RAM chips on the motherboard. Each RAM is modeled as a combination of a block and five heat sources. The conductivity value for the block is $0.4 \mathrm{~W} / \mathrm{mK}$ for the direction along the thickness and $40 \mathrm{~W} / \mathrm{mK}$ for the other directions which are commonly used values for PCB assemblies. In addition to blocks, each source is given a power dissipation value of $10 \%$ of their maximum power rating [32].

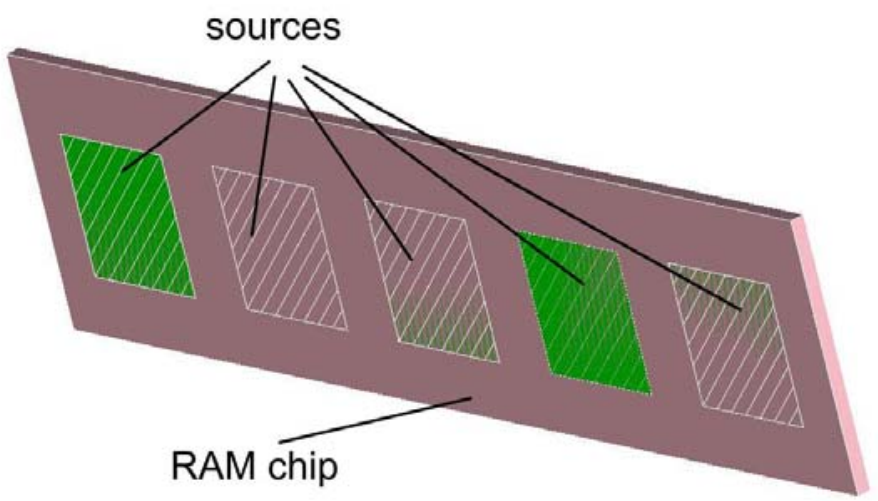

Figure 2.9 Details of the RAM chip. 


\subsubsection{Mainboard}

The mainboard is modeled as a 3D block. CPU, chipset and RAM blocks are directly placed on the motherboard. The conductivity value is chosen as $0.4 \mathrm{~W} / \mathrm{mK}$ along the thickness direction and $40 \mathrm{~W} / \mathrm{mK}$ in the other two directions as in modeling the RAM blocks.

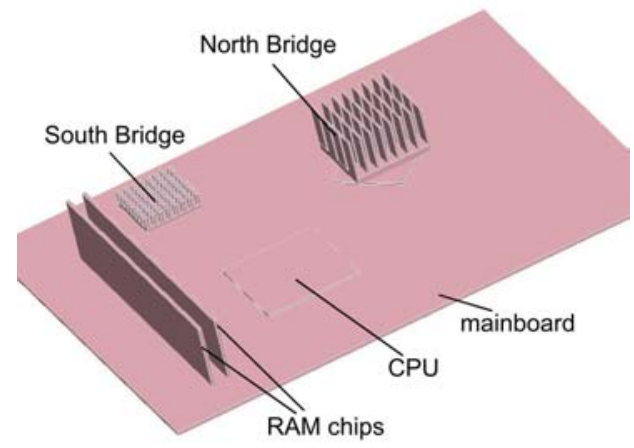

Figure 2.10 Mainboard and components on it.

\subsubsection{Hard Drive and DVD-Rom}

Hard drive and the DVD-Rom are modeled as hollow blocks since their details are not important for the purpose of this study. However, they occupy a relatively large space inside the chassis and they also generate some heat, therefore can not be neglected. Average power dissipation values of $15 \mathrm{~W}$ for the hard drive and $5 \mathrm{~W}$ for the DVD-Rom are assigned. 


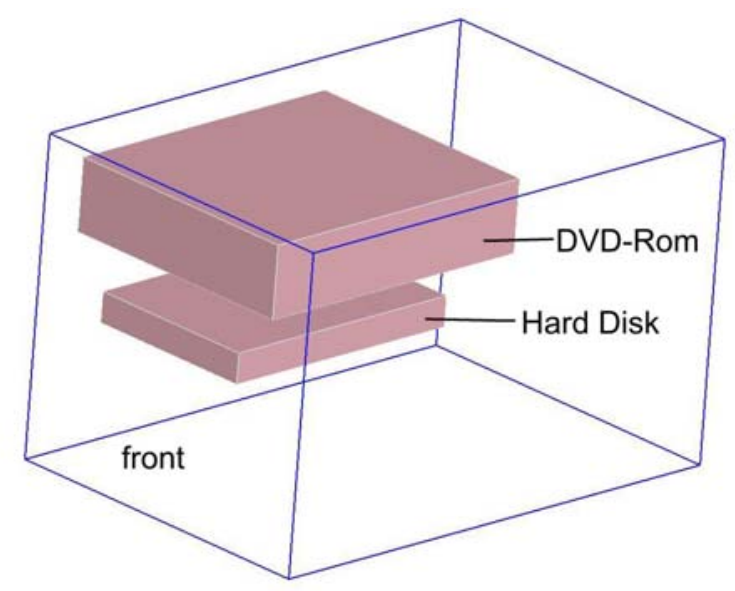

Figure 2.11 DVD-Rom and hard disk.

\subsubsection{Grilles}

There are five grilles in the model. Grilles are the components of the model through which air can flow in or out. Since the modeling of every hole on the cabinet or inside the chassis would be computationally very expensive, grilles are used with certain free area ratios. Based on these free area ratios, Icepak ${ }^{\mathrm{TM}}$ can calculate the pressure drop through a grille. Details and locations of the grilles can be seen in Figures 2.3 and 2.4 .

\subsection{Solver Execution}

Solver execution consists of the mathematical model together with the governing equations, several features of the flow and the boundary conditions. The details of these items are given in this part. 


\subsubsection{Governing Equations of Fluid Flow}

Here, the general forms of the governing equations of the fluid flow are represented. They include the compressibility and the turbulence effects as well as the source terms:

Conservation of

mass:

$$
\frac{\partial \rho}{\partial t}+\nabla \cdot(\rho \vec{V})=0
$$

X-momentum:

$$
\frac{\partial(\rho u)}{\partial t}+\nabla \cdot(\rho u \vec{V})=-\frac{\partial p}{\partial x}+\frac{\partial \tau_{x x}}{\partial x}+\frac{\partial \tau_{y x}}{\partial y}+\frac{\partial \tau_{z x}}{\partial z}+\rho f_{x}
$$

y-momentum:

$$
\frac{\partial(\rho v)}{\partial t}+\nabla \cdot(\rho v \vec{V})=-\frac{\partial p}{\partial y}+\frac{\partial \tau_{x y}}{\partial x}+\frac{\partial \tau_{y y}}{\partial y}+\frac{\partial \tau_{z y}}{\partial z}+\rho f_{y}
$$

z-momentum:

$$
\frac{\partial(\rho w)}{\partial t}+\nabla \cdot(\rho w \vec{V})=-\frac{\partial p}{\partial z}+\frac{\partial \tau_{x z}}{\partial x}+\frac{\partial \tau_{y z}}{\partial y}+\frac{\partial \tau_{z z}}{\partial z}+\rho f_{z}
$$

energy:

$$
\frac{\partial(\rho e)}{\partial t}+\nabla \cdot(\rho e \vec{V})=-p \nabla \cdot \vec{V}+\nabla \cdot(k \nabla T)+\Phi+\dot{q}
$$

equation of state:

$$
p=\rho R T
$$

For the above equations $\rho$ is the density; $u, v$ and $w$ are the velocity components in the $\mathrm{x}, \mathrm{y}$ and $\mathrm{z}$ respectively, $\vec{V}$ is the velocity vector, $f_{\mathrm{x},} f_{\mathrm{y}}$ and $f_{\mathrm{z}}$ are the body forces, $p$ is pressure, $q$ is the heat flux as a source term, $\mathrm{R}$ is the gas constant and $\tau$ is the viscous stress which can be defined for Newtonian fluids as:

$$
\begin{aligned}
& \tau_{x x}=\lambda\left(\frac{\partial u}{\partial x}+\frac{\partial v}{\partial y}+\frac{\partial w}{\partial z}\right)+2 \mu \frac{\partial u}{\partial x} \\
& \tau_{y y}=\lambda\left(\frac{\partial u}{\partial x}+\frac{\partial v}{\partial y}+\frac{\partial w}{\partial z}\right)+2 \mu \frac{\partial v}{\partial y} \\
& \tau_{z z}=\lambda\left(\frac{\partial u}{\partial x}+\frac{\partial v}{\partial y}+\frac{\partial w}{\partial z}\right)+2 \mu \frac{\partial w}{\partial z}
\end{aligned}
$$




$$
\begin{aligned}
& \tau_{x y}=\tau_{y x}=\mu\left(\frac{\partial u}{\partial y}+\frac{\partial v}{\partial x}\right) \\
& \tau_{x z}=\tau_{z x}=\mu\left(\frac{\partial u}{\partial z}+\frac{\partial w}{\partial x}\right) \\
& \tau_{y z}=\tau_{z y}=\mu\left(\frac{\partial v}{\partial z}+\frac{\partial w}{\partial y}\right)
\end{aligned}
$$

In these equations, $\mu$ is the molecular viscosity coefficient and $\lambda$ is the second viscosity coefficient which according to Stokes can be approximated as [23]:

$$
\lambda=-\frac{2}{3} \mu
$$

In the energy equation, Eq.2.5, $e$ is the internal energy, $k$, is the thermal conductivity of the fluid and $\Phi$ is the viscous dissipation function which represents the dissipation of mechanical energy into heat. It can be expressed as:

$$
\Phi=\lambda(\nabla \cdot \vec{V})^{2}+\mu\left[\begin{array}{l}
2\left(\frac{\partial u}{\partial x}\right)^{2}+2\left(\frac{\partial v}{\partial y}\right)^{2}+2\left(\frac{\partial w}{\partial z}\right)^{2}+ \\
\left(\frac{\partial u}{\partial y}+\frac{\partial v}{\partial x}\right)^{2}+\left(\frac{\partial u}{\partial z}+\frac{\partial w}{\partial x}\right)^{2}+\left(\frac{\partial v}{\partial z}+\frac{\partial w}{\partial y}\right)^{2}
\end{array}\right]
$$

Dissipation function is significant only for flows involving high speeds and high viscosity. Since the flow inside the computer is neither a high speed nor a high viscous flow, this function can be omitted.

\subsubsection{Governing Equations to be Solved}

The governing equations of the flow are modified according to the conditions of the simulated case. Since the problem is assumed to be steady state with low velocities. Therefore, time dependent parameters are dropped from equations 2.1 to 2.5, 
together with the viscous dissipation term. Equation 2.6, which is the equation of state, is also omitted due to the incompressibility of air. The resulting equations are:

Conservation of

mass:

$\mathrm{X}$-momentum:

y-momentum:

z-momentum:

energy:

$$
\nabla \cdot(\rho \vec{V})=0
$$

Since the flow in this study is turbulent, turbulence effects should be taken into account. Some details of turbulence modeling can be found in Appendix B. Here, Reynolds averaging will be used. Reynolds averaging is the standard method of determining the influence of the turbulent motion on the mean unsteady flow and heat transfer. The instantaneous flow variables appearing in the governing equations are first decomposed into mean and fluctuating components such as [27].

$$
\varphi=\bar{\varphi}+\varphi^{\prime}
$$

where $\bar{\varphi}$ and $\varphi^{\prime}$ are the mean and fluctuating components of any variable $\varphi$ such as the velocity component in $\mathrm{x}$ direction or pressure.

After substituting the mean and fluctuating components of the flow variables and applying Reynolds averaging gives: 
Conservation of

mass:

$$
\nabla \cdot(\rho \vec{V})=0
$$

X-momentum:

$$
\begin{aligned}
& \nabla \cdot(\rho u \vec{V})=-\frac{\partial p}{\partial x}+\nabla \cdot\left(\mu_{e f f} \nabla u\right)+ \\
& {\left[-\frac{\partial\left(\rho \overline{u^{\prime 2}}\right)}{\partial x}-\frac{\partial\left(\rho \overline{u^{\prime} v^{\prime}}\right)}{\partial y}-\frac{\partial\left(\rho \overline{u^{\prime} w^{\prime}}\right)}{\partial z}\right]+\rho f_{x}}
\end{aligned}
$$

y-momentum:

$$
\begin{aligned}
& \nabla \cdot(\rho v \vec{V})=-\frac{\partial p}{\partial y}+\nabla \cdot\left(\mu_{e f f} \nabla v\right)+ \\
& {\left[-\frac{\partial\left(\rho \overline{u^{\prime} v^{\prime}}\right)}{\partial x}-\frac{\partial\left(\rho \overline{v^{\prime 2}}\right)}{\partial y}-\frac{\partial\left(\rho \overline{v^{\prime} w^{\prime}}\right)}{\partial z}\right]+\rho f_{y}}
\end{aligned}
$$

z-momentum:

$$
\begin{aligned}
& \nabla \cdot(\rho w \vec{V})=-\frac{\partial p}{\partial z}+\nabla \cdot\left(\mu_{e f f} \nabla w\right)+ \\
& {\left[-\frac{\partial\left(\rho \overline{u^{\prime} w^{\prime}}\right)}{\partial x}-\frac{\partial\left(\rho \overline{v^{\prime} w^{\prime}}\right)}{\partial y}-\frac{\partial\left(\rho \overline{w^{\prime 2}}\right)}{\partial z}\right]+\rho f_{z}}
\end{aligned}
$$

energy:

$$
\nabla \cdot(\rho e \vec{V})=-p \nabla \cdot \vec{V}+\nabla \cdot\left(k_{e f f} \nabla T\right)+\dot{q}
$$

where $\mu_{e f f}$ is the effective viscosity and $k_{\text {eff }}$ is the effective thermal conductivity. Since there is the effect of turbulence, both of these terms are represented as the sum of molecular and turbulent components such as:

$$
\begin{aligned}
& k_{e f f}=k+k_{t} \\
& \mu_{e f f}=\mu+\mu_{t}
\end{aligned}
$$

Equations 2.21-2.25 are called Reynolds Averaged Navier Stokes (RANS) equations. In these equations flow variables are now represented by time averaged values instead of instantaneous ones. However, occurrence of the additional terms such as $\frac{\partial\left(\rho \overline{u^{\prime 2}}\right)}{\partial x}$ resembles the effect of turbulence. These additional terms are 
called Reynolds stresses and need to be modeled to be able to solve the governing equations.

Reynolds stresses can be related to the mean velocity gradients. According to this approach, Reynolds stresses can be modeled as [28]:

$$
\tau_{i j}=-\rho \overline{u_{i}^{\prime} u_{j}^{\prime}}=\mu_{e f f}\left(\frac{\partial u_{i}}{\partial x_{j}}+\frac{\partial u_{j}}{\partial x_{i}}\right)
$$

where $i$ or $j=1,2,3$ represents the three components of the variables in $x, y$ and $z$ directions respectively. Here comes the problem of modeling, $\mu_{t}$ turbulent viscosity of the effective viscosity $\mu_{\text {eff }}$. The modeling of turbulent viscosity can be different according to which turbulence model is employed. In this study, two basic turbulence models that reside in Icepak $^{\mathrm{TM}}$ will be used: Zero equation mixing length, and $\mathrm{k}-\varepsilon$ turbulence models.

Zero- equation Turbulence Model:

According to zero equation mixing length model, there is no additional equation. Therefore turbulent viscosity is defined as [26],

$$
\mu_{t}=\rho l^{2} S
$$

The mixing length $l$ is defined as;

$$
l=\min \left(\kappa d, 0.09 d_{\max }\right)
$$

where $d$ is the distance from the wall and $k=0.419$ is the von Karman constant. 
$S$ is the modulus of the mean rate of strain tensor which is defined as;

$$
S \equiv \sqrt{2 S_{i j} S_{i j}}
$$

where $S_{i j}$ is the mean strain rate and is given by;

$$
S_{i j}=\frac{1}{2}\left(\frac{\partial u_{j}}{\partial x_{i}}+\frac{\partial u_{i}}{\partial x_{j}}\right)
$$

\section{$\underline{k-\varepsilon \text { Turbulence Model: }}$}

In a case where $k-\varepsilon$ turbulence model is employed, two additional equations need to be solved in order to find turbulent viscosity. These are the equation of turbulence kinetic energy, $k$ and its rate of dissipation, $\varepsilon$. These equations can be expressed as:

$$
\begin{gathered}
\frac{\partial}{\partial x_{i}}\left(\rho k u_{i}\right)=\left[\frac{\partial}{\partial x_{j}}\left(\mu+\frac{\mu_{t}}{\sigma_{k}}\right) \frac{\partial k}{\partial x_{j}}\right]+G_{k}+G_{b}+\rho \varepsilon+S_{k} \\
\frac{\partial}{\partial x_{i}}\left(\rho \varepsilon u_{i}\right)=\left[\frac{\partial}{\partial x_{j}}\left(\mu+\frac{\mu_{t}}{\sigma_{\varepsilon}}\right) \frac{\partial \varepsilon}{\partial x_{j}}\right]+C_{1 \varepsilon} \frac{\varepsilon}{k}\left(G_{k}+C_{3 \varepsilon} G_{b}\right)-C_{2 \varepsilon} \rho \frac{\varepsilon^{2}}{k}+S_{\varepsilon}
\end{gathered}
$$

where $G_{k}$ represents the production of turbulence kinetic energy due to mean velocity gradients, $G_{b}$ is the generation of turbulence kinetic energy due to buoyancy. $C_{1 \varepsilon}, C_{2 \varepsilon}$ and $C_{3 \varepsilon}$ are constants. $\sigma_{k}$ and $\sigma_{\varepsilon}$ are the turbulent Prandtl numbers for $k$ and $\varepsilon$ respectively. $S_{k}$ and $S_{\varepsilon}$ are the user defined source terms [26].

For this turbulence model, turbulent viscosity is defined as:

$$
\mu_{t}=\rho C \mu \frac{k^{2}}{\varepsilon}
$$

where $C_{\mu}$ is a constant. 
The production of turbulent kinetic energy is defined as;

$$
G_{k}=\mu_{t} S^{2}
$$

for which the model constants are;

$C_{1 \varepsilon}=1.44$

$C_{2 \varepsilon}=1.92$

$C_{\mu}=0.09$

$\sigma_{k}=1.0$

$\sigma_{\varepsilon}=1.3$

These are the default values which can be found in the study of Launder and Spalding [35] adapted to Icepak ${ }^{\mathrm{TM}}$. These coefficients are obtained from experiments with air and water for basic turbulent flows and were reasonable for a wide range of wall bounded and free shear flows [26].

\subsubsection{Boundary Conditions}

In this study, since Navier-Stokes equations are solved, the boundary conditions for velocity and temperature fields are needed.

\subsubsection{Velocity Boundary Conditions}

No-slip boundary conditions are applied at all walls. Therefore for all walls and for all other interior surfaces,

$$
u=v=w=0
$$




\subsubsection{Heat Transfer Coefficients at Chassis Walls}

Since the computational domain is selected as the computer chassis, heat transfer coefficients outside the computer chassis walls should be calculated according to free convection heat transfer correlations. Free convection heat transfer coefficients, in general, are between 2 and $25 \mathrm{~W} / \mathrm{m}^{2} \mathrm{~K}$.

There are several procedures to calculate this heat transfer coefficient. One is an iterative process in which a coefficient is assigned for the walls and then an analysis is run. From the temperature distribution on the chassis wall, heat transfer coefficient is calculated form the correlations and then updated for the next analysis. This iterative procedure is ended when there is a match-up between the correlation and the analysis results. However, if one can measure the ambient temperature and the temperature value on the chassis walls, then it is very easy to calculate the heat transfer coefficient from the correlations. From the experiments, which are discussed in Chapter 3 in detail, ambient temperature is measured as 28 ${ }^{\circ} \mathrm{C}$. Then a wall temperature of $33{ }^{\circ} \mathrm{C}$ is assumed considering that the chassis is made out of brushed aluminum. For these temperature values Rayleigh number can be calculated as [25],

$$
R a_{L}=G r_{L} \operatorname{Pr}=\frac{g \beta\left(T_{s}-T_{\infty}\right) L^{3}}{v \alpha}
$$

where, gravitational acceleration $g$, is $9.81 \mathrm{~m} / \mathrm{s}^{2}$, kinematic viscosity $v$, is $15.89 \times 10^{-6}$, thermal diffusivity $\alpha$, is $22.50 \times 10^{-6}$ for $300 \mathrm{~K}$. The length of the vertical plate, $L$ is $0.18 \mathrm{~m}$, average wall temperature, $T_{s}$ is $33{ }^{\circ} \mathrm{C}$ and ambient temperature, $T_{\infty}$ is $28^{\circ} \mathrm{C}$. Using these values Rayleigh number is,

$$
R a_{L}=\frac{9.81 \frac{1}{301}(33-28)(0.18)^{3}}{15.89 \times 10^{-6} .22 .50 \times 10^{-6}}=2.66 \times 10^{6}
$$


Since Rayleigh number is less than $1 \times 10^{9}$, then the flow is laminar. From the correlation of free convection on a vertical plate for laminar flow [25],

$$
\begin{gathered}
\overline{N u}_{L}=0.68+\frac{0.670 R a_{L}{ }^{1 / 4}}{\left[1+(0.492 / \mathrm{Pr})^{9 / 16}\right]^{4 / 9}} \\
\overline{N u}_{L}=0.68+\frac{0.670\left(2.66 \times 10^{6}\right)^{1 / 4}}{\left[1+(0.492 / 0.707)^{9 / 16}\right]^{4 / 9}}=20.75 \\
h=\frac{\overline{N u}_{L} k}{L}
\end{gathered}
$$

where thermal conductivity of air $k=26.3 \times 10^{-3} \mathrm{~W} / \mathrm{mK}$ for $300 \mathrm{~K}$.

$$
h=3.03 \approx 3 \quad \mathrm{~W} / \mathrm{m}^{2} \mathrm{~K}
$$

This value is applied to all vertical walls of the chassis. For the horizontal plate, which is the upper wall, heat transfer coefficient can be calculated from the horizontal plate correlation for laminar flow [25]. For horizontal plates, instead of the true length, a characteristic length, $L_{c h}$ is calculated from $L_{c h}=A / P$ where $A$ is the surface area of the plate and $P$ is the perimeter of the plate.

$$
\begin{gathered}
L=\frac{0.29 \times 0.198}{2(0.29+0.198)}=0.059 \\
R a_{L}=\frac{9.81 \frac{1}{301}(33-28)(0.059)^{3}}{15.89 \times 10^{-6} .22 .50 \times 10^{-6}}=9.36 \times 10^{4}
\end{gathered}
$$

For this value of Rayleigh number, Nusselt number is defined as,

$$
\overline{N u}_{L}=0.54 R a_{L}{ }^{1 / 4} \text { for } 10^{4} \leq R a_{L} \leq 10^{7}
$$




$$
\begin{gathered}
\overline{N u}_{L}=0.54\left(9.36 \times 10^{4}\right)^{1 / 4}=9.45 \\
h=\frac{8.88 \times 26.3 \times 10^{-3}}{0.059}=4.2 \mathrm{~W} / \mathrm{m}^{2} \mathrm{~K}
\end{gathered}
$$

This heat transfer coefficient is applied only to the top surface of the chassis since the space between the ground and the bottom surface of the chassis is very small. Therefore the flow under the bottom surface is neglected and the heat transfer coefficient for the bottom surface is taken as 0 . When these heat transfer coefficients are applied and another analysis is run, the wall temperature is found to be $34{ }^{\circ} \mathrm{C}$. So there is no need for further iterations, these coefficients can be used for later analyses.

\subsubsection{Power Budget for the Chassis}

Power ratings for the components inside the chassis are given in Table 2.1. The decision of these power ratings is a kind of cumbersome task. Especially, the power ratings of the $\mathrm{CPU}$, north and south bridge chips are found out after an iterative process since the real heat dissipation values of these components are not known to anyone other than the manufacturer. The heat dissipation of the power supply is also assigned after some discussions and survey [32]. These values are decided by comparing the experimental results with the CFD results. When a reasonable agreement is achieved, the iterations are terminated. Power ratings of the DVD and the hard drive are taken from the study of Öztürk [12]. 
Table 2.1 Power budget of the components

\begin{tabular}{|c|c|c|c|}
\hline \multirow[b]{2}{*}{ Object Name } & \multirow[b]{2}{*}{ Material } & \multicolumn{2}{|c|}{ Heat Dissipation Rates (W) } \\
\hline & & $\begin{array}{l}\text { SK21G } \\
\text { (AMD ) }\end{array}$ & $\begin{array}{l}\text { SS59GV2 } \\
\text { (Pentium) }\end{array}$ \\
\hline $\mathrm{CPU}$ & Package & 25 & 50 \\
\hline DVD & $\mathrm{Al}$ & 5 & 5 \\
\hline Hard drive & $\mathrm{Al}$ & 15 & 15 \\
\hline North Bridge & Package & 2.5 & 3.5 \\
\hline South Bridge & Package & 1.25 & 1.5 \\
\hline North Bridge heat sink & $\mathrm{Al}$ & - & - \\
\hline South Bridge heat sink & $\mathrm{Al}$ & - & - \\
\hline Heat pipe system & $\mathrm{Al}-\mathrm{Cu}$ & - & - \\
\hline Power supply & Porous & 25 & 30 \\
\hline Mainboard & FR4 & - & - \\
\hline DIMM & FR4 & $0.5 \times 2$ & $0.5 \times 2$ \\
\hline
\end{tabular}

\subsubsection{Fans}

There are two fans used inside the chassis one of which is associated with the power supply while the other one is related with the heat pipe. Each of these fans, are modeled using one solid block, one fluid block and a 2D fan. This is in fact the modeling idea behind a 3D fan in Icepak ${ }^{\mathrm{TM}}$. 2D fan is not a real fan, but it is a lumped parameter model for which you can define a momentum source added to the fluid. This addition can be based on a linear or a non-linear flow approach. In this study, fan performance curves for each fan, Figure 2.12, are entered. Fan of the heat pipe system can be seen in Figure 2.8. 


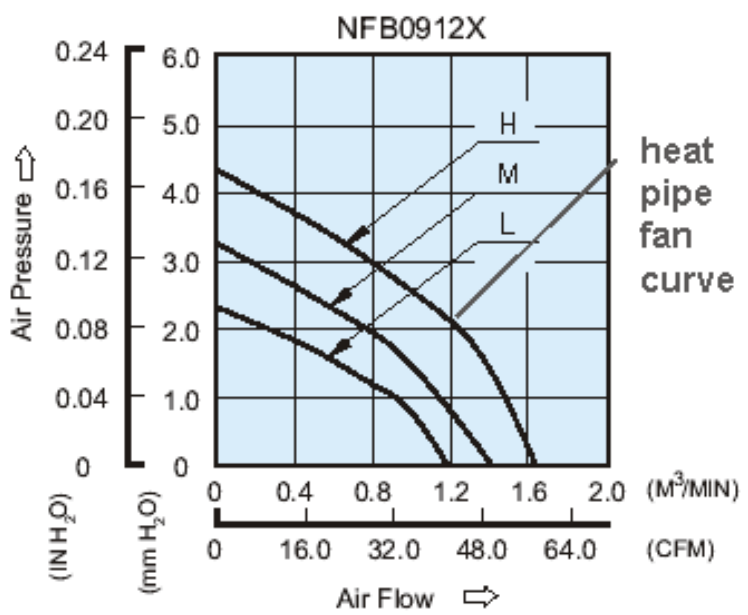

\section{Performance Curves}

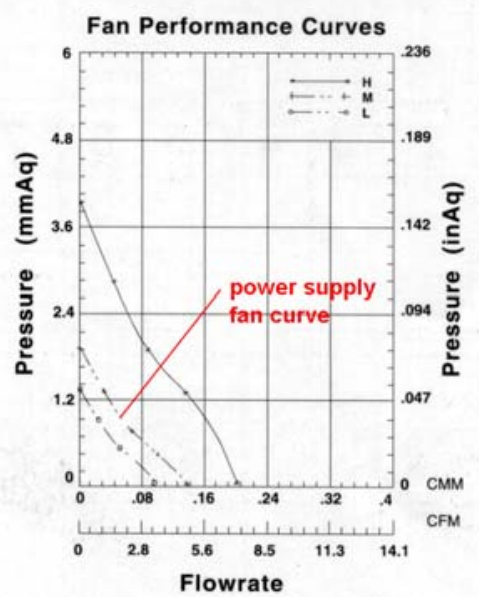

Figure 2.12 Performance curves for the heat pipe fan and power supply fan.

\subsubsection{Power supply}

The modeling of the power supply is totally different than other components in this study. The power supply is a resistance to flow; therefore, it is modeled using resistance feature in Icepak ${ }^{\mathrm{TM}}$. The effect of resistance is modeled as a pressure drop through its volume [26]. However; there are two possible methods to calculate the pressure drop, approach velocity and device velocity methods which only differ by a factor which is called the free area ratio.

As a general practice in Icepak ${ }^{\mathrm{TM}}$, for laminar flows a linear velocity relationship should be selected $(n=1)$, whereas a quadratic relationship $(n=2)$ should be selected for a turbulent flow. In this study approach velocity method is used together with a quadratic relation between the pressure drop and the fluid velocity. The approach velocity method in Icepak ${ }^{\mathrm{TM}}$ can be defined as; 


$$
\Delta p=\rho \frac{l}{2} v_{a p p}^{n}
$$

where $\rho$ is the density of the fluid, $v_{a p p}$ is the approach velocity in the appropriate direction computed by Icepak ${ }^{\mathrm{TM}}$ and $l_{c 1}$ is the user defined loss coefficients defined in all directions. Here the value of $n$ is used for the velocity dependence, and $n=2$ is chosen for quadratic relation. The values for $l_{c 1}$ are taken as 30 in $x$ direction and 300 in $y$ and $z$ directions respectively [32].

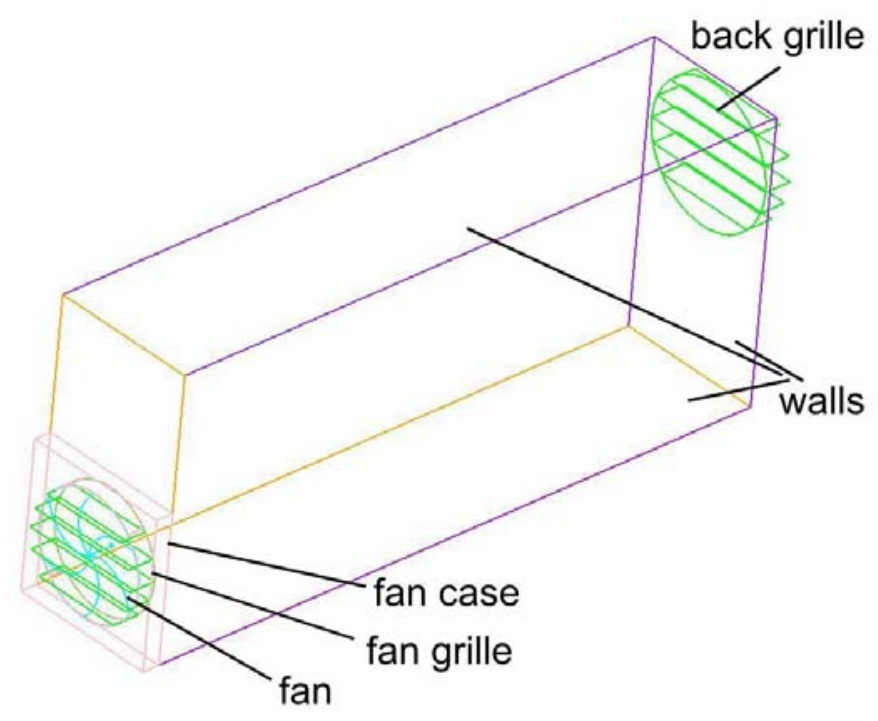

Figure 2.13 Details of the power supply.

\subsection{Experimental Procedure}

CFD is a complement to experiments for most applications. Therefore, an experimental study is needed. However, the experiments, here, can not fully complement CFD since they should be conducted in more controlled environments. 
Two different experiments are conducted in this study. The first experiment is performed using Shuttle SK21G which has an AMD Sempron 3000+ CPU and the second one is using Shuttle SS59GV2 with an Intel Pentium 4 (3.2 GHz) CPU. The experimental procedure is almost the same for both of the G-type SFF case computers, however; there are some differences regarding the types and locations of the chipsets and CPUs.

Four thermocouples are attached to the most critical locations inside the chassis. One of them is on the heat pipe system which is located on the CPU, two of them are inserted into the heat sink bases of the chipset and the last one is on the power supply. Since the locations of the chipset and the CPU are different in two chassis configurations, the thermocouple locations also differ. The details of the thermocouple locations can be found in Appendix C.

\subsubsection{Details of the Experimental Setup}

In this part, the experimental setup is discussed in detail. The specifications of the data logger system and the thermocouples are given. Finally, an explanation of the experimental procedure is presented.

\subsubsection{Data Logger System}

For data management in the experiments, Elimko E680 eight channel data logger system which can be seen in Figure 2.14, is used. The system prints data out through the RS485 port. This port is diverted to RS232 by a converter and connected to the computer via RS232. With the help of the data logger software, it is possible to obtain data from eight different channels. After the collection of data, it can be post-processed using Excel. 


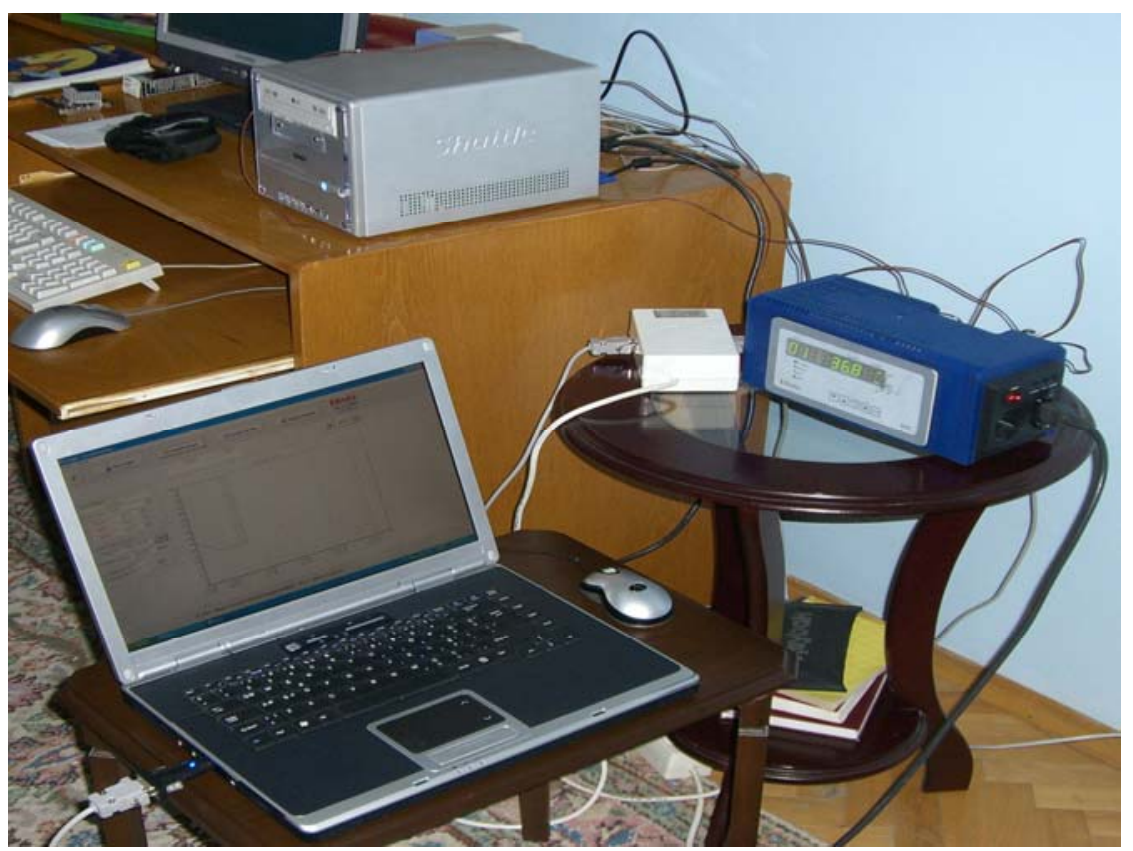

Figure 2.14 Data logger system during temperature measurements.

\subsubsection{Thermocouples}

Together with the data logger system, thermocouples are used for temperature measurements. To measure temperature, the most common way is to acquire thermocouples.

Thermocouples are simple devices, which are produced by soldering two different alloys from one end. The welded end is considered as hot spot and the other two open ends are considered as cold spots. The working principle of thermocouples is based on measuring the temperature difference between the hot spot and the cold spot. And depending on this temperature difference, a voltage on $\mathrm{mV}$ level is generated. 
All the thermocouples used are $\mathrm{NiCr}-\mathrm{Ni}$, K-type ones. K-type thermocouples are general purpose ones, with their low cost. Therefore, they are very common for experimental use. They can be used in the range of $-200^{\circ} \mathrm{C}$ to $+1200^{\circ} \mathrm{C}$.

The thermocouples used in the experiments, are the products of Stanford Research Institute. The accuracy of the thermocouples is $\pm 0.1{ }^{\circ} \mathrm{C}$. This value together with the accuracy of the data logger system which is $\pm 0.005 \mathrm{mV}$ will be used in the uncertainty analysis is presented in section 3.3.3. Additional check is done for the thermocouples measuring the freezing point in an ice-bath and the boiling point in a cup. $0{ }^{\circ} \mathrm{C}$ and $97{ }^{\circ} \mathrm{C}$ were obtained for freezing and boiling points, respectively. The measurements were accurate enough so they are used for the experiments. The bead size of the thermocouples, on the other hand, is relatively large for the experiments. This, of course, decreases the sensitivity of the measurements.

\subsubsection{Temperature Measurements}

As mentioned above, the temperature measurements are performed in four distinct locations inside the chassis. One of the thermocouple locations can be seen in Figure 2.15 and the details of the other locations can be found in Appendix C.

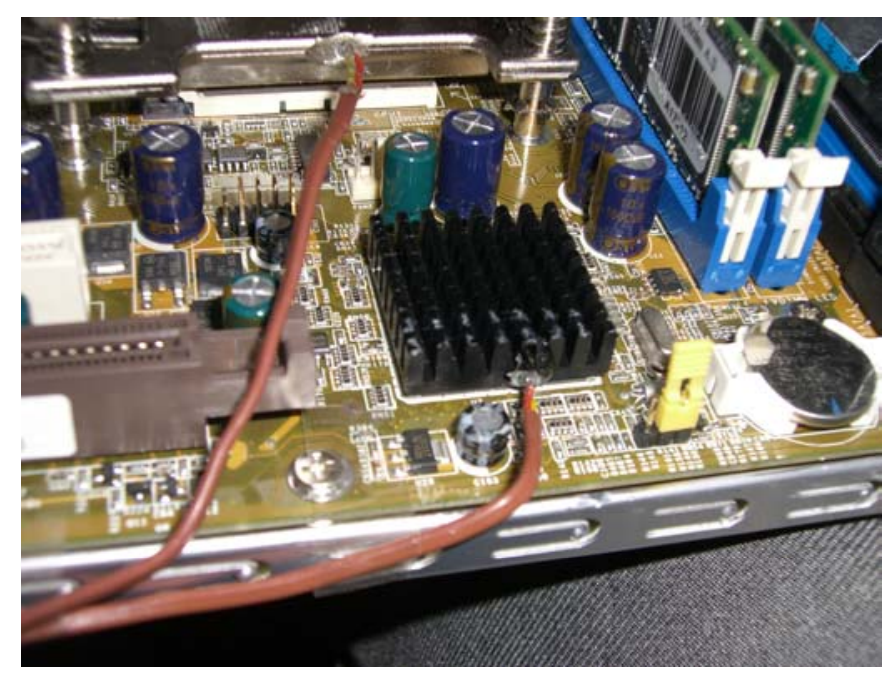


Figure 2.15 Thermocouples on the heat pipe block and the south bridge heat sink.

The choice of these locations is not arbitrary. When inserting the thermocouples, the most critical and crucial components are considered and chosen. On the other hand, insertion of the thermocouples was not easy for such small form factor computers. To attach the thermocouples inside the heat sink bases and heat pipe block, these components are drilled using a small driller. Then the thermocouples are inserted and kept in place using epoxy. Since the epoxy is not a thermal one, a very small amount is used just to fix the thermocouples. Finally, the thermocouple on the power supply is fixed on one of the sides of the power supply. Therefore, the contact area of that thermocouple is not as good as the other ones. All thermocouple locations are measured using a caliper, to be able to fix their locations in the CFD models.

When the insertion of the thermocouples is complete, the system is ready for temperature measurements. After initializing the system, CPU is stressed, using a burn-in software which keeps the CPU load at 100\% for about thirty minutes. Hyper-threading feature is kept off during the measurements. In this period, temperature values are observed and recorded until they reach steady state. Finally, these results are saved as an Excel file and analyzed. An example of a recording reaching steady state can be seen in Figure 2.16. 


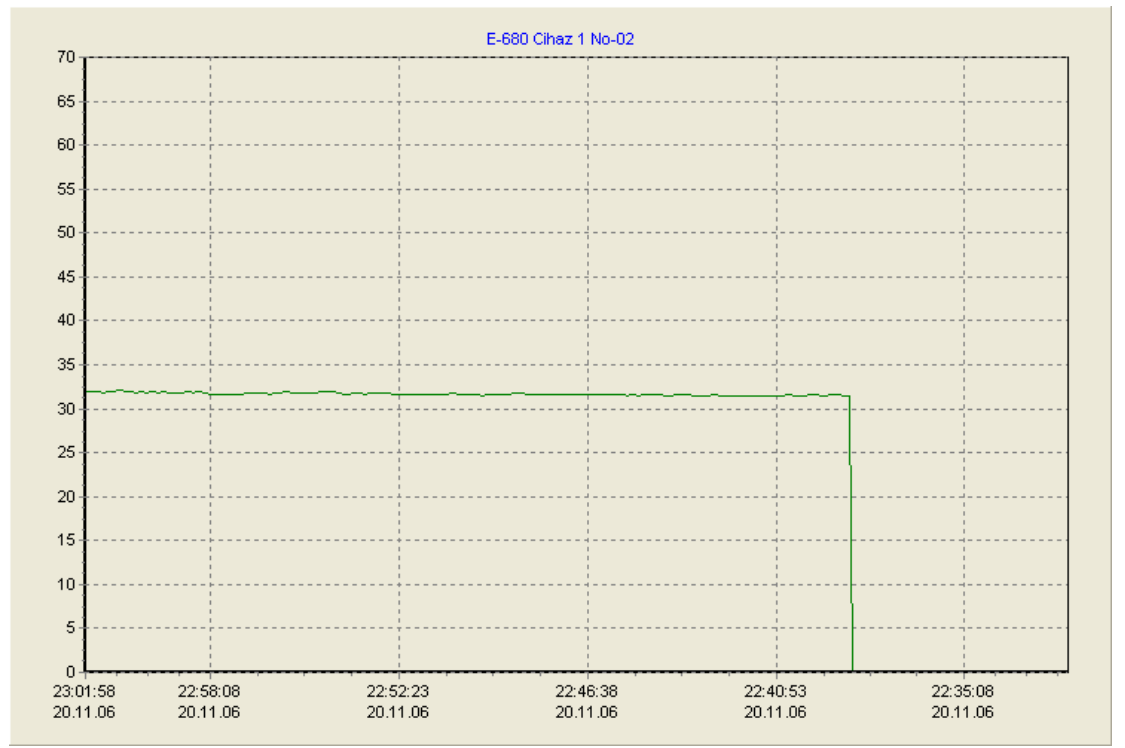

Figure 2.16 Sample of temperature recordings reaching steady state. 


\section{CHAPTER 3}

\section{RESULTS AND DISCUSSION}

In this part of the study, the results of the CFD analyses are presented and compared with the experimental results. It should be kept in mind that, there is always a level of error in a numerical study. However, it is very important to know what contributes to this error and the estimated value of it. In CFD calculations, there are several reasons for computational errors. The first source of error can be considered as the discretization method. Icepak ${ }^{\mathrm{TM}}$ uses Finite Volume Method and this method imposes some errors as other methods like Finite Difference and Finite Element Methods. Other sources of error can result from the incorrect choices of boundary condition definition and turbulence model. Since boundary conditions should closely represent the real case conditions, it is very important to use the best possible boundary conditions. In addition, turbulence modeling involves some errors since it is not possible to fully model the practical applications. Therefore the decision of the right turbulence model is very important to minimize the error.

Other than computational error, convergence is also an important concern to consider. There should be convergence criteria to decide where to stop the solution. In Icepak ${ }^{\mathrm{TM}}$ convergence is decided by checking the residuals. In order to obtain an accurate solution, enough number of iterations should be run and residuals of a variable should fall below some predetermined value. This value is decided by the user and in this study, it is chosen as $10^{-4}$ for the continuity and momentum equations and $10^{-7}$ for the energy equation. However, residual checking is not completely enough to decide whether a solution is converged or not. Several critical locations in the computational domain should be monitored in terms of velocity, 
pressure and temperature. These monitors are also indicators of convergence if they do not change significantly for successive iterations.

The results presented in this chapter were obtained using a laptop computer (1.6 $\mathrm{GHz}$ Intel Centrino CPU and 1 GB RAM). It took 7-8 hours per simulation run for the base mesh defined in section 3.1.1. The simulation times for coarse and fine mesh can be seen in Appendix D with some other solution details.

The presentation of the results is divided into three main groups. First of all, a numerical discussion is done based on mesh selection and discretization schemes. Later, a physical discussion is given regarding recirculation zones, turbulence modeling and relaminarization. This chapter ends with the presentation of the experimental results and a comparison with the computational results.

After the modeling phase is completed, a mesh selection procedure should be applied to discuss other parameters later. For this mesh selection procedure, three different computational grid combinations are generated: coarse, base and fine. The results of these three computational grids are compared and the base grid is used as a basis for all the other solutions.

The next aspect to consider is the application of different discretization schemes. A computational method is employed here, so there is an error through the discretization of the governing flow equations. There are several discretization schemes available but two of them are discussed here which are first order discretization and second order discretization schemes. The base computational grid is used for both first and second order schemes. Then the results from both schemes are compared.

Recirculation and relaminarization are two very important flow features. These affect the heat transfer and the characteristics of the flow. Therefore, a discussion based on these physical aspects is done. 
Since the flow inside the chassis is mildly turbulent, comparison of different turbulence models should be considered. By default, zero equation turbulence model is used. However; there are several different turbulence models available in Icepak $^{\mathrm{TM}}$. In this study, two different analyses are carried out to see the differences between the turbulence models. Other than the zero equation model, as an example of a two equation model, $k-\varepsilon$ turbulence model is employed and a comparison of the results is presented.

The last step is the comparison of CFD results with experimental data. In this part, two experiments are conducted and temperatures are measured at specific locations inside the two Shuttle computers, SK21G and SS59GV2. There are four different temperature measurement locations for each of the computers. The results of the CFD analyses are also given in these four points to compare the results. The details of the temperature measurement locations can be found in Appendix C.

All of the comparisons are based on a temperature difference, $\Delta \mathrm{T}$, which is defined as:

$$
\Delta T=T-T_{\text {ambient }}
$$

where $T$ is the temperature measured in experiments or calculated at a point in Icepak ${ }^{\mathrm{TM}}$ and $T_{\text {ambient }}$ is the ambient temperature which is $28^{\circ} \mathrm{C}$ for this study. This ambient temperature is obtained from the data logger system during the experimental measurements. 


\subsection{Numerical Discussions}

In this section of the study, CFD results are examined regarding the effects of mesh selection and the application of different discretization schemes.

\subsubsection{Mesh Selection}

For the selection of a reasonable mesh, three different mesh configurations are generated. First one is a coarse mesh with 144,034 elements. This mesh configuration is obtained by keeping the default meshing parameters in Icepak ${ }^{\mathrm{TM}}$. The second is the base mesh with 598,211 elements and the last one is a fine mesh with 938,037 elements. For base and fine mesh configurations; the parameters are tuned to get a finer mesh, especially in the regions where there are large gradients of the variables. The aim of checking three different configurations is to find a threshold for the number of elements constructing the computational domain that, as this number increases; the results will not change significantly.

Table 3.1 is a good indication of how results change using different mesh configurations. It can be seen that there is a significant difference for all the points other than the point on the power supply. This is because of the fact that, although the mesh resolution for the whole domain changes, the resolution for these particular region remains unchanged. However, in regions where there are large gradients, the parameters are tuned to make the resolution finer. For example, the mesh density around the hard disk drive and the DVD does not change much whereas it is refined around the heat sinks due to large gradients. 
Table 3.1 Temperature values, $\Delta \mathrm{T}$, for different grids for an ambient temperature of $28^{\circ} \mathrm{C}$.

\begin{tabular}{|c|c|c|c|c|}
\hline \multirow{2}{*}{} & \multirow{2}{*}{ Point } & \multicolumn{3}{|c|}{ Temperature Values, $\Delta \mathbf{T}\left({ }^{\circ} \mathbf{C}\right.$ ) } \\
\cline { 3 - 5 } & & $\begin{array}{c}\text { Coarse } \\
\text { Mesh }\end{array}$ & $\begin{array}{c}\text { Base } \\
\text { Mesh }\end{array}$ & $\begin{array}{c}\text { Fine } \\
\text { Mesh }\end{array}$ \\
\hline $\mathbf{1}$ & North Bridge Heat Sink & 7.7 & 7 & 7.2 \\
\hline $\mathbf{2}$ & South Bridge Heat Sink & 14.5 & 14 & 13.8 \\
\hline $\mathbf{3}$ & Heat Pipe Block & 14.2 & 11.4 & 11.1 \\
\hline $\mathbf{4}$ & Power Supply & 4.1 & 4.2 & 4.2 \\
\hline
\end{tabular}

Another comparison is done using a reference line passing through the middle of the heat pipe block. The exact location of the line can be seen $n$ Figure 3.1. Figure 3.2 shows the results of the temperatures on this line for different mesh configurations. Temperatures for the coarse mesh are considerably different from the other two configurations. Although there are some minor temperature differences between the base and the fine mesh, the base mesh is selected since the computational time nearly is two times less than the fine mesh. 


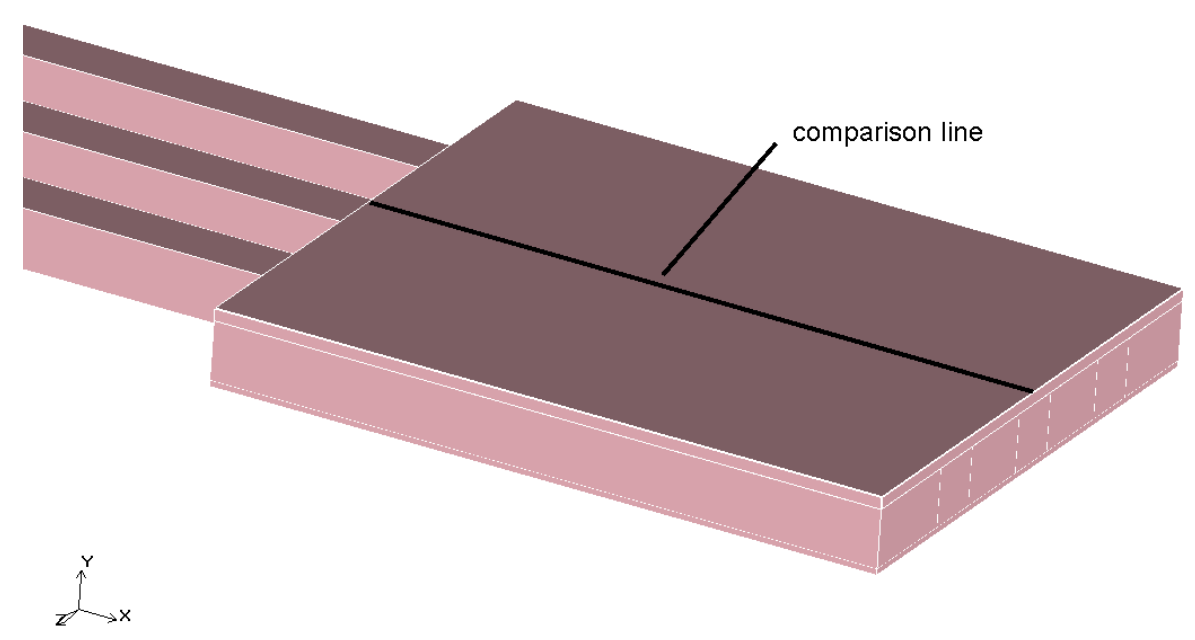

Figure 3.1 Location of the comparison line on the heat pipe block.

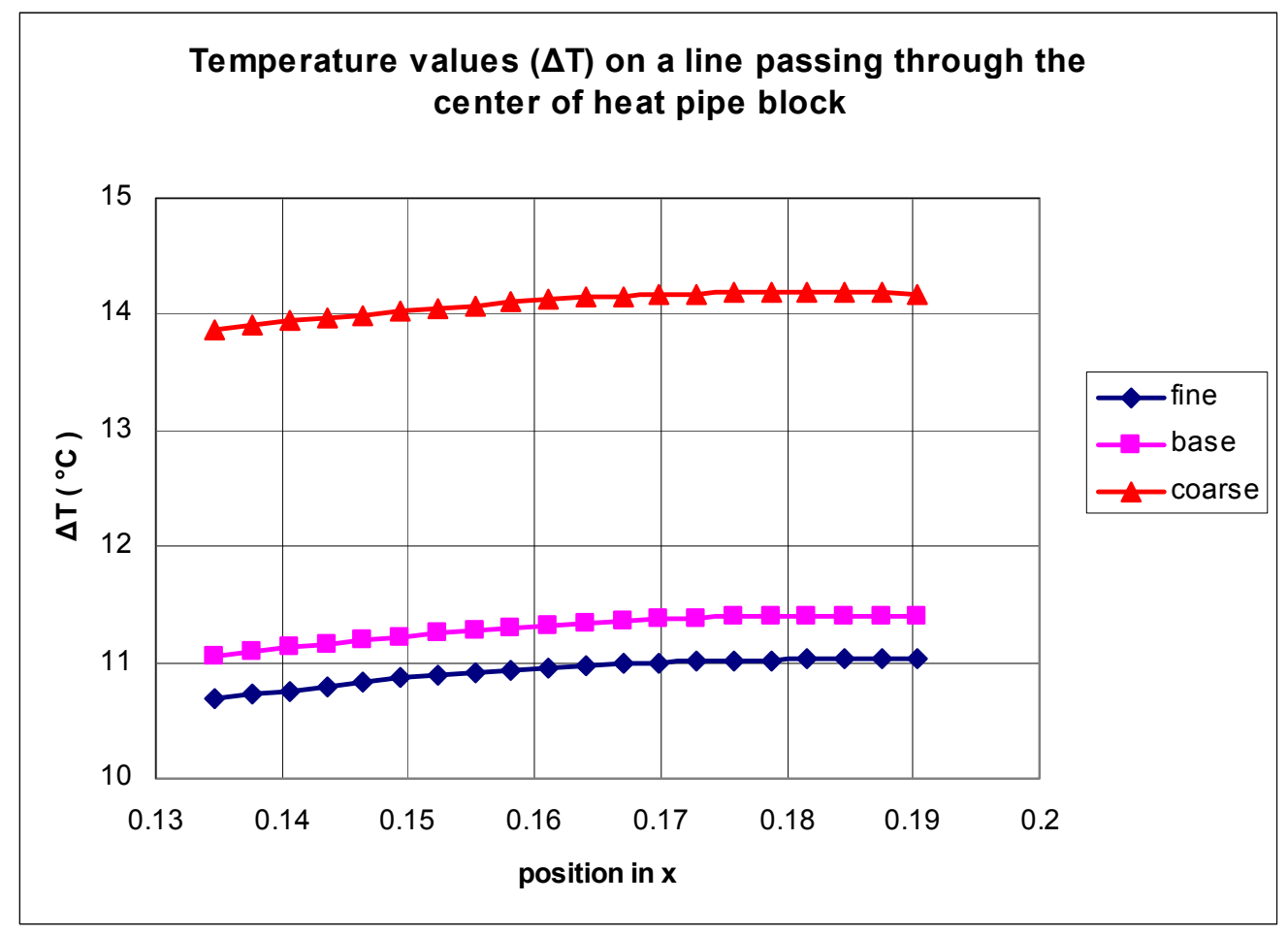

Figure 3.2 Temperature values drawn for a line passing through the center of the heat pipe block. 
Figure 3.3 shows the 2-D velocity vector cuts passing through center of the north bridge heat sink. All three plots are in the same scale, 0 to $0.6 \mathrm{~m} / \mathrm{s}$, to represent the differences clearly. This approach is repeated in Figure 3.4 where temperature contours on the CPU are drawn. From these two figures, Figure 3.3 shows the importance of grid points to be able to resolve the flow characteristics. Therefore base mesh is sufficient to see the general flow field around the heat sink; however, a more detailed investigation may need a finer mesh. In terms of temperature, coarse mesh fails to capture the core region of the CPU. It over-predicts the temperature on the die region and the distribution is also significantly different from the other two configurations. However, there is a maximum $3 \%$ of difference between the base and the fine mesh. Therefore, the base mesh configuration is selected and used for the rest of the study. 

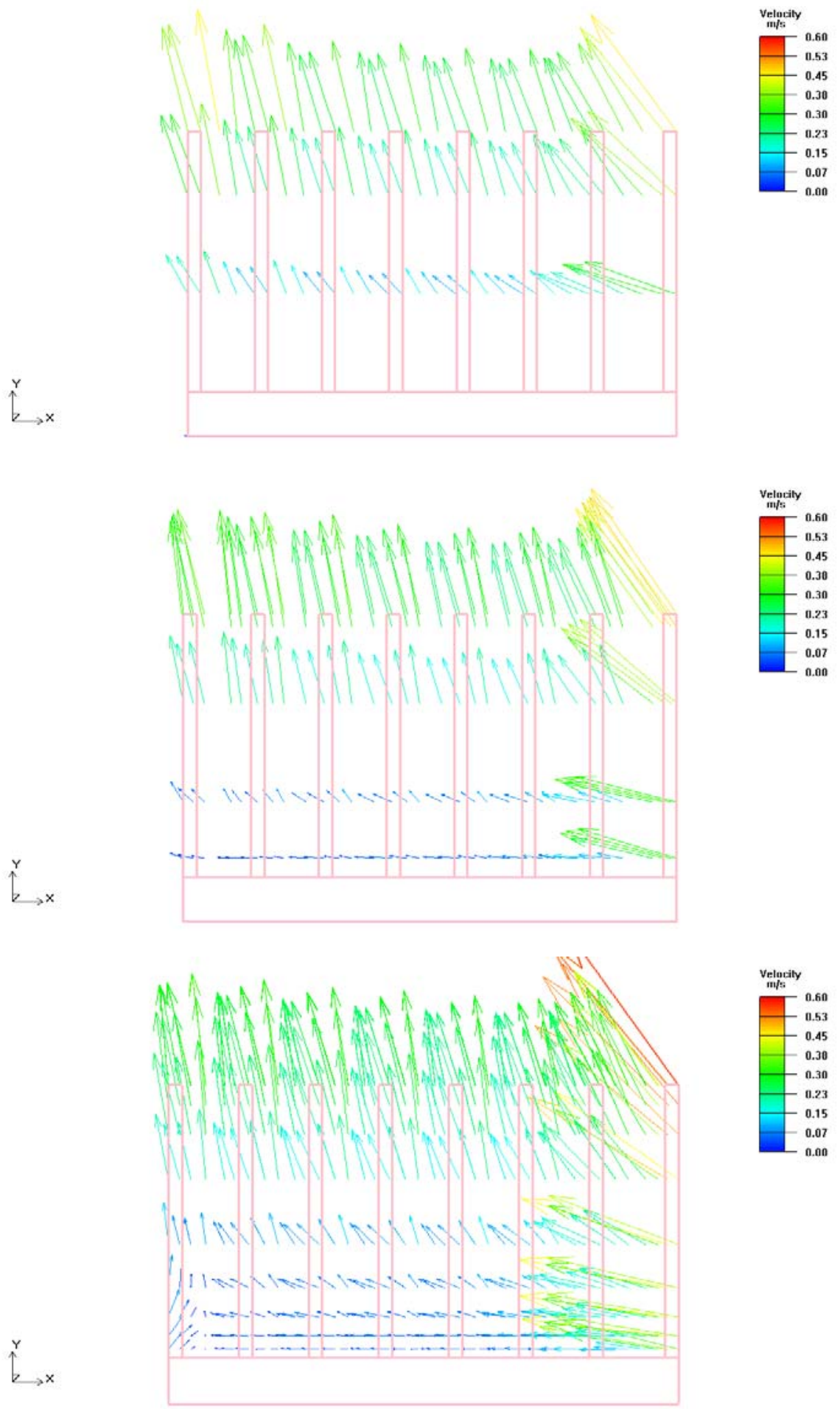

Figure 3.3 2-Dvelocity vectors passing through the center of the north bridge heat sink for coarse, base and fine meshes (top to bottom). 

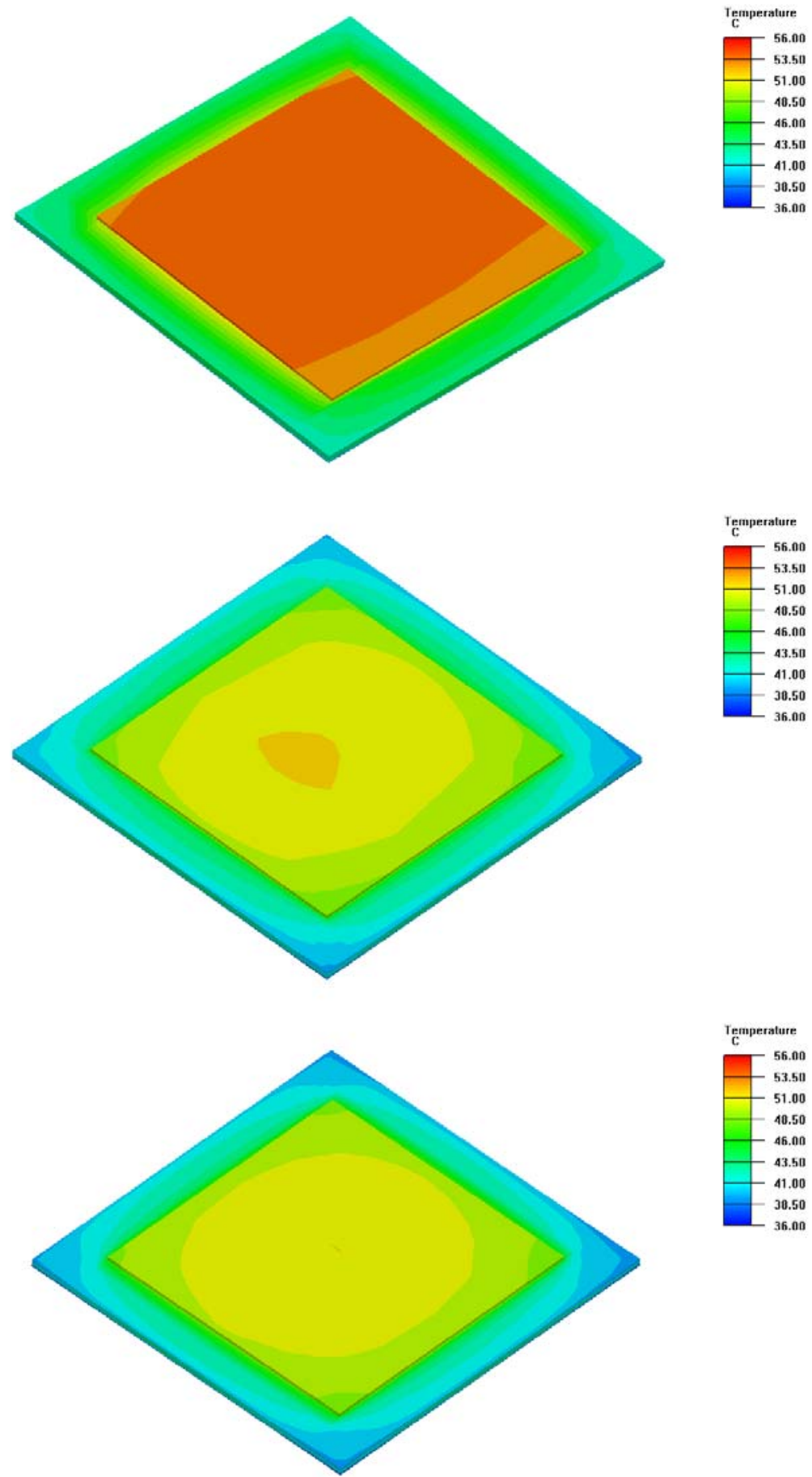

Figure 3.4 Temperature contours of CPU for coarse, base and fine meshes (top to bottom). 


\subsubsection{Discretization}

In this part, results of two different discretization schemes are compared. These are the first order and the second order upwind schemes. These schemes are used to calculate the convective fluxes of the variables at the cell faces. The first order scheme assumes that the quantity at the cell center is a cell averaged value and is equal to the cell face values. However; in the second order discretization, the cell face values are calculated using the cell center value together with its gradient in the upstream cell. Although, in general, the use of the first order scheme leads to easier convergence, it is recommended to use the second order schemes when an unstructured grid is used. This is needed to obtain a smoother interpolation of the convective fluxes of the variables. Therefore, a comparison should be done between the first and the second order schemes.

Table 3.2 implies that there are no dramatic changes between the results for each location. Actually this is kind of a result to be expected. Because the second order upwind scheme is especially necessary when the grid is not uniformly distributed and the aspect ratios are relatively high. For such kind of grids, the second order upwind scheme can interpolate between the cell values better since it contains a gradient term together with the cell center value of the upstream cell. However, in the base mesh confirmation, uniformity of the grid and the aspect ratios are fine enough that the first order upwind scheme is enough to obtain the desired results, so that the results do not change significantly. 
Table 3.2 Temperature values, $\Delta \mathrm{T}$, for different discretization schemes for an ambient temperature of 28 .

\begin{tabular}{|c|c|c|c|}
\hline \multirow{2}{*}{} & \multirow{2}{*}{ Point } & \multicolumn{2}{|c|}{ Temperature Values, $\Delta \mathbf{T}\left({ }^{\circ} \mathbf{C}\right)$} \\
\cline { 3 - 4 } & & First Order & Second Order \\
\hline $\mathbf{1}$ & North Bridge Heat Sink & 7 & 7.3 \\
\hline $\mathbf{2}$ & South Bridge Heat Sink & 14 & 13.9 \\
\hline $\mathbf{3}$ & Heat Pipe Block & 11.4 & 11.5 \\
\hline $\mathbf{4}$ & Power Supply & 4.2 & 4.1 \\
\hline
\end{tabular}

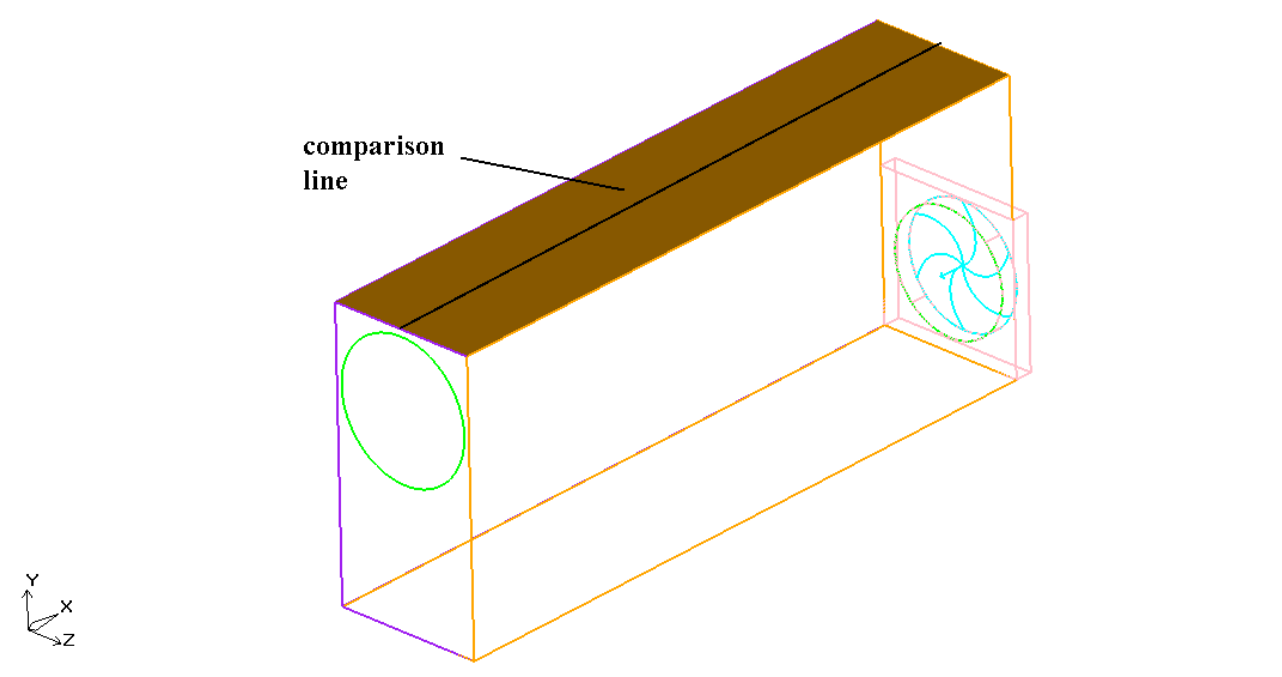

Figure 3.5 Comparison line on the top plate of the power supply. 
In addition to the tabulated results, in Figure 3.6 temperature differences are drawn for a reference line. This reference line is passing through the center of the top plate of the power supply which can be seen in Figure 3.5. According to Figure 3.6, the second order upwind scheme predicts higher temperature values for the reference line. However, the highest temperature difference between the two schemes is nearly $1{ }^{\circ} \mathrm{C}$. The decreasing trend in the line is due to the highest velocities occurring near the fan meaning lower temperatures around that region.

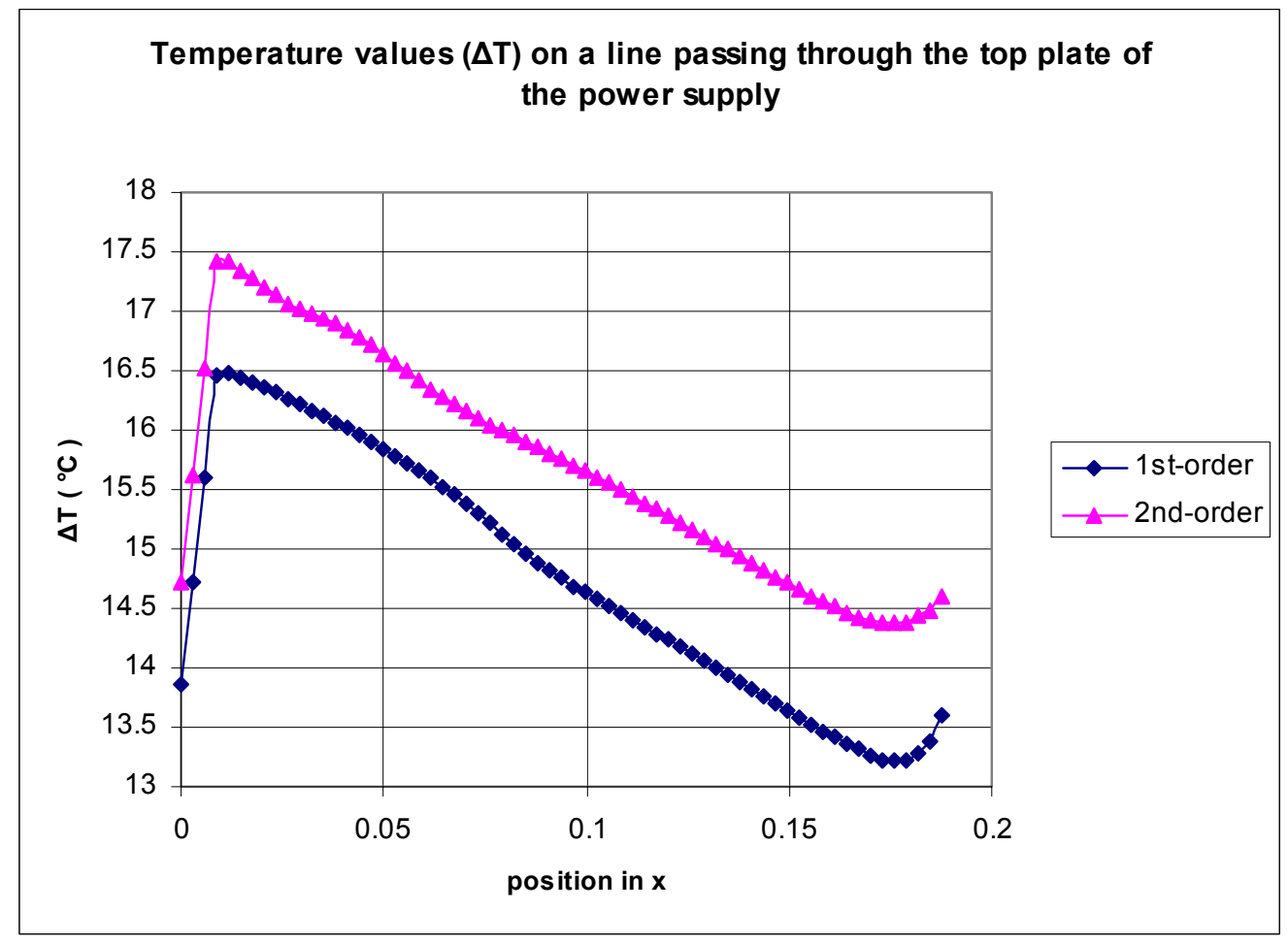

Figure 3.6 Temperature values drawn for a line passing through the center of the top plate of the power supply.

Figures 3.7 and 3.8 are the representative plots related to the above discussions. Figure 3.7 shows the 2-D velocity vectors passing through the center of the north bridge heat sink. The velocity vectors are not significantly different. Only the values 
for the maximum $\mathrm{X}$ direction change. This similarity can also be seen in the temperature contours of the CPU more easily. The temperature contours in Figure 3.8 are almost identical again that there is only a small difference in the hot spot region.

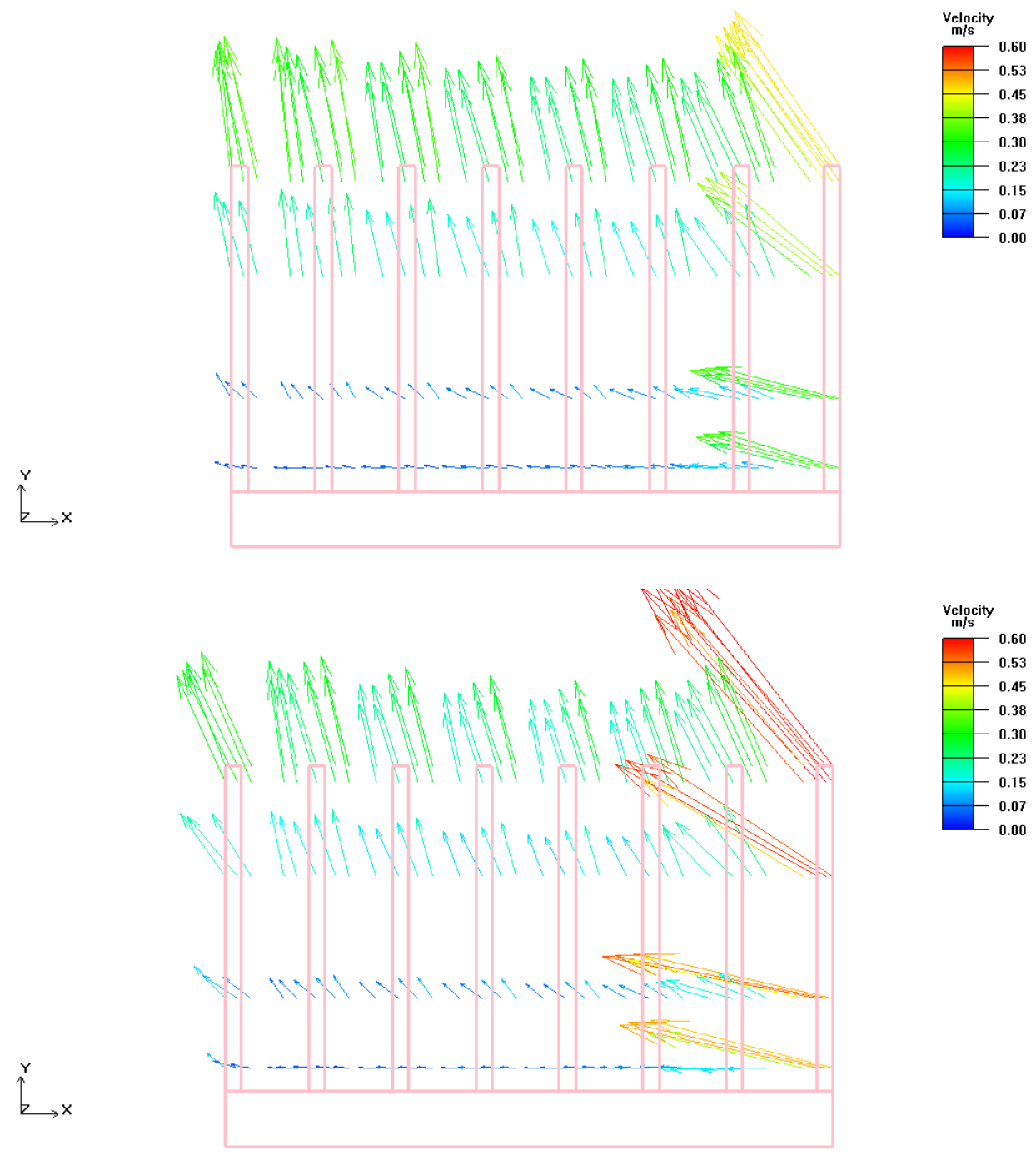

Figure 3.7 2-Dvelocity vectors passing through the center of the north bridge heat sink for the first and the second order discretization schemes (top to bottom). 

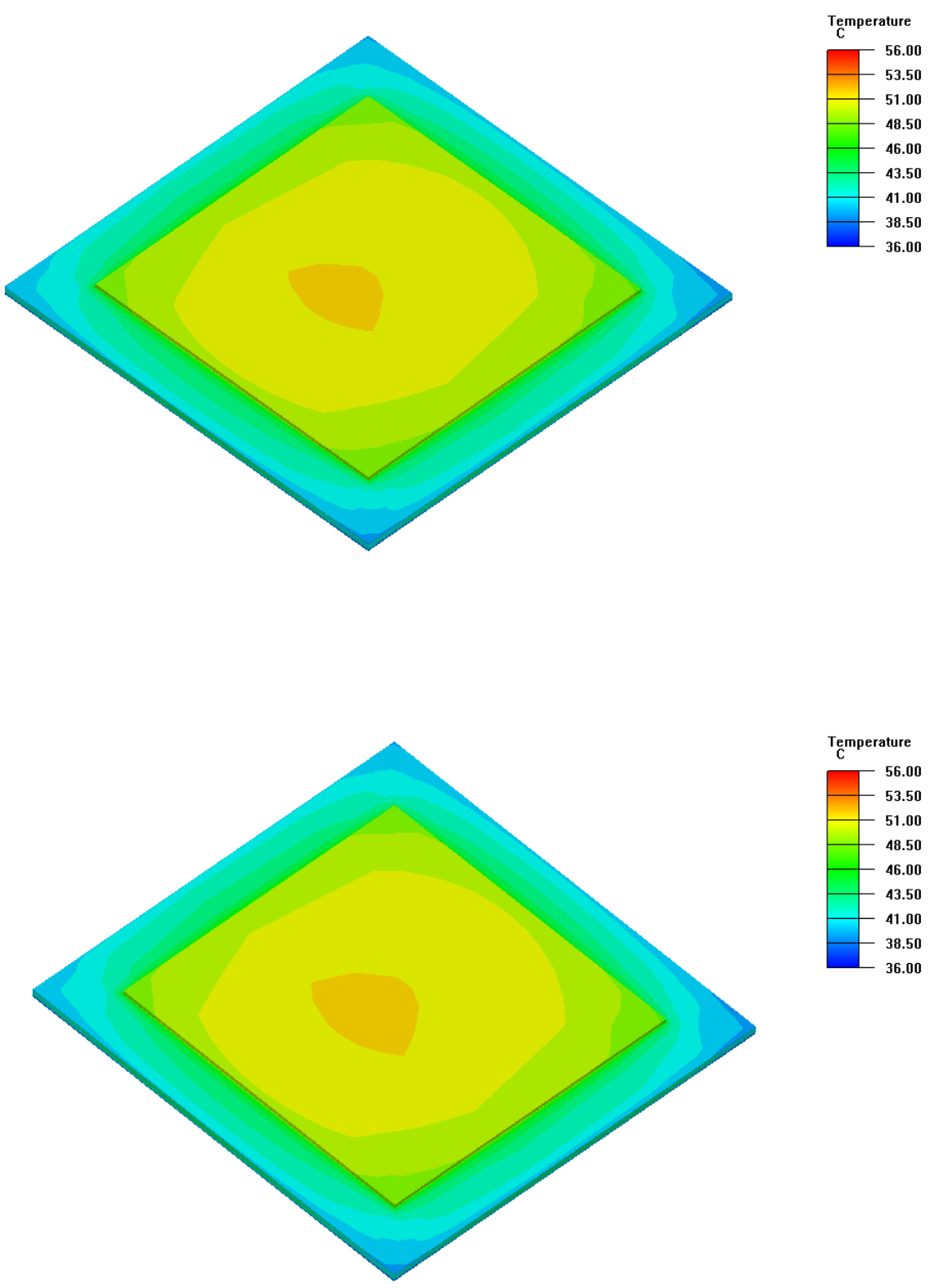

Figure 3.8 Temperature contours of CPU for first and second order discretization schemes (top to bottom). 


\subsection{Physical Discussions}

The most important physical features of the system are discussed in this section of the study and the results related to these features are presented.

\subsubsection{Recirculation Regions}

There are several recirculation regions inside the chassis that affect the flow and heat transfer. These regions can be identified by examining the general flow field which can be seen in Figure 3.9 in detail. There are different regions being affected by recirculation but the size and strength of these regions differ.

Since the heat pipe fan is the main driving mechanism inside the chassis, most of the recirculation zones are located around the fan and the back wall. In Figure 3.10, three of the recirculation zones can be identified. One of the recirculation regions is just below the power supply which has a maximum speed of $1.28 \mathrm{~m} / \mathrm{s}$. Next to this, there is the strongest recirculation zone just below the heat exchanger plates with a maximum velocity of nearly $4.5 \mathrm{~m} / \mathrm{s}$. Recirculation zone 3 , has a maximum velocity of nearly $2 \mathrm{~m} / \mathrm{s}$ and is located at the opposite corner. Recirculation zone 5, Figure 3.11 , is located just above the heat pipe fan. The maximum velocity reaches up to $3.75 \mathrm{~m} / \mathrm{s}$ in this zone and this is mainly due to the level difference between the fan and the heat exchanger plates. Air does not want to go through the heat exchanger plates since they form a resistance there, it flows over them and forms a recirculation zone. Finally, the weakest recirculation zone, Figure 3.12, is at the front right corner of the chassis with a maximum velocity of nearly $0.7 \mathrm{~m} / \mathrm{s}$. 


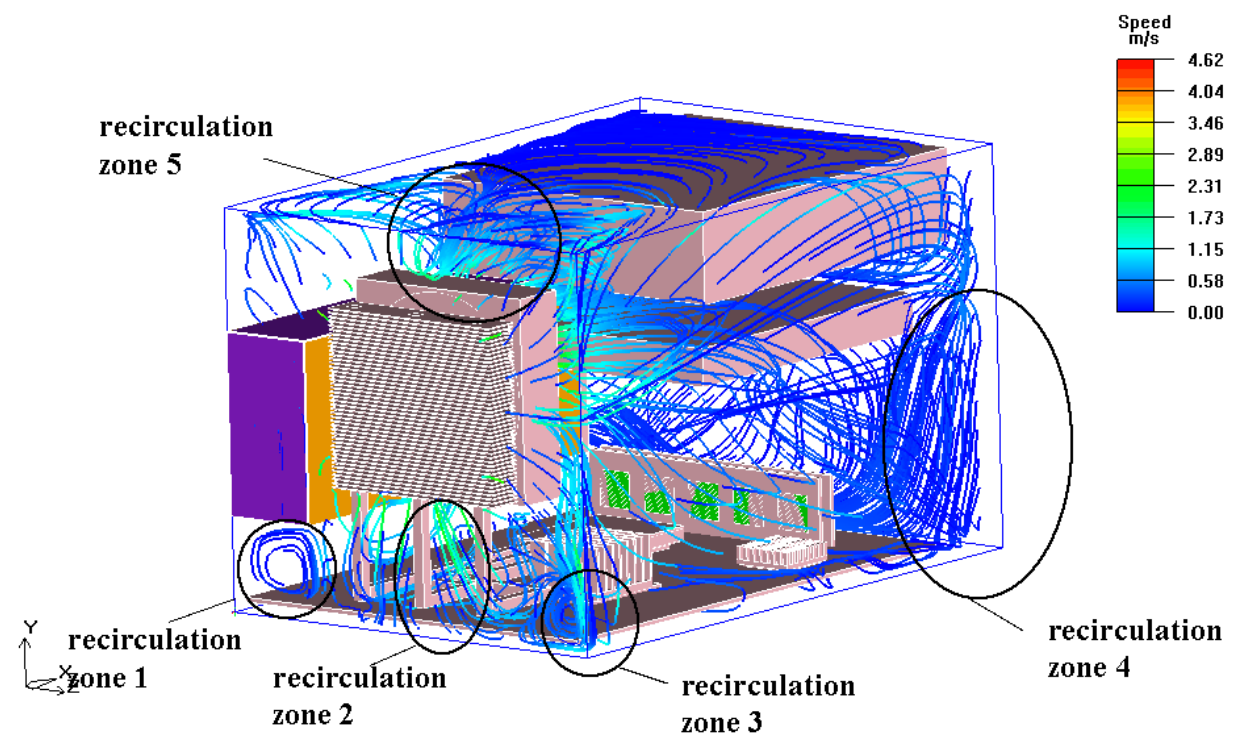

Figure 3.9 General visualization of the flow field inside the computer chassis and the recirculation zones.

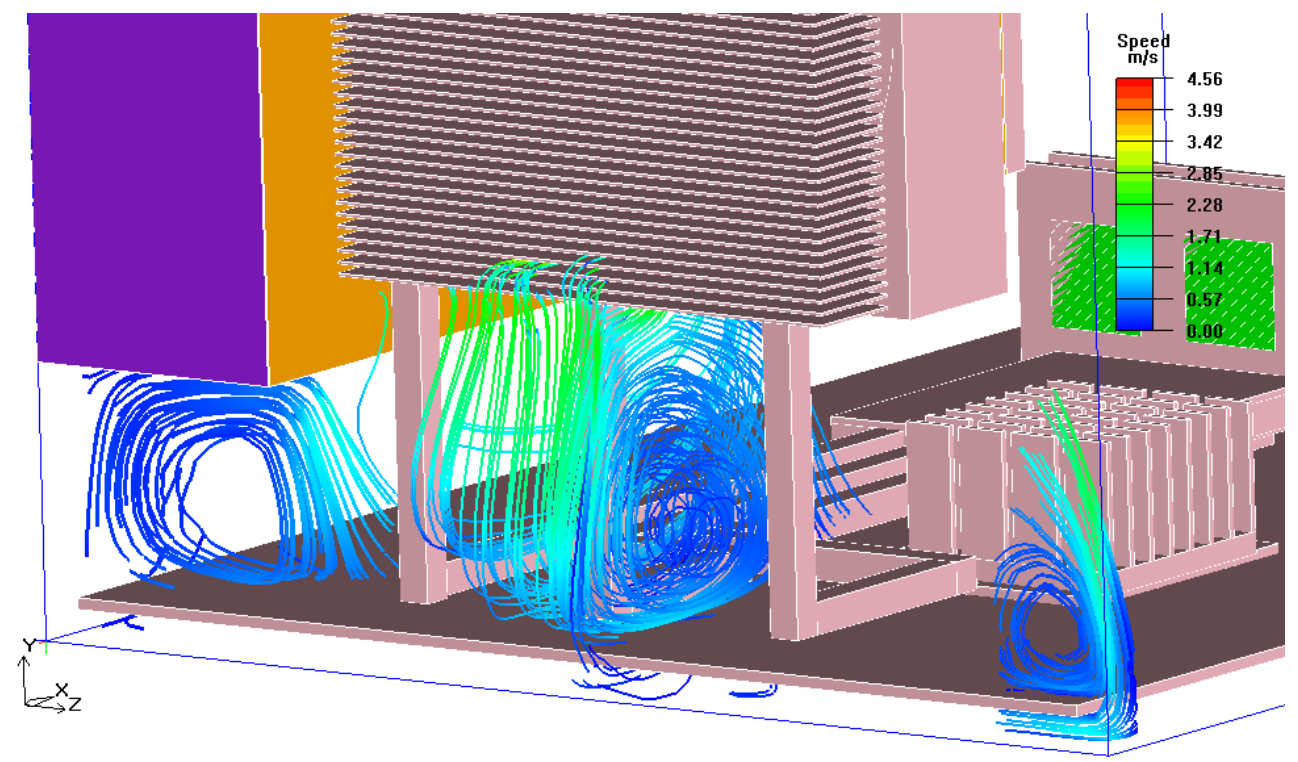

Figure 3.10 Particle traces of the recirculation zones from 1-3 in detail. 


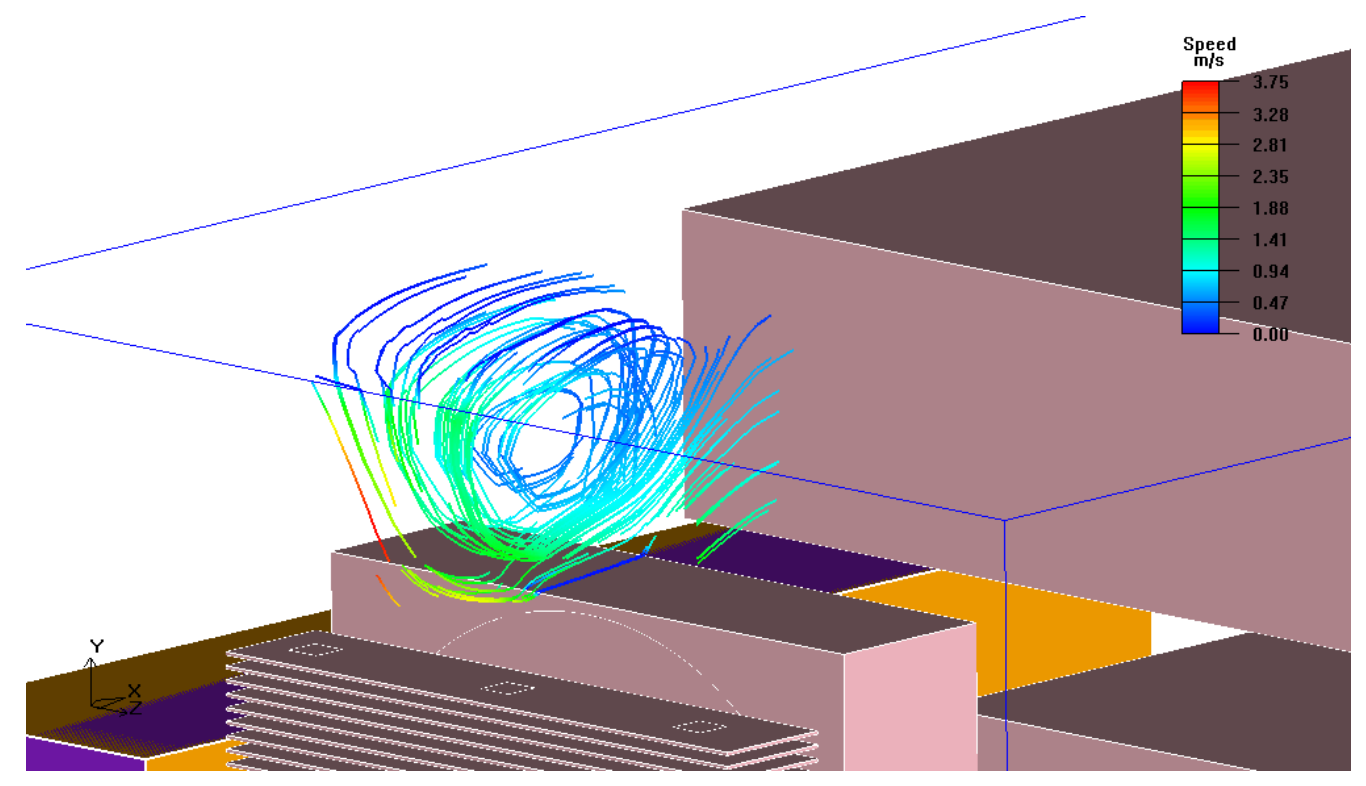

Figure 3.11 Particle traces of the recirculation zone 5 in detail.

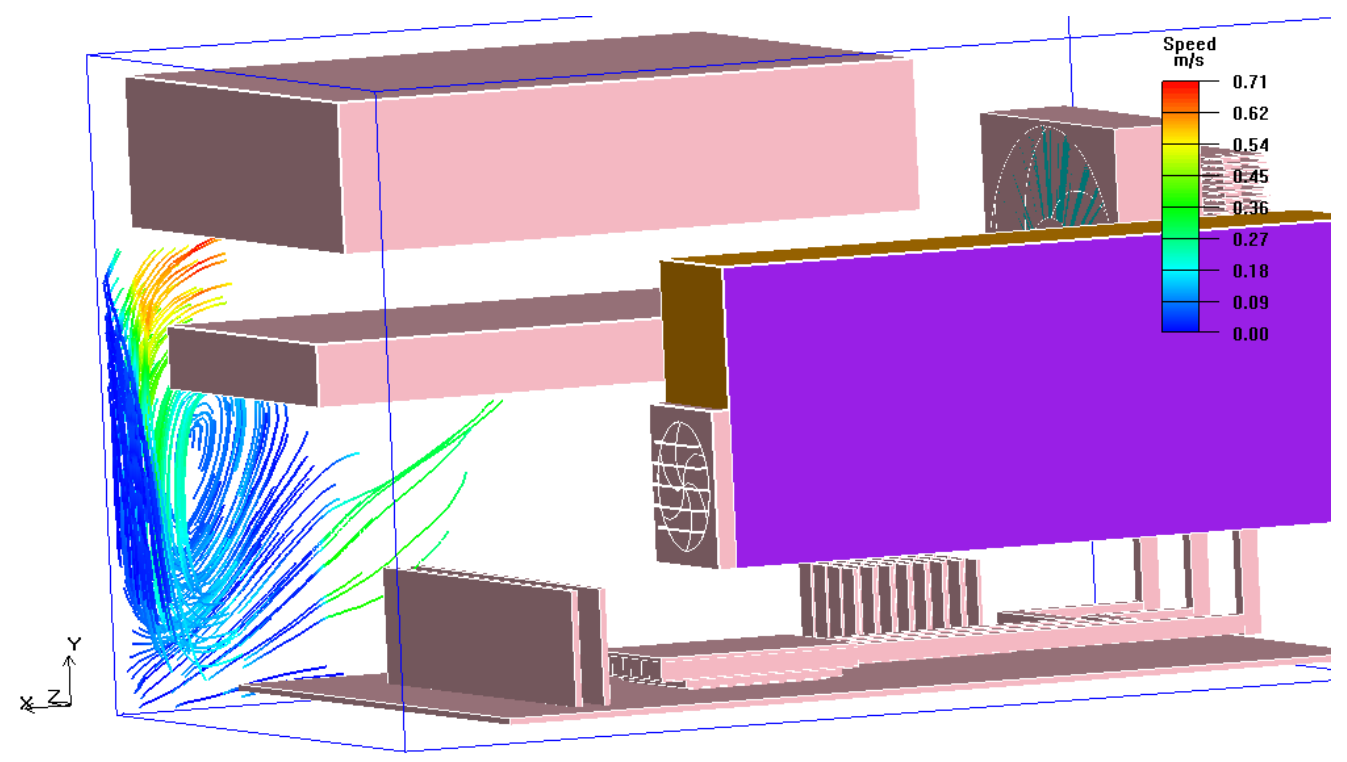

Figure 3.12 Particle traces of the recirculation zone 4 in detail. 


\subsubsection{Turbulence Modeling}

This section deals with the comparison of two turbulence models applied to the solution of the problem. Among all the turbulence models, the two most common two models are used and the results are compared and discussed. These are the mixing length zero equation turbulence model and the $k-\varepsilon$ two equation turbulence model.

Algebraic models are the easiest and simplest ones to implement among all turbulence models [33]. Among the algebraic models, the mixing length model, in its generalized form, is applicable to all turbulent flows and it may be considered as the simplest turbulence model [36]. However, as all the algebraic models, the mixing length model is incomplete since the mixing length has to be specified according to the type of the flow. This means that it has to be tuned to give reasonable results.

On the other hand, the $k-\varepsilon$ turbulence model is considered as the most widely used two equation turbulence model [33]. It has been used to compute the flow field in many different types of industrial applications accurately. However, as all other turbulence models, it has some drawbacks. The major problem in this model is that, it is difficult and expensive to perform near wall calculations compared to the zero equation model. This problem is solved by introducing the concept of wall functions. Then this model, when used in conjunction with wall functions is computationally expensive [36]. In order to use wall functions, special care needs to be taken when generating the computational grid. Grid intensity should be reasonable to be able to resolve $k$ and $\varepsilon$ which vary strongly in the near wall region.

In the presence of the above discussions, Table 3.3 presents the temperature differences for two different turbulence models. The results are in good agreement for all of the points. The biggest difference is for the point on the power supply. 
Table 3.3 Temperature values, $\Delta \mathrm{T}$, for different turbulence models for an ambient temperature of $28^{\circ} \mathrm{C}$.

\begin{tabular}{|c|c|c|c|}
\hline \multirow{2}{*}{} & \multirow{2}{*}{ Point } & \multicolumn{2}{|c|}{ Temperature Values, $\Delta \mathbf{T}\left({ }^{\circ} \mathbf{C}\right)$} \\
\cline { 3 - 4 } & & Zero Equation & $\boldsymbol{k}-\boldsymbol{\varepsilon}$ \\
\hline $\mathbf{1}$ & North Bridge Heat Sink & 7 & 7.4 \\
\hline $\mathbf{2}$ & South Bridge Heat Sink & 14 & 13.9 \\
\hline $\mathbf{3}$ & Heat Pipe Block & 11.4 & 11.2 \\
\hline $\mathbf{4}$ & Power Supply & 4.2 & 5.2 \\
\hline
\end{tabular}

In Figure 3.13, temperature differences are drawn on the reference line shown in Figure 3.1. The results of the zero equation turbulence model nearly overlap with those of the two equation $k-\varepsilon$ turbulence model. The biggest difference is $0.2{ }^{\circ} \mathrm{C}$.

Similar correspondence applies to Figures 3.14 and 3.15. In Figure 3.14, the 2-D velocity vectors passing through the center of the north bridge heat sink are presented. There are minor differences but the results are alike. The temperature contours of the CPU, as shown in Figure 3.15, are also similar except for the hot spot region in the middle.

All of the above discussions imply that, two equation $k-\varepsilon$ turbulence model has no superior performance over the zero equation mixing length turbulence model. However, the computational time related with the $k-\varepsilon$ model, is far more because of the solution of the two additional turbulence transport equations. Therefore zero equation mixing length model can be used in similar analyses. 


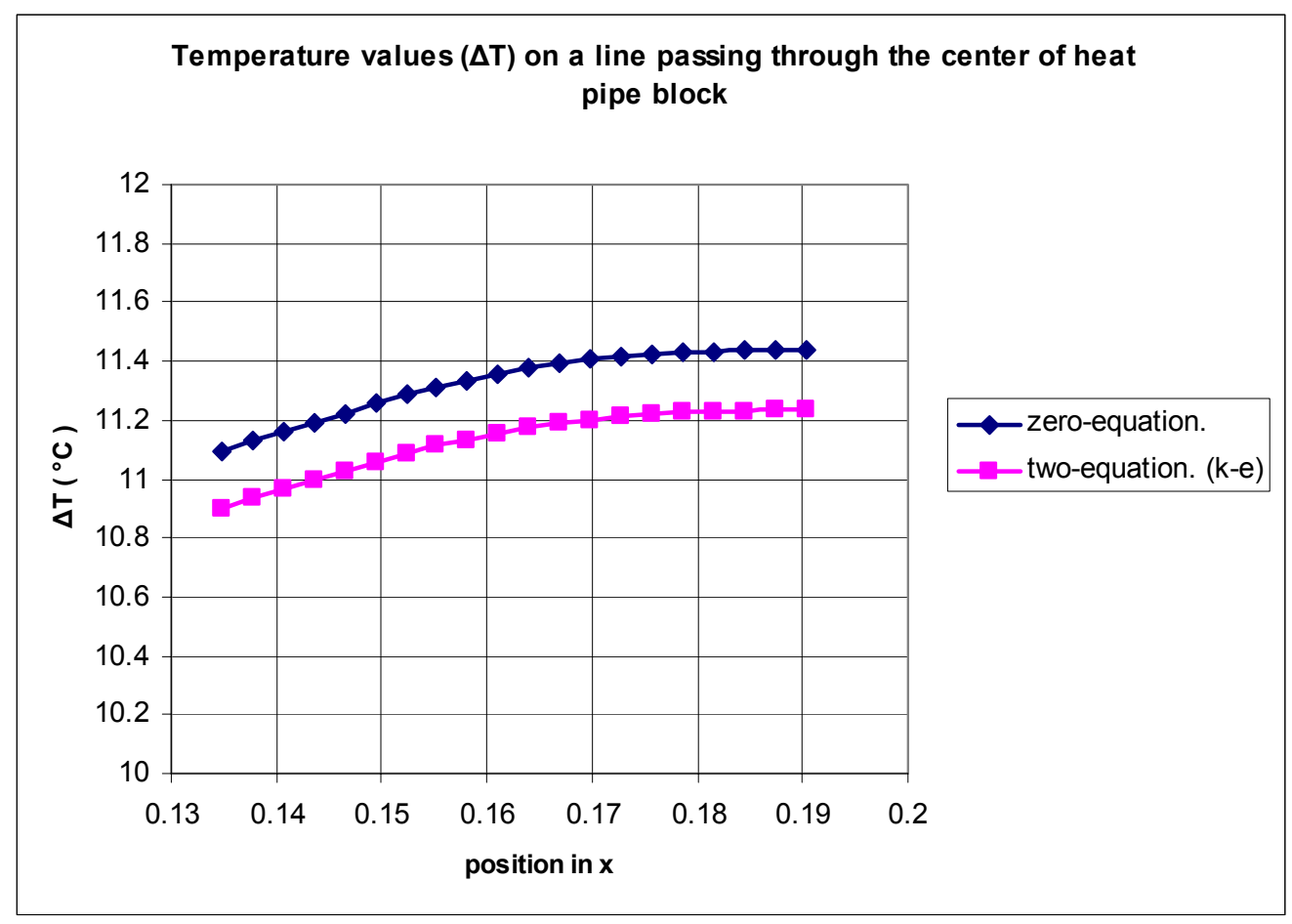

Figure 3.13 A graphical comparison of a line passing through the center of the heat pipe block for zero and two equation $(k-\varepsilon)$ turbulence models. 

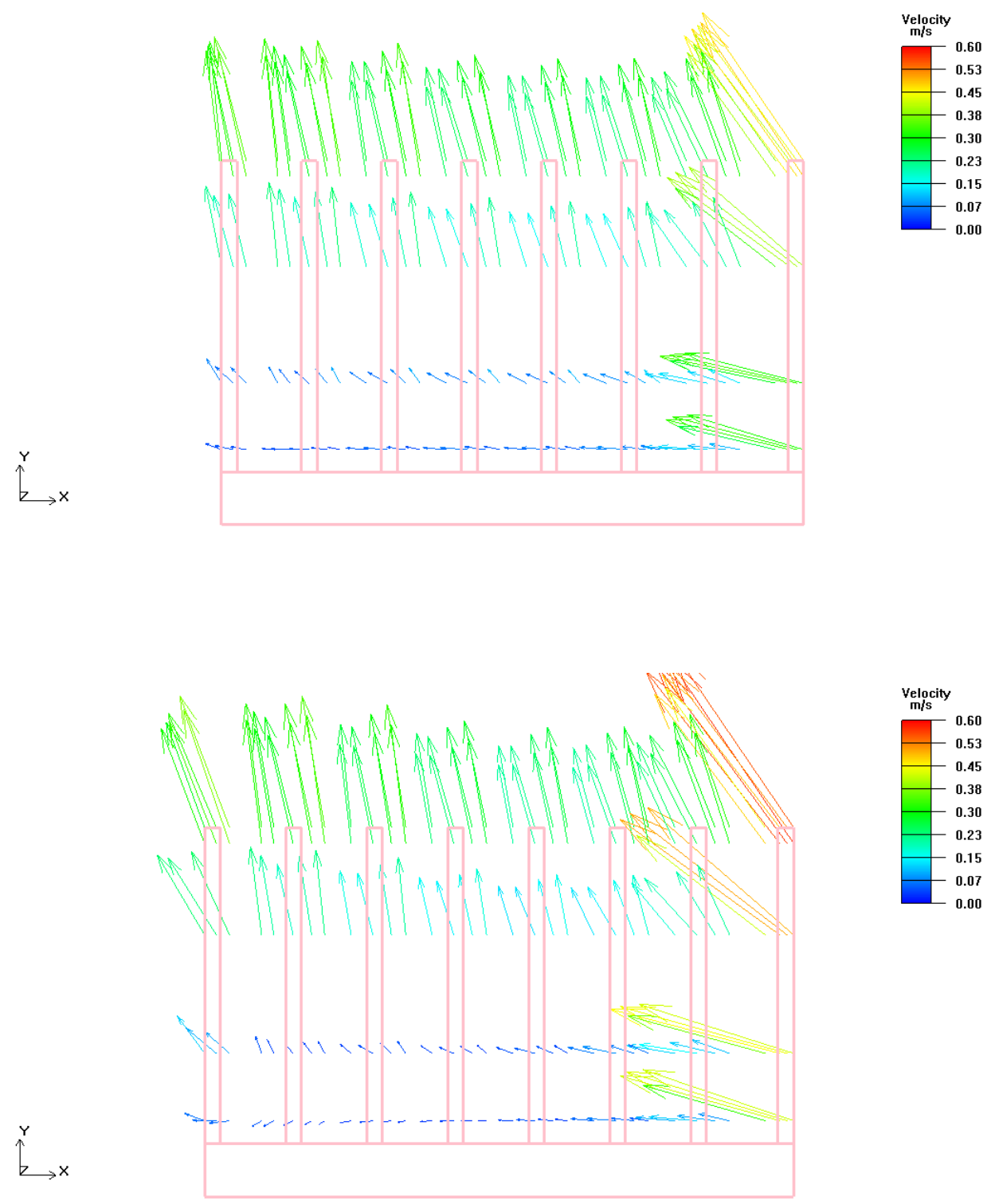

Figure 3.14 2-Dvelocity vectors passing through the center of the north bridge heat sink for zero and two equation $(k-\varepsilon)$ turbulence models (top to bottom). 

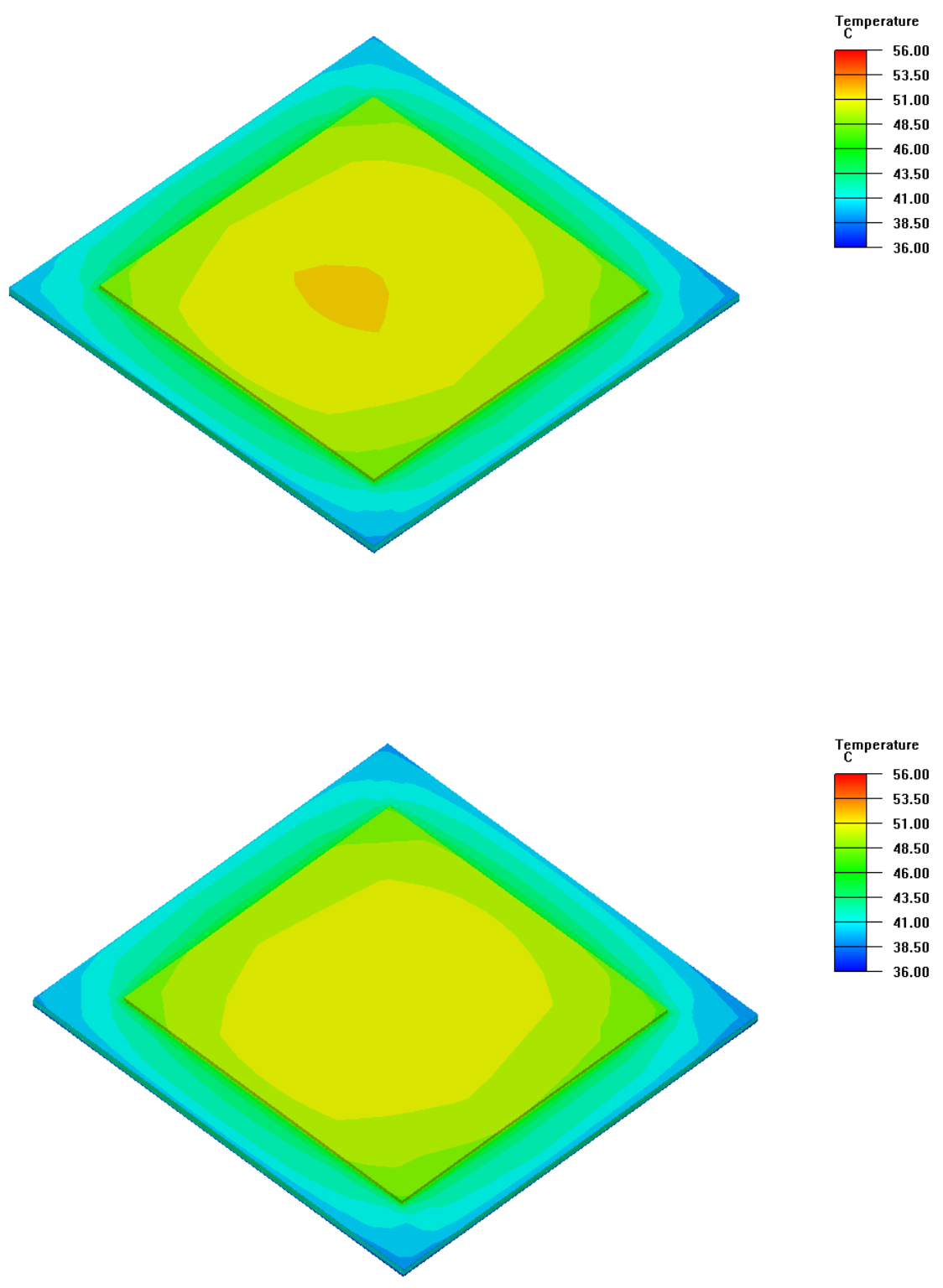

Figure 3.15 Temperature contours of CPU for zero and two equation $(k-\varepsilon)$ turbulence models (top to bottom). 


\subsubsection{Relaminarization}

The final physical issue to be discussed is relaminarization. Relaminarization is defined as a phenomenon which causes an already turbulent flow, retard back to the laminar state [34].

The flow regions where relaminarization is likely to occur are the regions around the heat sinks. Therefore the flows around the heat sinks are observed together with the corresponding Reynolds numbers. To be able to decide for the main flow direction, velocity magnitude contours are drawn for the locations in Figure 3.16. For these locations, velocity magnitude contours of the north and south bridge heat sinks are given in Figure 3.17.
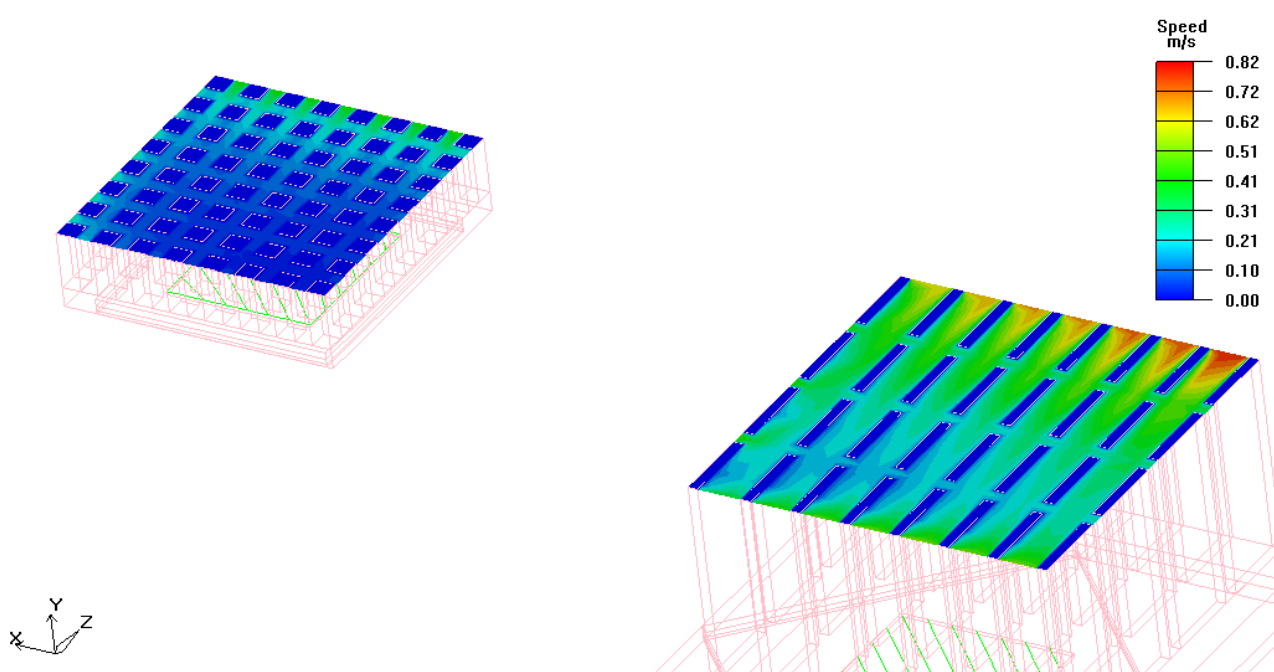

Figure 3.16 Locations of the plane cuts on the heat sinks. 
From Figure 3.17, it is clear that the flow direction is in $-Z$. Although the flow in between the heat sink plates is an open channel flow, the flow is mostly contained inside the channel. Therefore, the calculation of the corresponding Reynolds number requires the hydraulic diameter. Hydraulic diameter $D_{h}$ can be calculated for a rectangular cross section with sides $L$ and $W$;

$$
D_{h}=\frac{4 L W}{2(L+W)}
$$

From equation 3.2 , the hydraulic diameters are $1.78 \mathrm{~mm}$ and $1.96 \mathrm{~mm}$ for the north bridge and south bridge heat sinks. The velocities are taken as the maximum velocities to be conservative. The maximum velocity is $0.82 \mathrm{~m} / \mathrm{s}$ and $0.47 \mathrm{~m} / \mathrm{s}$ for the north and south bridges, respectively. Using these values, Reynolds numbers are calculated to be $\operatorname{Re}_{n b}=92$ and $\operatorname{Re}_{s b}=58$. When compared to the critical Reynolds number of a channel flow $\left(\operatorname{Re}_{\text {critical }}=2300\right)$, the Reynolds numbers south bridge indicate that there is possibly laminar flow in these areas. 

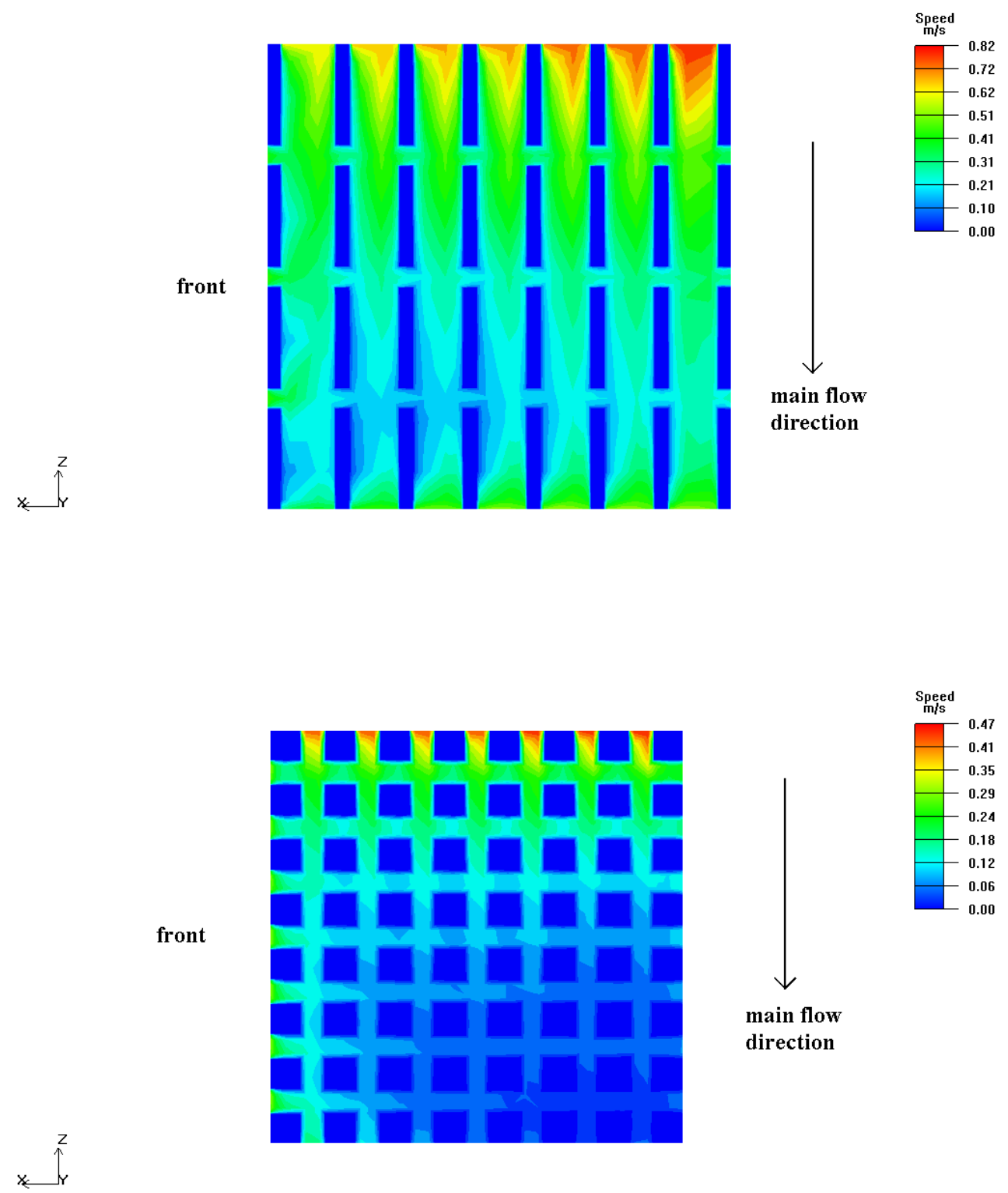

Figure 3.17 Velocity magnitude contours of the north and south bridge heat sinks (top to bottom).

Since there is the possibility of a laminar flow, this region can be examined using a laminar fluid block around heat sinks in Icepak ${ }^{\mathrm{TM}}$. Although the whole flow field is turbulent, it is possible to turn off the turbulence model used and calculate the flow 
field around the heat sinks as laminar. Therefore two fluid blocks are modeled slightly bigger than the heat sinks and a laminar solution is obtained for the flow around the heat sinks.

Figure 3.18 shows the particle traces for turbulent and laminar solutions around the heat sinks respectively. Although the flow field around the heat sinks is taken as laminar, it can be concluded that the particle traces for both of the situations are similar.
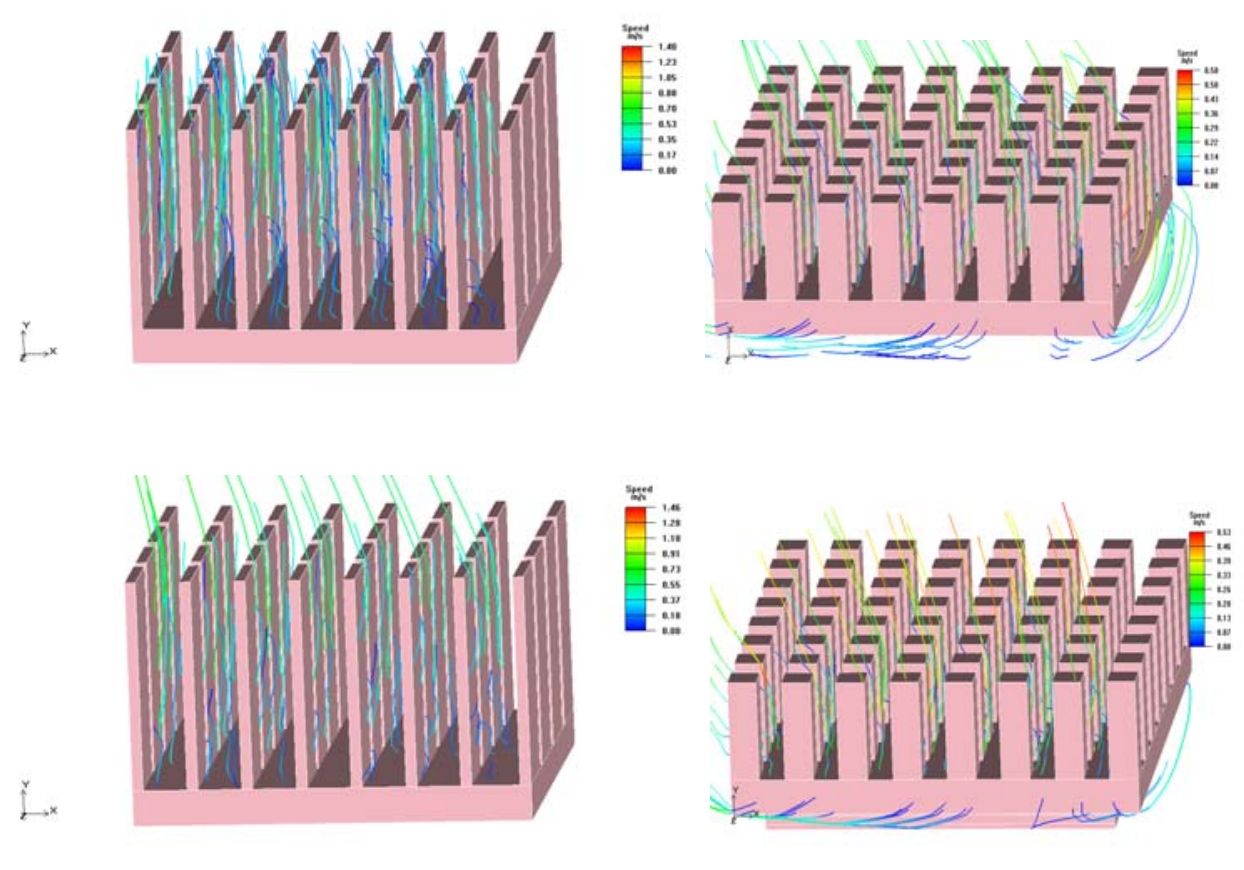

Figure 3.18 Particle traces for turbulent and laminar solutions around the heat sinks (top to bottom).

A final check can be done by comparing the velocity magnitudes for the plane cut location given in Figure 3.16. The velocity magnitude contours are also drawn for the laminar solution around the heat sinks and presented in Figure 3.19. When compared to Figure 3.17, the difference is very small and the distributions are alike. 


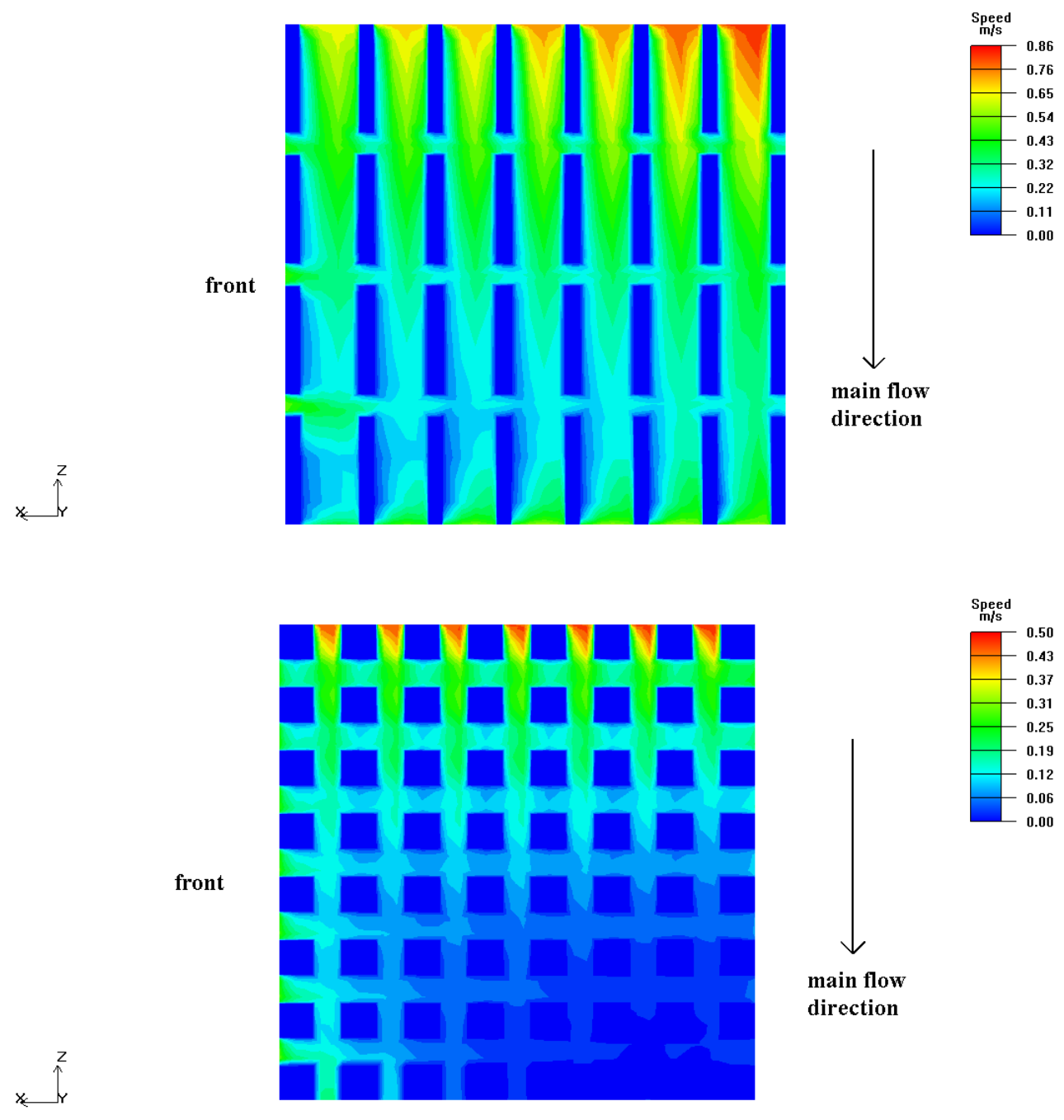

Figure 3.19 Velocity magnitude contours of the north and south bridge heat sinks after a laminar solution is obtained around them (top to bottom). 


\subsubsection{Effects of the DVD and the Hard Disk Drive Power Ratings on the Flow}

In this study, the power ratings of the DVD and the hard disk drive (HDD) are used as $5 \mathrm{~W}$ and $15 \mathrm{~W}$, respectively. However, when the CPU is stressed to work under full load using a burn-in software, both the DVD and the HDD do not function much. Therefore, assigning such power ratings on these components, over predicts the temperature values on them.

Table 3.4 lists the temperature values on the components when the DVD and the HDD work with and without power consumption. However, for the condition in which they are working with the given power ratings, the temperatures on the HDD are not reasonable. So, a condition for which these components are working without power consumption should be checked. Therefore, one more case study is conducted for such a condition

Temperature values on the HDD are more reasonable, when the DVD and the HDD work with negligible power consumption. This case is closer to the ideal case. Although, there has been a great difference for the temperatures over the HDD, other components are not affected much by this change. The biggest changes occur on the power supply and the RAM chips. This is expected because; these components are placed very near to the DVD and the HDD. On the other hand there are not any drastic changes on the other components. 
Table 3.4 Maximum and mean temperature values on several components.

\begin{tabular}{|l|c|c|c|c|}
\hline & \multicolumn{2}{|c|}{ With power consumption } & \multicolumn{2}{c|}{ Without power consumption } \\
\hline & $\begin{array}{c}\text { Maximum } \\
\text { temperature }\left({ }^{\circ} \mathrm{C}\right)\end{array}$ & $\begin{array}{c}\text { Mean } \\
\text { temperature }\left({ }^{\circ} \mathrm{C}\right)\end{array}$ & $\begin{array}{c}\text { Maximum } \\
\text { temperature }\left({ }^{\circ} \mathrm{C}\right)\end{array}$ & $\begin{array}{c}\text { Mean } \\
\text { temperature }\left({ }^{\circ} \mathrm{C}\right)\end{array}$ \\
\hline DVD & 47.4 & 37.4 & 29.8 & 29.3 \\
\hline HDD & 102.7 & 85.3 & 29.4 & 29.1 \\
\hline CPU & 51.9 & 46.5 & 50.8 & 45.4 \\
\hline North bridge & 37.4 & 35.3 & 37.1 & 35 \\
\hline NB heat sink & 35.3 & 34.7 & 35 & 34.5 \\
\hline South bridge & 43.7 & 41.2 & 43.2 & 40.7 \\
\hline SB heat sink & 42.2 & 42 & 41.7 & 41.6 \\
\hline Power supply & 54.5 & 39.5 & 52 & 37.5 \\
\hline RAM chips & 35.3 & 34.3 & 33.8 & 33.1 \\
\hline Mainboard & 40.2 & 33.5 & 39.3 & 32.8 \\
\hline
\end{tabular}




\subsection{Uncertainty Analysis of Temperature Measurements}

Experiments are important for a CFD study in a sense that, they form a basis for the improvement of the current model and they provide the needed reference data for future studies. Each measurement taken in an experiment has a level of error due to several different parameters affecting it. The error of a measurement is usually defined as the difference between its true value and the measured value [37]. However, in most measurements it is not possible to know the true value of the parameter such that this definition may not have a meaning. However, it may be possible to estimate the limits of that error, and this includes uncertainty analysis. Moffat [37] defines this as the process of estimating how great an effect the uncertainties in the individual measurements have on the calculated results. He also describes the experiments as single-sample or multiple-sample according to the number of observations and data-sampling rate.

The experiment that is conducted in this study is a single-sample one due to the fact that a single observation is done for each measurement location. And there are several uncertainties associated with these measurements. First of all, there are uncertainties coming from the measurement system and thermocouples. In this experiment, the bead size of the thermocouples is relatively large. Thermocouples having a smaller diameter could be more appropriate.

Since the variable to be measured is temperature, it should be decided what are the parameters affecting temperature distribution. At a first glance, it is clear that temperature is a function of the voltage created when there exists temperature difference. In addition to this, temperature is also a function of the spatial coordinates. The location of the thermocouple is determined by caliper measurements. Therefore, temperature can be represented as a function of these four variables: 


$$
T=T(x, y, z, V)
$$

where $x, y$ and $z$ are the spatial coordinates and $V$ is the potential difference between the two ends of thermocouples.

Then, the uncertainty of $T, \delta T$, can be defined as:

$$
\delta T=\sqrt{\left(\frac{\partial T}{\partial x} \delta x\right)^{2}+\left(\frac{\partial T}{\partial y} \delta y\right)^{2}+\left(\frac{\partial T}{\partial z} \delta z\right)^{2}+\left(\frac{\partial T}{\partial V} \delta V\right)^{2}}
$$

Here the coefficients of the uncertainties, $\frac{\partial T}{\partial x}, \frac{\partial T}{\partial y}, \frac{\partial T}{\partial z}$ and $\frac{\partial T}{\partial V}$ are defined as the sensitivities of $T$ with respect to the selected parameter. To be able to calculate the uncertainty in $T$ these sensitivity values should be calculated together with the uncertainties in the selected parameters. The uncertainties in the spatial coordinates are found from the manufacturer specifications of the caliper as:

$$
\delta x=\delta y=\delta z=0.01 \mathrm{~mm}
$$

and the uncertainty in the potential difference is obtained using the specifications supplied by the manufacturer of the data logger system;

$$
\delta V=0.005 \mathrm{mV}
$$

On the other hand, it is not easy to obtain the sensitivity values of the spatial coordinates analytically. Therefore sensitivity values are obtained from the CFD analysis results. The sensitivity values given in Table 3.5 are for the temperature measurement locations inside the chassis. The temperature values of two very close points, $0.1 \mathrm{~mm}$ apart, are read and the sensitivities are calculated. 
Table 3.5Sensitivity values for the temperature measurement locations

\begin{tabular}{|c|c|c|c|c|}
\hline & Point & $\frac{\partial T}{\partial x}\left({ }^{\circ} \mathrm{C} / \mathrm{mm}\right)$ & $\frac{\partial T}{\partial y}\left({ }^{\circ} \mathrm{C} / \mathrm{mm}\right)$ & $\frac{\partial T}{\partial z}\left({ }^{\circ} \mathrm{C} / \mathrm{mm}\right)$ \\
\hline $\mathbf{1}$ & North Bridge Heat Sink & 0.00181 & 0.00429 & 0.000685 \\
\hline $\mathbf{2}$ & South Bridge Heat Sink & 0.00157 & 0.04938 & 0.0105 \\
\hline $\mathbf{3}$ & Heat Pipe Block & 0.0595 & 1.312 & 0.00056 \\
\hline $\mathbf{4}$ & Power Supply & 0.0102413 & 0.009625 & 0.18045 \\
\hline
\end{tabular}

From Table 3.5, it is clear that the highest sensitivity values are for the heat pipe block point. Therefore, the calculations are based on this point. The sensitivities related with the $\mathrm{x}$ and $\mathrm{z}$ coordinates are very small compared to the sensitivity of $\mathrm{y}$ coordinate. Since their contributions would be very small, they can be neglected. Hence, Equation 3.4 reduces to,

$$
\delta T=\sqrt{\left(\frac{\partial T}{\partial y} \delta y\right)^{2}+\left(\frac{\partial T}{\partial V} \delta V\right)^{2}}
$$

The sensitivity of temperature with respect to potential difference which is directly found using calibration data of thermocouples:

$$
\frac{\partial T}{\partial V}=24.83{ }^{\circ} \mathrm{C} / \mathrm{mV}
$$

When the corresponding values are inserted, the uncertainty value of the temperature is found to be;

$$
\delta T=0.12^{\circ} \mathrm{C}
$$


With this uncertainty value calculated, temperature measurements are said to lie in the range $\pm 0.12{ }^{\circ} \mathrm{C}$.

\subsection{Comparison of Experimental Results with CFD Results}

Two different experiments are conducted for two different computer configurations. First configuration is Shuttle SK21G with an AMD Sempron 3000+ processor. The other one is SS59GV2 with a Pentium $4(3.2 \mathrm{GHz}) \mathrm{CPU}$. Mainly, the configurations are similar; however, there are some basic differences. Other than the CPU, the chipset is also different. Although the north bridge and south bridge heat sinks are almost the same, there is a fan at the top of the north bridge heat sink which makes it an active heat sink for SS59GV2. This is a major difference affecting the flow field inside the chassis. The model of Shuttle SS59GV2 can be seen in Figure 3.20. For the sake of simplicity, south bridge and its heat sink and the CPU is modeled flat instead of rhombus in this model.

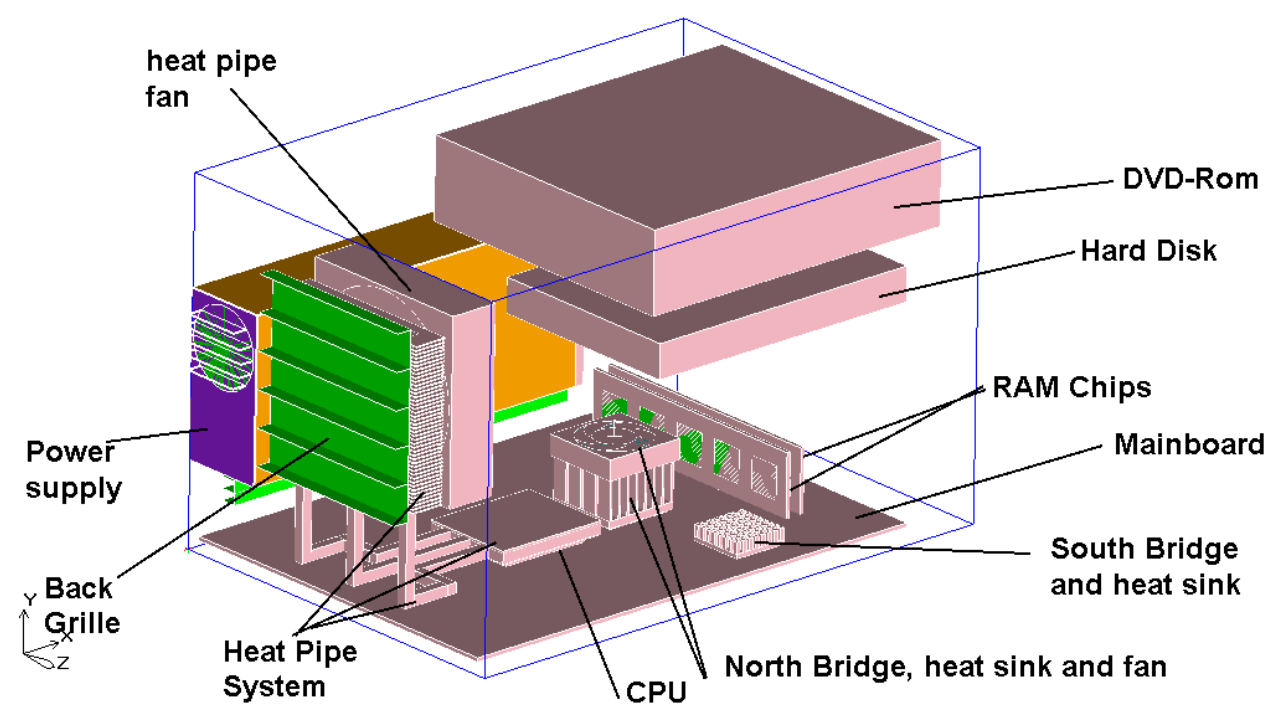

Figure 3.20 Model of the SS59GV2 in Icepak ${ }^{\mathrm{TM}}$ 
On the other hand, the experiments are not conducted in fully controlled environments. Therefore, these experiments can not thoroughly used to verify the results of the CFD results. However, they can give an idea on a comparative basis.

Tables 3.6 and 3.7 are the comparisons of the CFD results with the experiments for Shuttle SK21G and Shuttle SS59GV2. The comparison is based on the temperature measurements taken from four different points inside the chassis. The exact locations of the measurement points can be seen in Appendix C. The percent relative errors are calculated taking the experimental results as true values.

The largest error is calculated for the heat pipe block of Shuttle SK21G. However, for nearly the same location on the heat pipe of Shuttle SS59GV2, the magnitude of the error differs. This may result from the modeling of the heat pipe system. Pipes of the heat pipe system in SK21G are longer than the actual pipes of the system in SS59GV2. Therefore modeling of pipes as rectangular solid blocks in Icepak ${ }^{\mathrm{TM}}$ brings out additional thermal resistance in SK21G than SS59GV2.

Although the power ratings of the power supplies are close, the temperatures on the power supplies are considerably different. This is an indication of dissimilar flow fields inside the chassis and around the power supplies as expected. Figure 3.21 shows the particle traces originating from the same cut plane normal to the $\mathrm{X}$ axis $(\mathrm{x}=0.17 \mathrm{~m})$. The HDD and the DVD are made invisible for a clearer appearance. The intensity and the velocity magnitudes of the particle traces around the power supplies are also different which affects the temperature distribution. 

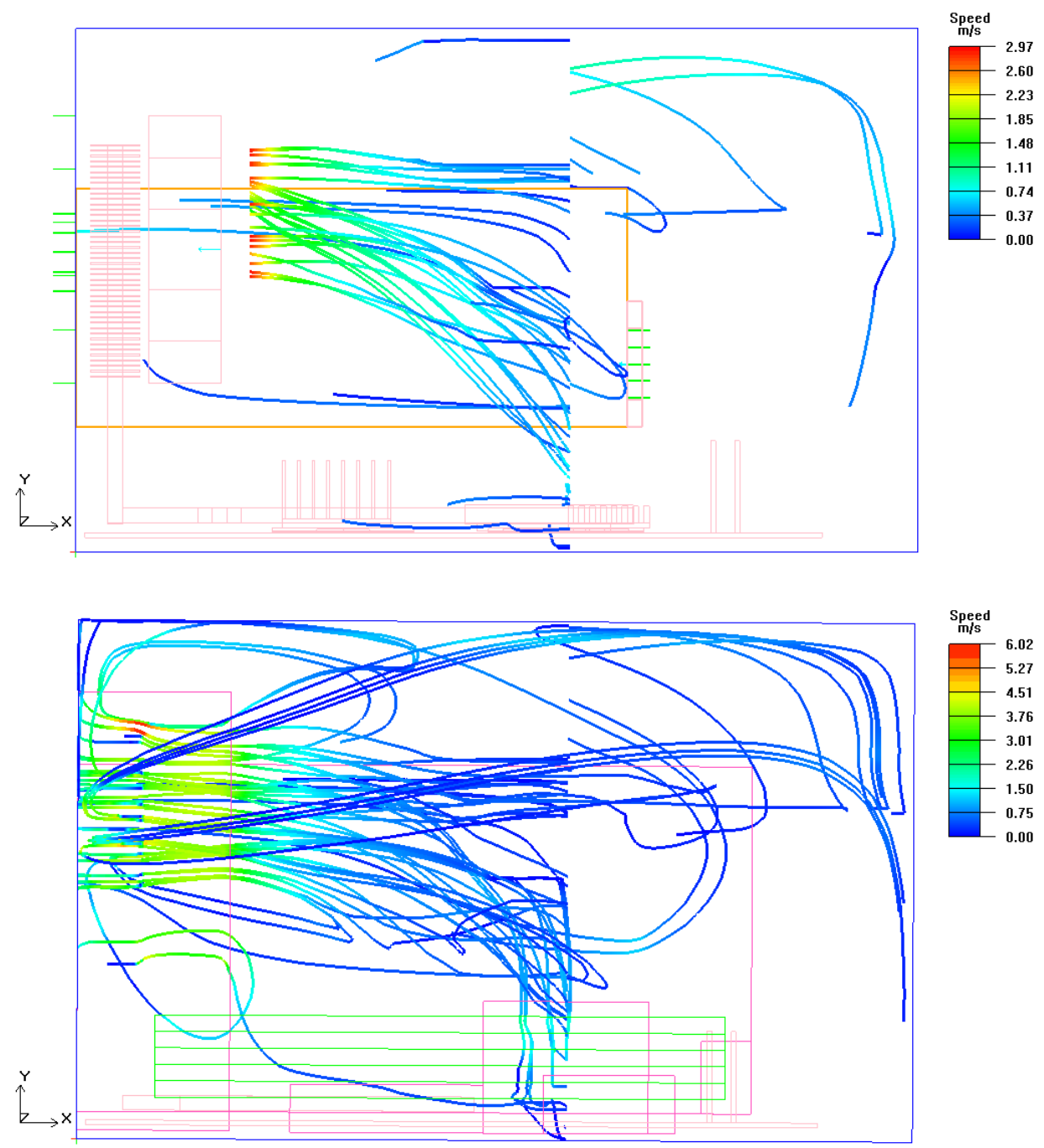

Figure 3.21 Particle traces from a cut plane $(\mathrm{x}=0.17 \mathrm{~m})$ for SK21G and SS59GV2 (top to bottom).

Thermocouple attachments on the power supplies are not as reliable as the other attachment locations. Since it is difficult to attach the thermocouple inside one of the sides of the power supply, temperature measurements are recorded when the thermocouple cable is glued on the plate. Therefore, relatively large errors are calculated for the measurements on the power supply. 
Considering the temperature values, there is a considerable difference between the heat pipes also. This is mainly due to the higher power consumption of the Pentium 4 CPUs. The power consumption of Pentium CPU is taken as $50 \mathrm{~W}$, while the power consumption of the AMD Sempron $3000+$ CPU is just $25 \mathrm{~W}$. This is also an indication of an effective cooling system. Although the power rating of the Pentium $4 \mathrm{CPU}$ is twice the AMD Sempron counterpart, the system can also cool it to reasonable temperatures.

Table 3.6 Comparison of experimental results of Shuttle SK21G with CFD results for an ambient temperature of $28^{\circ} \mathrm{C}$.

\begin{tabular}{|c|c|c|c|c|}
\hline \multirow{2}{*}{} & \multirow{2}{*}{ Point } & \multicolumn{3}{|c|}{ Temperature Values, $\Delta$ T $\left({ }^{\circ} \mathbf{C}\right)$} \\
\cline { 2 - 5 } & & $\Delta$ T Experiment & $\Delta$ T CFD & $\begin{array}{c}\text { \% } \\
\text { Error }\end{array}$ \\
\hline $\mathbf{1}$ & North Bridge Heat Sink & 6.6 & 7 & 5.7 \\
\hline $\mathbf{2}$ & South Bridge Heat Sink & 15.1 & 14 & 7.3 \\
\hline $\mathbf{3}$ & Heat Pipe Block & 10.4 & 11.4 & 9.6 \\
\hline $\mathbf{4}$ & Power Supply & 3.9 & 4.2 & 7.7 \\
\hline
\end{tabular}


Table 3.7 Comparison of experimental results of Shuttle SS59GV2 with CFD results for an ambient temperature of $28^{\circ} \mathrm{C}$.

\begin{tabular}{|c|c|c|c|c|}
\hline \multirow{2}{*}{} & \multirow{2}{*}{ Point } & \multicolumn{3}{|c|}{ Temperature Values, $\Delta$ T ( $\left.{ }^{\circ} \mathbf{C}\right)$} \\
\cline { 2 - 5 } & & $\Delta$ T Experiment & $\Delta$ T CFD & $\begin{array}{c}\text { \% } \\
\text { Error }\end{array}$ \\
\hline $\mathbf{1}$ & North Bridge Heat Sink & 8.4 & 8.5 & 1.2 \\
\hline $\mathbf{2}$ & South Bridge Heat Sink & 15.6 & 16.1 & 3.2 \\
\hline $\mathbf{3}$ & Heat Pipe Block & 19.3 & 19.1 & 1 \\
\hline $\mathbf{4}$ & Power Supply & 8.9 & 8.1 & 9 \\
\hline
\end{tabular}




\section{CHAPTER 4}

\section{CONCLUSION AND RECOMMENDATIONS}

\subsection{Conclusions}

In this study, cooling of small form factor (SFF) computers is investigated. Since SFF computers are new to the market compared with the other form factors such as ATX, there is not much study about the cooling performance of SFF computers. However, it is relatively more important in SFF computers, since the chassis is smaller than the other form factors.

Therefore, two different SFF configurations, which are Shuttle SK21G and Shuttle SS59GV2, are modeled. These models are analyzed to be able to fulfill the thesis goals that are defined in Section 1.3.

The modeling phase of the study involves several assumptions and simplifications. Since, it is not possible to model every detail in the computer chassis, only the critical components are modeled. Components like transistors, capacitors, cables, etc. are left out since they do not affect the flow like other components. Therefore modeling of them brings out additional computational complexity which is not worth modeling. On the other hand, difficulties occurred when modeling some critical components such as the heat pipe system and the packages. Due to the complex geometry of the heat pipe system, this part is modeled with simplifications. Pipes of the system are modeled as rectangular blocks with very high axial conductivities. Other than the geometrical complexity, there is a complexity related with the power ratings of some critical components such as the CPU, the chipset 
and the power supply. The exact operating power ratings of these components are impossible to determine, therefore reasonable values are assigned. These reasonable values are obtained by trial and error. This trial and error involves several successive analyses and comparison of them with experimental results.

After the modeling and mesh generation phase, numerical and physical modeling issues are discussed. In terms of numerical study, the effect of mesh selection and discretization schemes are presented. Mesh selection is important since the decision of an accurate number of elements may save computational effort and time.

Other than the grid selection, the choice of a suitable discretization scheme is another concern that saves computational time. From the two possible schemes which are first order upwind and second order upwind, it is decided that the first order one is more suitable for this study. Its performance is as good as the second order upwind scheme, although it is easier to converge.

In terms of physical concerns, three main aspects are discussed; recirculation, relaminarization and turbulence modeling. Recirculation is an important feature of flow because it affects the heat transfer inside the chassis in a negative manner. Therefore, the locations for the most important recirculation zones are determined. It is seen that these zones are likely to occur near the heat pipe fan.

When heat transfer is involved in a study, turbulence modeling also becomes very important. Mixing length and $k-\varepsilon$ turbulence models are discussed in detail. Results showed that the $k-\varepsilon$ model has no superior performance over the zero equation turbulence model However, it has two additional equations which increase the CPU time by a considerable amount. Therefore the zero equation turbulence model can be used to solve the turbulent features inside the chassis.

Final issue of the physical discussions is relaminarization. There are possible regions for the flow where relaminarization may occur, because the flow is mildly 
turbulent inside the chassis. The most possible location is the flow around a heat sink. Therefore, the flows around the north and south bridge heat sinks are closely examined and laminar solutions are obtained. However, there is not a considerable difference between the turbulent and laminar solutions.

When the discussion of the computational results is complete, experimental results are needed for comparison. For this purpose, two different experiments are conducted for two different models of Shuttle. Computational results are in good agreement with both of the experiments, partially due to the aforementioned trial and error procedure followed to obtain some power ratings. However, multiple numbers of experiments should be done in more controlled environments.

Finally, this study shows that it is possible to simulate a very complicated model using CFD, although there are some limitations and assumptions involved. CFD is a very powerful tool in the sense that, it minimizes the design time and cost in an effective way. It provides a huge amount of data that an experiment can never provide. Therefore, it is a complementary tool that needs to be used in different stages of engineering. And this study is an example of how CFD and experiments can complement each other for resolving the cooling characteristics of an SFF computer. 


\subsection{Recommendations}

Recommendations regarding the CFD investigation of the cooling of an SFF computer can be summarized as follows:

- The decision making process for the assignment of accurate power ratings is the most difficult and cumbersome part of the study. Heat dissipations of the components, if possible, should be calculated or measured by experiments.

- During the solver execution, there are many numerical and physical issues. It is not possible to compare all of them. However, the most related ones should be chosen and the effects of them may be compared. The final form the model should be determined after these comparisons.

- In this study, single sample experiments are conducted. However, multiple sample experiments may be better since the same experiment is repeated. Therefore, if possible experiments should be repeated for as many points as possible in a controlled environment.

- The problem itself is an unsteady problem. Therefore, for future studies, the problem can be remodeled by considering the unsteady effects 


\section{REFERENCES}

[1] S. J. Kim, S. W. Lee, “Air Cooling Technology for Electronic Equipment”, CRC Press, 1996.

[2] D. S. Steinberg, "Cooling Techniques for Electronic Equipment”, Second Edition, John Wiley \& Sons, 1991.

[3] W. L. Rosch, "Hardware Bible”, Sixth Edition, Que Publishing, 2003.

[4] R. B. Thompson, B. F. Thompson, "PC Hardware in a Nutshell: A Desktop Quick Reference”, Second Edition, O’Reilly \& Associates Inc., 2002.

[5] V. 'Aurora' Beal, Webopedia, encyclopedia for computer technology, http://www.webopedia.com/DidYouKnow/Hardware_Software/2005/motherboard_ form_factors.asp, April 2005.

[6] Intel Corporation, Form factors website, http://www.formfactors.org/developer /specs/atx2_1.pdf, June 2002.

[7] Intel Corporation, Form factors website http://www.formfactors.org/developer /specs/matxspe1.2.pdf, October 2006.

[8] Intel Corporation, Form factors website, http://www.formfactors.org/developer /specs/nlx1_8.pdf, October 2006.

[9] Intel Corporation, Form factors website, http://www.formfactors.org/developer /specs/BTX_Specification\%20v1.0a.pdf, October 2006. 
[10] Wikipedia contributers, Wikipedia, http://en.wikipedia.org/wiki/Small_ form_factor, October 2006.

[11] Mark Kyrnin, About website, http://compreviews.about.com/odcases/a/ SFFPCs_2.htm, October 2006.

[12] E. Öztürk, "CFD Analyses of Heat Sinks for CPU Cooling with Fluent”, Middle East Technical University, December 2004.

[13] P. G. Tucker, "CFD Applied to Electronic Systems", IEEE Transactions on Components, Packaging, and Manufacturing Technology-Part A, Vol. 20, No. 4, December 1997.

[14] M. J. Marongiu, B. Kusha, G. S. Fallon and A. A. Watwe, "Micro Heat Pipes and Other High Thermal Conductivity Materials into Micro-channel Heat Sinks", Electronics Components and Technology Conference, pp. 18-26, 1998.

[15] C-W Yu, R. L. Webb, “Thermal Design of a Desktop Computer System Using CFD Analysis", 17 $17^{\text {th }}$ IEEE Semi-Therm Symposium, pp. 18-26, 2001.

[16] L. T. Yeh, "A CFD Analysis of an Electronic Box", Inter Society Conference on Thermal Phenomena, pp. 710-717, 2002.

[17] Y. A. Abakr, M. I. Ahmed, A. F. Ismail, "CFD Thermal Analysis of a Telecommunication Board". $4^{\text {th }}$ National Conference on Telecommunication Proceedings, pp. 181-184, 2003.

[18] X. H. Sun, "Thermal Characterization of a Fan-sink for an AGP Card”, $20^{\text {th }}$ IEEE Semi-Therm Symposium, 2004. 
[19] A. A. Ali, "Design and Analysis of a Compact Two Phase Cooling System for a Laptop Computer”, Georgia Institute of Technology, June 2004.

[20] F. Roknaldin, R. A. Sahan, "Cooling Solution for Next Generation High Power Processor Boards in 1U Computer Servers", International Electronic Packaging Technical Conference and Exhibition, pp. 1-6, July 6-11 2003.

[21] S. C. Lin, C. L. Huang, “An Integrated Experimental and Numerical Study of Forward Curved Centrifugal Fan”, Experimental Thermal and Fluid Science, pp. 421-434, vol. 26, 2002.

[22] T. Kobayashi, M. Nakamura, T. Ogushi , A. Iwamaru, M. Fujii, “Thermal Design of a Closed Cabinet with a Heat Exchanger for Inner Air Cooling”, Heat Transfer-Asian Research, vol. 30, pp. 267-279, 2001.

[23]. J. D Anderson Jr., "Computational Fluid Dynamics: The Basics with Applications", McGraw-Hill, 1995.

[24] J. D Anderson Jr., "Introduction to Flight," Fifth Edition, McGraw Hill, 2005.

[25] F. P. Incropera, D. P. Dewitt, "Fundamentals of Heat and Mass Transfer," Fourth Edition, John Wiley \& Sons, 1996.

[26] Icepak 4.2.6, User's Guide, Austin, TX, 2006.

[27] V. K. Garg, “Applied Computational Fluid Dynamics”, Marcel Dekker, Inc., 1998.

[28] H. K. Versteeg, W. Malalasekera, "An Introduction to Computational Fluid Dynamics, The finite Volume Method,” Longman Scientific \& Technical, 1995. 
[29] Fluent 6.2.16 User's Guide, Lebanon, New Hempshire, 2005.

[30] A. Bejan, A. D. Kraus, "Heat Transfer Handbook", John Wiley and Sons Inc., 2003.

[31] Icepak 4.2 Training Notes, 2006.

[32] M. B. Dogruoz, Personal Communication, 2006.

[33] D. C. Wilcox, "Turbulence Modelling for CFD", Second Edition, DCW Industries Inc., 2000.

[34] İ. Sahin, "The effects of cooling on relaminarization", Joint Propulsion Conference, 23rd, San Diego, CA, June 29-July 2, pp 1-6, 1987.

[35] B.E. Launder, D. B. Spalding, "Lectures in Mathematical Models of Turbulence", Academic Press, London, England, 1972

[36], S. B. Pope. “Turbulent Flows”, Cambridge University Press, 2000.

[37] R. J. Moffat, "Describing the Uncertainties in Experimental Results", Experimental Thermal and Fluid Science, vol.1, pp 3-17, 1988. 
APPENDIX A

\section{MESH GENERATION AND QUALITY OF THE MESH}

After designing and modelling the problem, now it is time to generate the computational grid which forms the basis of the solution procedure. The mesh consists of discrete elements located throughout the computational domain and Icepak solves the governing equations of flow within each cell inside the domain [26].

Mesh generation can be said to be the most time consuming and important part of the pre-processing. If the generated grid is coarse, the resulting solution may not be accurate enough to resolve the flow characteristics. On the other hand, if the grid is very fine, the solution may be unnecessarily expensive. Therefore a good mesh is needed for an accurate solution in a reasonable time.

In Icepak, mesh generation is an autonomous process, however by controlling the meshing parameters one can refine the mesh and adjust the optimization level between the computational cost and solution accuracy. Icepak follows a set of rules to decide how each object will be meshed. It operates on "cocooning" methodology whereby each object is meshed individually, as tightly as the specifications permit, in order to resolve the physics of the solution optimally [26]. For example, elements are smaller near objects to account for the velocity and temperature gradients, whereas elements are bigger in the open spaces to minimize computational cost.

There are some properties that a reasonable mesh should have such as:

- Proper Resolution 
- Smoothness

- Quality

- Total number of elements.

Proper Resolution: A good mesh should be fine enough to resolve the flow features in the computational domain. And at the end, the grid should have a proper resolution, in order for the solution to be grid independent. A grid independent solution is the one, which does not change as the number of elements in the computational grid increase.

Smoothness: The mesh must be smooth enough to capture velocity and temperature gradients near the viscosity affected regions such as cabinet walls, heat sinks, heated blocks, etc. Generally, expansion ratio from one mesh element to another should be in the range between 2 and 5 [26]. However, lower values can be applied in some critical areas. In this study, finer mesh is used near heat sinks of the chipset and CPU.

Quality There are two parameters that affect the quality of the mesh elements created in Icepak. The first one is skewness and the second one is aspect ratio. In terms of quality, a cube is an optimal element. However, since it is not always possible to have optimal elements, the aim should be to obtain a low aspect ratio and a regular element which is not highly skewed. Therefore, reducing the number of long, thin and distorted elements which can decrease the accuracy and stability, improves the quality of the computational grid together with the solution. 


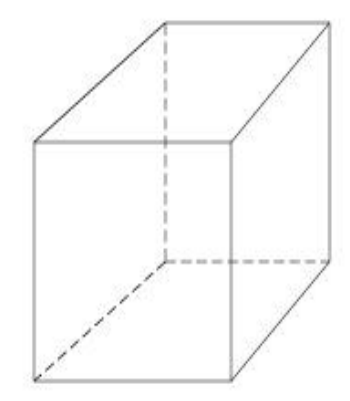

Element with low skew

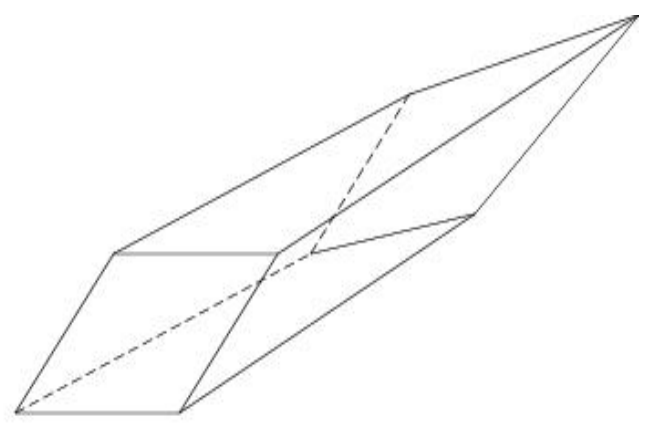

Element with high skew

Figure A.1 Elements with low and high skewness values (adapted from [26]).

In Icepak the quality measure of the elements ranges between 0 and 1 , with better elements closer to 1 . It is said that elements with quality value less than 0.15 are skewed elements and needs to be revised.

Total number of elements: The last issue to consider in forming the computational grid is the total number of elements. As a general rule total number of elements should be large enough to be able to resolve the flow field and small enough to minimize the computational time. To reduce the number of elements in the computational grid, it is possible to have non-conformal mesh in certain regions of the computational domain. Non-conformal meshing zones are very useful to reduce the total number of cells while improving the quality. In this study, there are six non-conformal meshing zones inside the computer chassis.

- There are three different mesher algorithms in Icepak which are Hexahedral Cartesian, Hexahedral Unstructured and Tetrahedral mesher algorithms. Hexahedral Cartesian mesher can create the best quality elements however; it is very limited to simple geometries only. Tetrahedral mesher can produce better results for complicated geometries such as ellipsoids, elliptical cylinders and polygonal ducts, but the total number of elements will 
drastically increase compared to hexahedral mesher. Hexahedral unstructured mesher, on the other hand is the default option in Icepak.

After all the objects inside the computer chassis are modeled and all the above mentioned aspects are considered, a general meshing procedure can be applied to generate the optimum computational mesh for the problem. For best results, mesh generation should be an iterative procedure [26]:

- For all different meshing parameters, it is seen that without non-conformal interfaces, the total number of elements go beyond logical limits. Therefore, in all the models, non-conformal assemblies are used, around chipset, CPU, heat pipe, power supply and RAM chips, to improve the quality while decreasing the number of elements.

- Then, the minimum count mesh is generated using Icepak's default coarse mesh parameters. After generating this mesh, several parameters are checked such as the number of elements on the flow boundaries, the number of elements in critical regions and the total number of elements. It is advisable to have 2 cells in the narrowest air gap and 1 cell across solid blocks [12].

- Since this mesh is generated using the default coarse meshing parameters, it is not enough to resolve the flow field inside the computer chassis. Therefore, mesh is refined in regions where there are large velocity and temperature gradients. In addition, to avoid very large cells on the computer chassis walls, the maximum cell size is constrained to one twentieth of the domain size in all directions. However, this refinement action generates some highly skewed elements. These elements are mostly generated around heat sinks and fans since fans are circular in shape. So additional refinement is done for these highly skewed elements. 
Finally, when all the criteria are met, computational grid is ready to be set up for the solution parameters.

Figures A.2 to A.4 show the details of the generated mesh from different parts of the computer chassis.

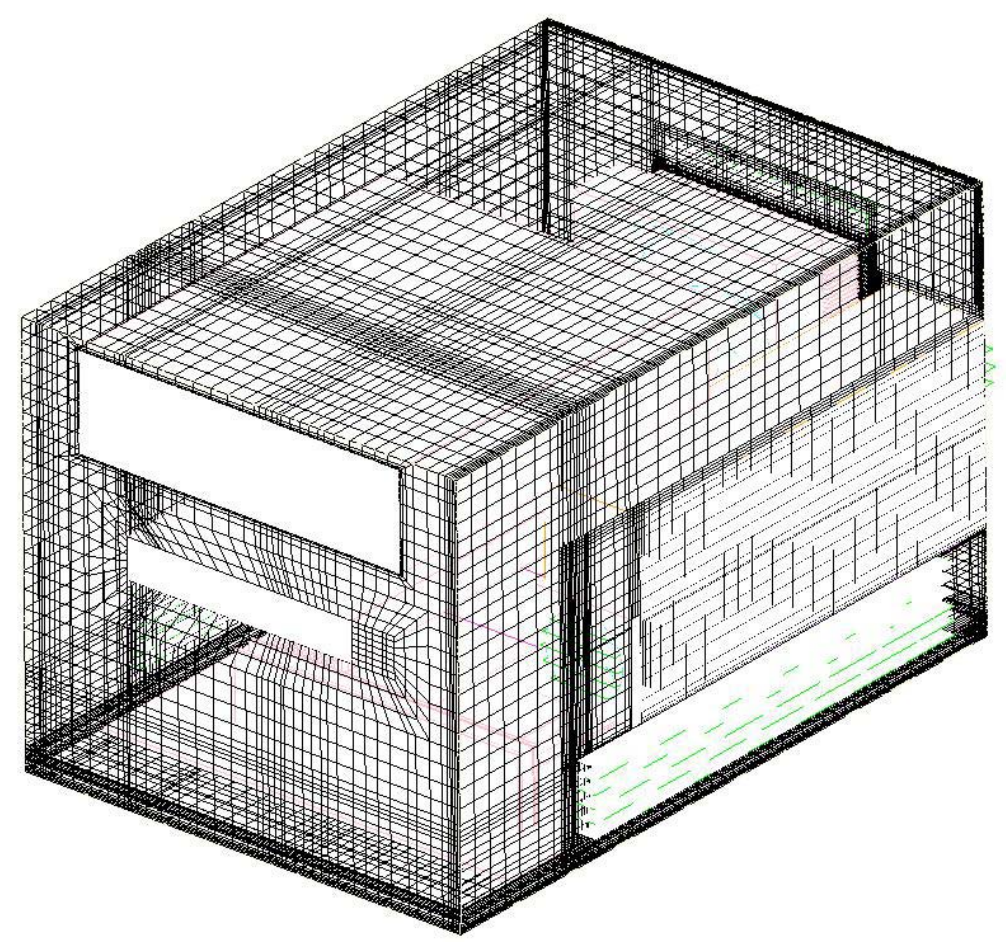

Figure A.2 General view of the generated mesh. 


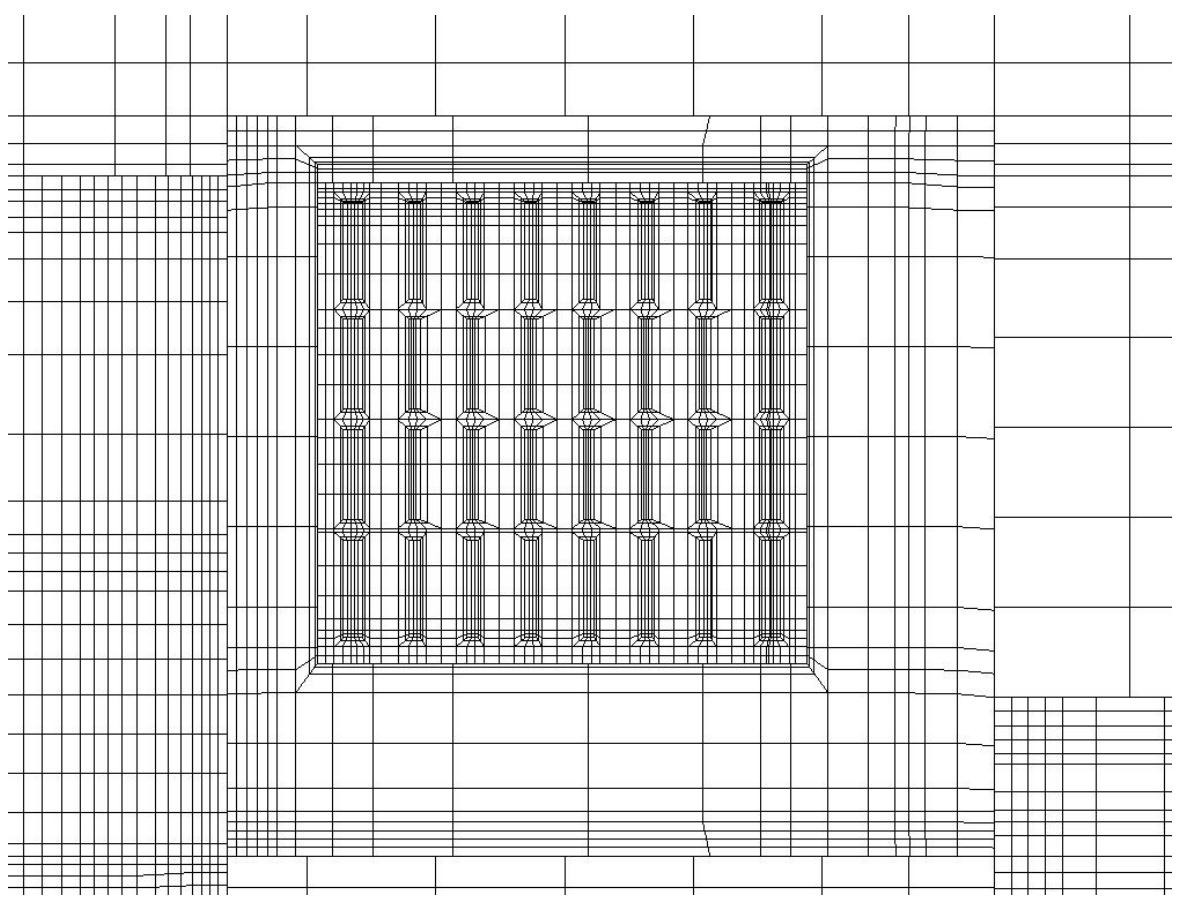

Figure A.3 Example of a non-conformal mesh.

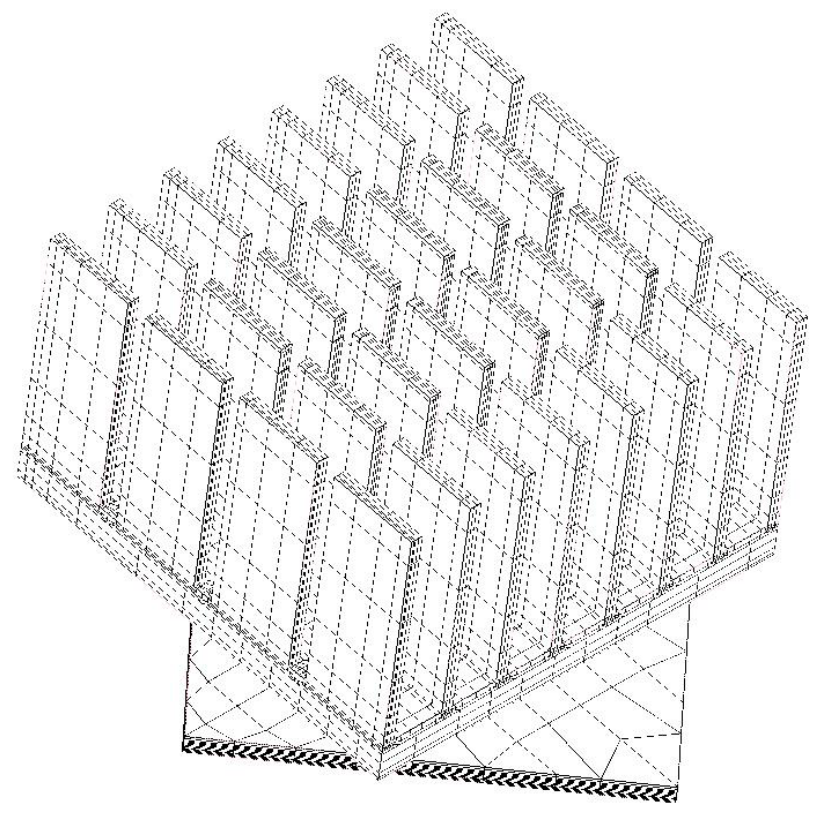

Figure A.4 North Bridge Heat Sink Mesh 


\section{APPENDIX B}

\section{TURBULENCE MODELLING}

Turbulence modeling is one of the most important and difficult areas in CFD. Although very good theories have been developed for grid generation and algorithm development, the precision in turbulence modeling is far less than these two. Therefore, turbulence modeling is a very challenging phenomenon with its physical nature and properties. All flows are said to be turbulent over a certain Reynolds number which is defined as the ratio of inertial forces to viscous forces.

For low Reynolds number flows, in which small scales and low velocities dominate, the equations of flow have steady and well defined solutions. Since the Reynolds number is low, viscous forces are important, meaning that the flow is controlled by viscous diffusion of vorticity and momentum. These flows are termed as laminar and can be observed experimentally and in nature [33].

For higher Reynolds number, the viscous forces are overcome by the inertia forces and the laminar characteristics of the flow become unstable. Rapid velocity and pressure oscillations occur in different regions of the flow. This makes the flow inherently three dimensional and unsteady. When all these happen, these flows are considered as turbulent.

All flows related to practical engineering are turbulent. Flow past vehicles such as rockets, airplanes, ships and automobiles, is always turbulent. Turbulence is everywhere in geophysical applications such as river currents and cloud motion and even at the breakfast table, in mixing of sugar, cream and coffee [33]. 
When dealing with general applications, related with water and air both of which have relatively small viscosity, turbulence corresponds to a small proportion. Thus to analyze fluid motion for general applications, we must deal with turbulence [33]. To be able to deal with it, several aspects of turbulence should be understood:

- Turbulence is an irregular motion which has a wide range of time and length scales. This irregularity comes from the fact that flow is no longer in smooth layers.

- Turbulence is characterized by random fluctuations and has a chaotic behavior. Therefore statistical methods should be used to analyze turbulence. However, even these methods may not resolve all the characteristics of turbulence.

- Turbulence is three dimensional and time dependent. Three dimensional feature of turbulent comes from the vorticity in the flow. When large eddies in the flow interact with the mean flow. This interaction results in a transfer of energy causing a process called vortex stretching.

- Turbulent flows are dissipative like any viscous flow. As turbulence becomes weaker, larger eddies transfer their energies to smaller eddies. Finally, the smallest eddies dissipate into heat through the action of molecular viscosity [33].

- One of the most important features of turbulence, from the engineering point of view, is enhanced diffusivity [33]. Mass, momentum and energy transfer can be greatly increased in turbulent flows. 
There are three common approaches in turbulence modeling. These are Reynolds Averaged Navier Stokes (RANS), Direct Numerical Simulation (DNS) and. Large Eddy Simulation (LES).

There are many different turbulence models that are developed using RANS approach, however; they can be classified in four basic categories:

1. Algebraic (zero-equation) models

2. One-equation models

3. Two-equation models

4. Stress-transport models

Algebraic (Zero Equation) models, as the name implies do not solve an additional equation to include the effects of turbulence and is based on the mixing-length hypothesis introduced by Prandtl. Cebeci-Smith and Boldwin-Lomax are examples of zero equation models. Although they are simple models, they can be used in a variety of applications especially for most attached boundary layers [33].

In one equation models, the eddy viscosity is linked to the kinetic energy of the turbulent fluctuations and an additional equation is solved together with the governing flow equations. However, one equation models are said to be incomplete turbulence models since they do not provide a length scale of turbulence. Spalart and Allmaras is one of the most accurate models that is used in a wide range of applications especially in aerodynamics.

With the introduction of two equation models, complete models of turbulence started to evolve. In these models, other than the kinetic energy of fluctuations, an additional equation is solved for the rate of dissipation of energy. There are many types of these models Kolmogorov's $k-w$ being the first. There is also $k$ - $\varepsilon$ model and variations of it used in many engineering applications. 
Together with the stress-transport methods, a totally new approach was utilized diminishing the Boussinesq approximation. The primary conceptual advantage of a stress-transport model is the natural manner in which non-local and history effects are incorporated [33]. For a three dimensional flow, additional seven equations are solved for a stress-transport model, one for the turbulence scale and six for the components of the Reynolds stress tensor. Since there are additional seven equations, they are used in a relatively small number of applications compared to algebraic and two-equation models.

Direct Numerical Simulation, shortly DNS, is a complete three dimensional and time dependent solution of the Navier Stokes and continuity equation. The grid in DNS should be fine enough to capture the smallest eddies. Since the size of the smallest eddies are in the order of Kolmogorov length scale, an enormous number of grid points is needed even for a flow with low Reynolds number. Although DNS continues to develop as computer technology goes further, most of the engineering applications are still far away from having DNS solutions.

Large Eddy Simulation (LES), is a totally different approach from RANS, in the manner that large eddies are computed while smaller ones are modeled. The underlying philosophy, here, is that largest eddies are directly affected by the boundary conditions, carry most of the Reynolds stresses, and must be computed. The small scale turbulence is weaker, contributing less to the Reynolds stresses, therefore less critical and can be modeled. Because LES involves modeling of smallest eddies, the smallest finite difference cells can be made larger than the Kolmogorov length scale and much larger time steps can be taken than are possible in DNS [33]. This makes LES more attractive in the computational sense but it is still an expensive model for most of the practical applications. 
APPENDIX C

THERMOCOUPLE LOCATIONS

\section{C.1 Shuttle SK21G}

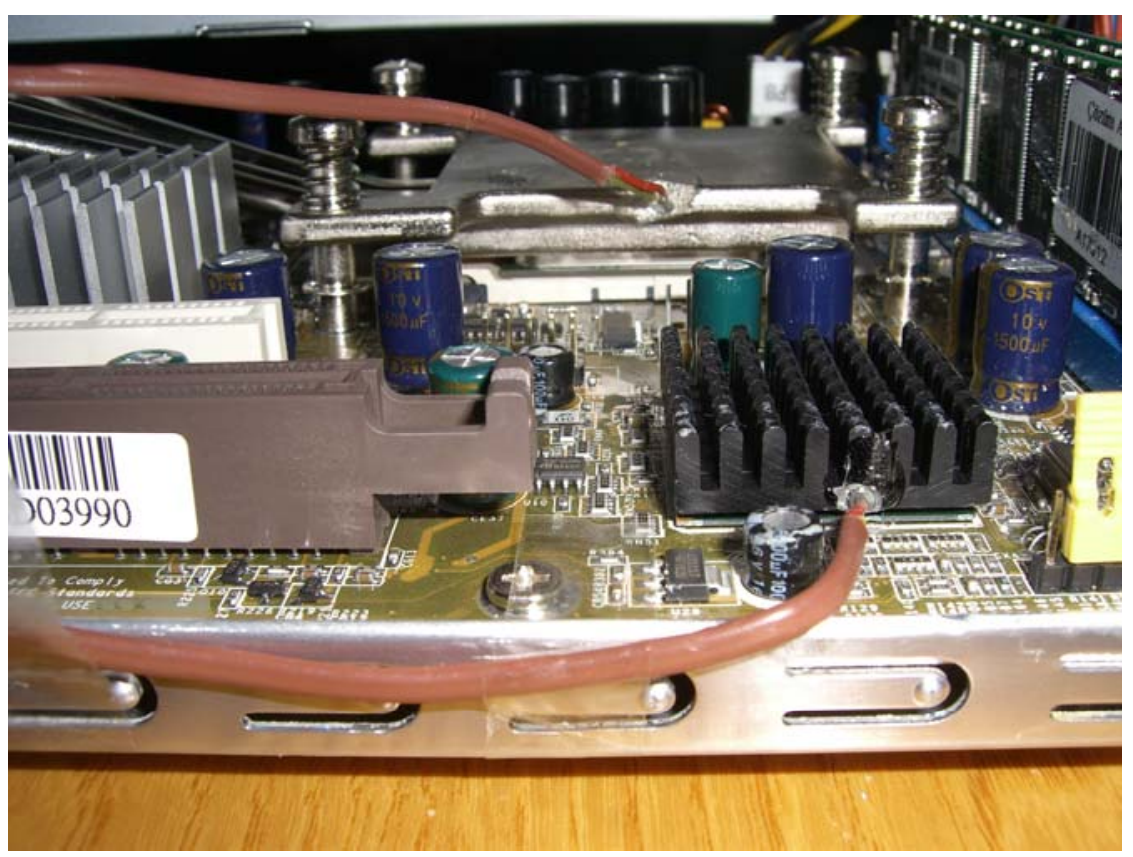

Figure C.1 Thermocouples inside the heat pipe block above the CPU and south bridge heat sink base. 


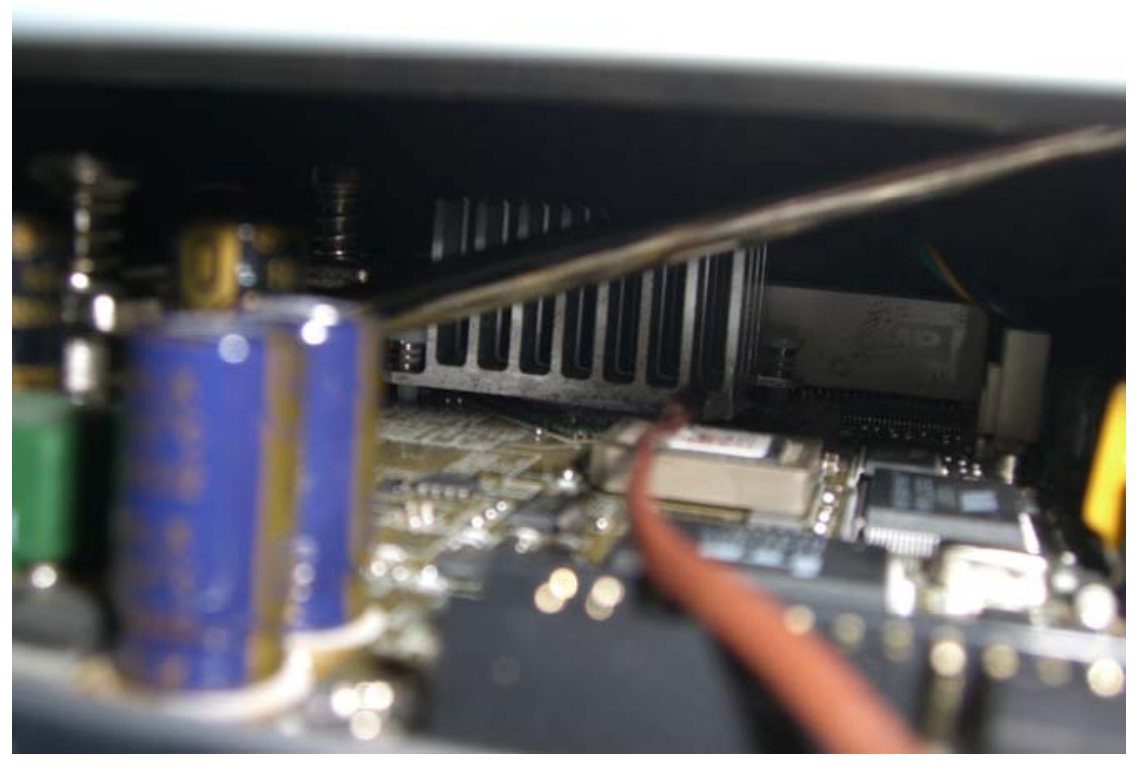

Figure C.2 Thermocouple inside the north bridge heat sink base.

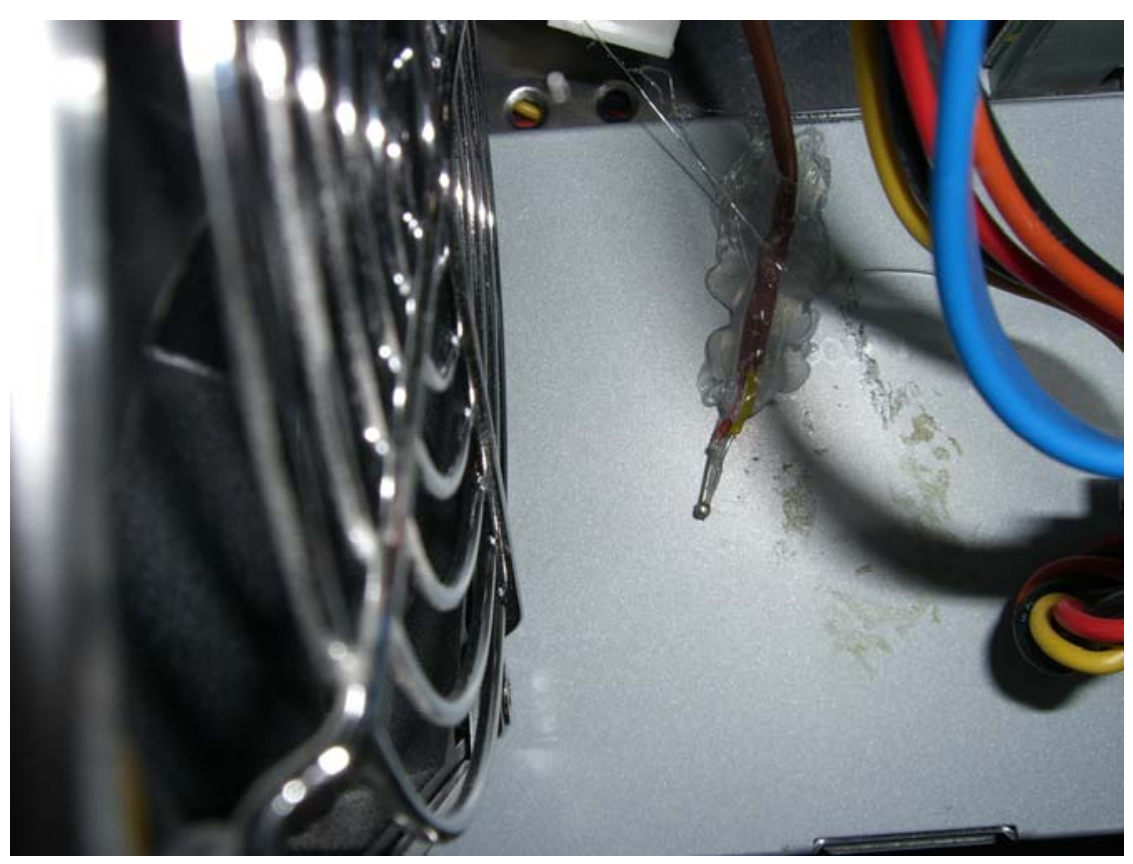

Figure C.3 Thermocouple on the power supply plate. 


\section{C.2 Shuttle SS59GV2}

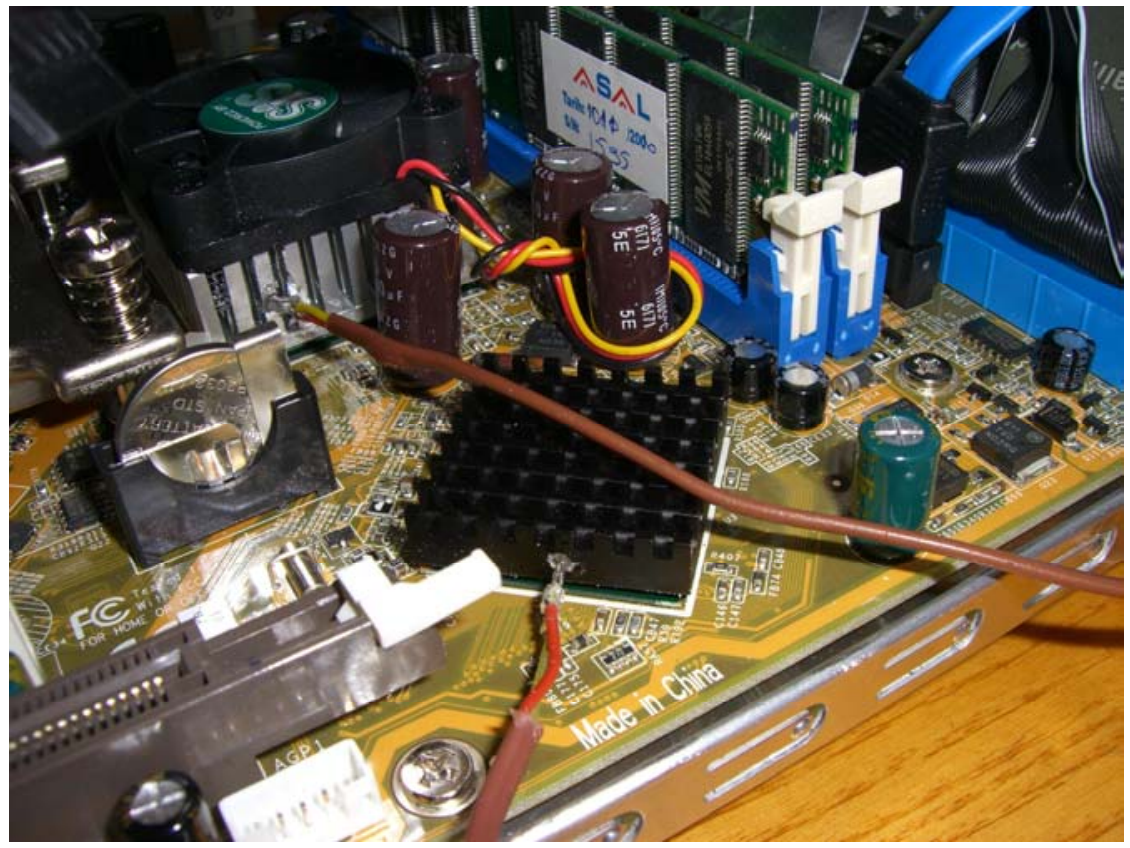

Figure C.4 Thermocouples inside the north bridge and south bridge heat sink bases. 


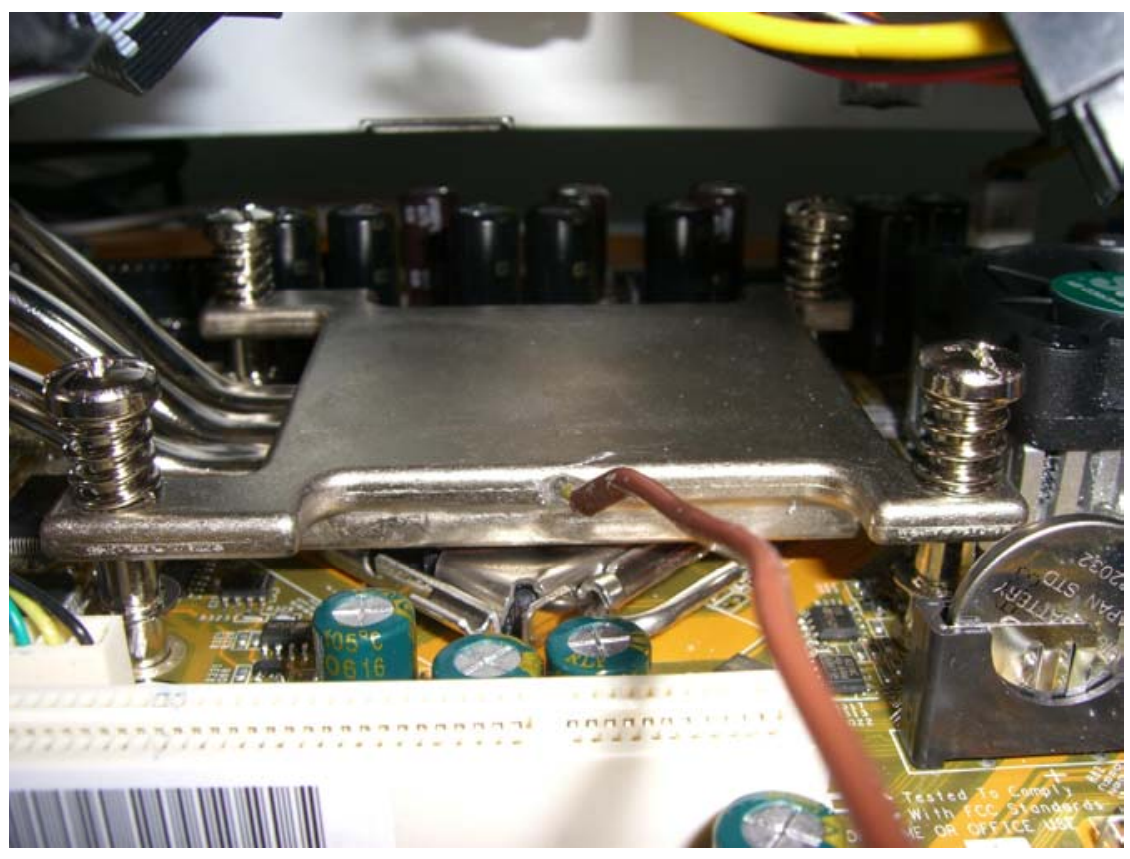

Figure C.5 Thermocouple inside the heat pipe block over the CPU.

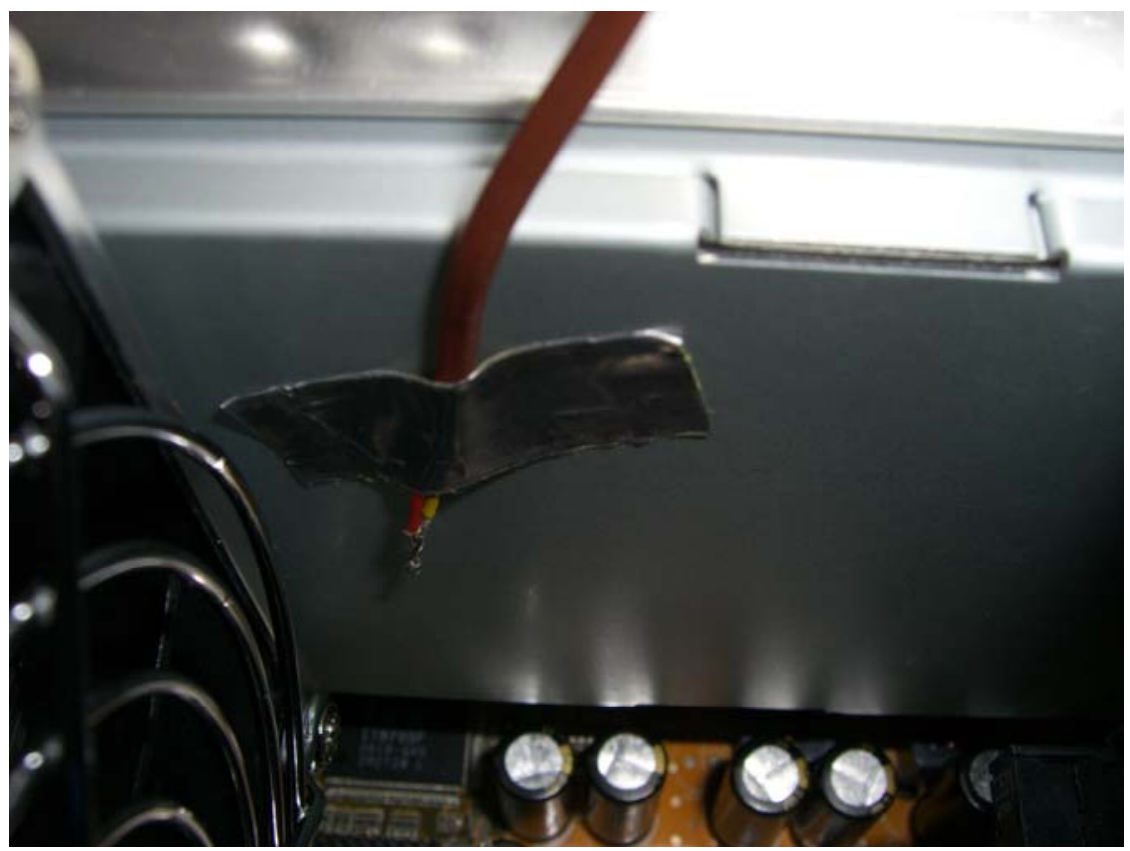

Figure C.6 Thermocouple on the power supply plate. 
APPENDIX D

\section{SOLUTION DETAILS}

Table D.1 Simulation times for different mesh configurations

\begin{tabular}{|c|c|}
\hline Mesh Configuration & Simulation Time (hours) \\
\hline Coarse & 4 \\
\hline Base & $7-8$ \\
\hline Fine & 14 \\
\hline
\end{tabular}

The following results are for the base mesh configuration:

Table D.2 Volumetric flow rates through the grilles

\begin{tabular}{|c|c|}
\hline Grille & Volumetric Flow Rate $\left(\mathbf{m}^{\mathbf{3}} \mathbf{s}\right)$ \\
\hline Grille right & 0.0045 \\
\hline Grille left & 0.0044 \\
\hline Grille back 1 & -0.0078 \\
\hline Grille back 2 & -0.0011 \\
\hline Grille power supply & -0.0011 \\
\hline
\end{tabular}


Table D.3 Fan Operating Points

\begin{tabular}{|c|c|c|}
\hline Fan & Volumetric Flow Rate $\left(\mathbf{m}^{\mathbf{3}} \mathbf{s}\right)$ & Pressure Rise (Pa) \\
\hline Heat Pipe Fan & 0.01845 & 21.94 \\
\hline Power Supply Fan & 0.001112 & 16.9 \\
\hline
\end{tabular}

